\title{
AGR-3/4 Irradiation Test Train Disassembly and Component Metrology First Look Report
}

John D. Stempien, Francine J. Rice, Phil L. Winston, Jason M. Harp

September 2016

The INL is a

U.S. Department of Energy

National Laboratory

operated by

Battelle Energy Alliance

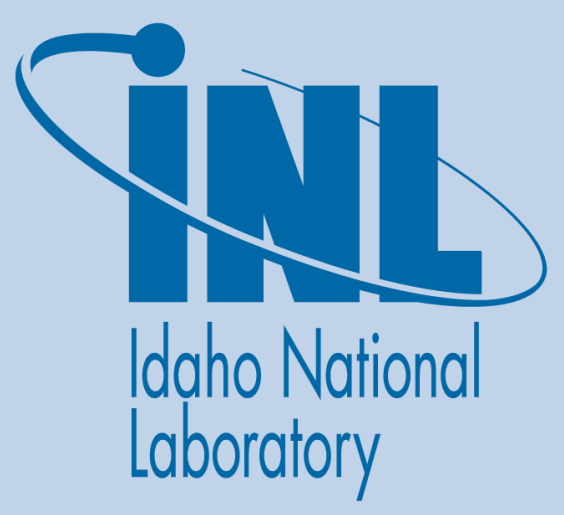

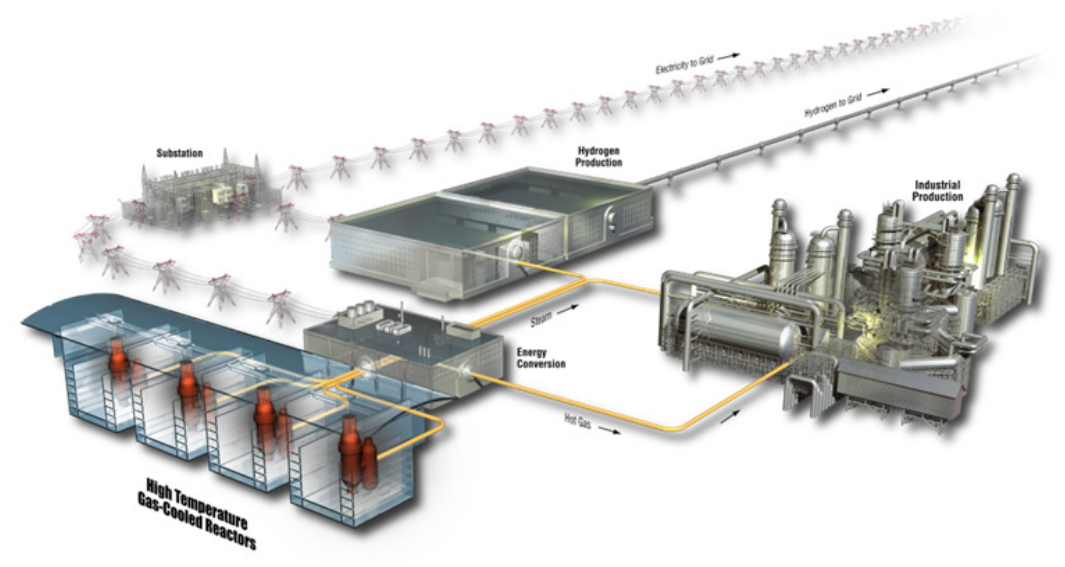




\section{DISCLAIMER}

This information was prepared as an account of work sponsored by an agency of the U.S. Government. Neither the U.S. Government nor any agency thereof, nor any of their employees, makes any warranty, expressed or implied, or assumes any legal liability or responsibility for the accuracy, completeness, or usefulness, of any information, apparatus, product, or process disclosed, or represents that its use would not infringe privately owned rights. References herein to any specific commercial product, process, or service by trade name, trade mark, manufacturer, or otherwise, does not necessarily constitute or imply its endorsement, recommendation, or favoring by the U.S. Government or any agency thereof. The views and opinions of authors expressed herein do not necessarily state or reflect those of the U.S. Government or any agency thereof. 
INL/EXT-16-38005

Revision 1

\section{AGR-3/4 Irradiation Test Train Disassembly and Component Metrology First Look Report}

John D. Stempien, Francine J. Rice, Phil L. Winston, Jason M. Harp

September 2016

Idaho National Laboratory

INL ART TDO Program

Idaho Falls, Idaho 83415

http://www.inl.gov

Prepared for the

U.S. Department of Energy

Office of Nuclear Energy

Under DOE Idaho Operations Office

Contract DE-AC07-05ID14517 

INL ART TDO Program

\title{
AGR-3/4 Irradiation Test Train Disassembly and Component Metrology First Look Report
}

\author{
INL/EXT-16-38005 \\ Revision 1 \\ September 2016
}

Prepared by:
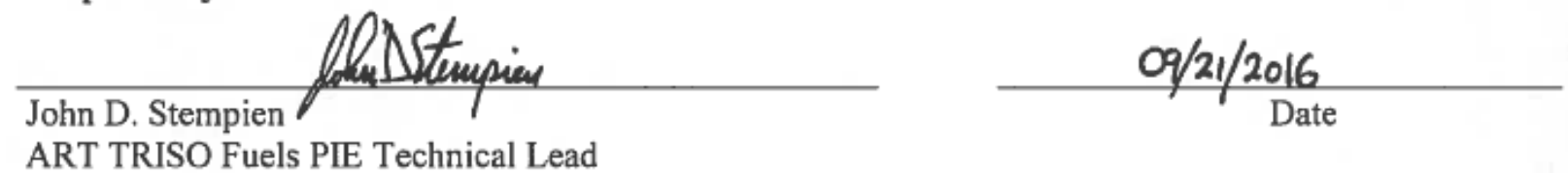

ART TRISO Fuels PIE Technical Lead

Reviewed by:

John T. Maki

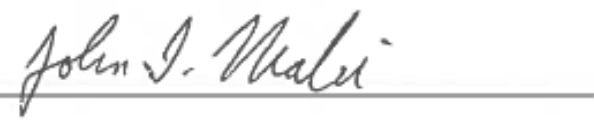

ART TRISO Fuel Performance Technical Lead

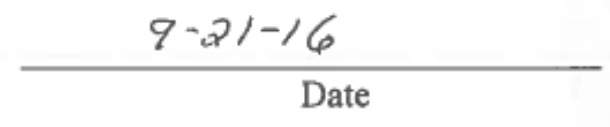

Approved by:

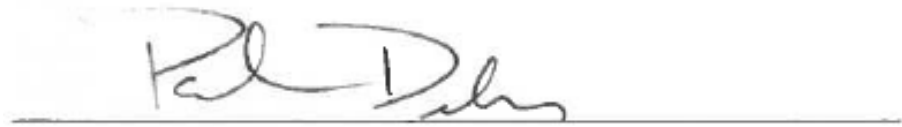

Paul A. Demkowicz

ART TRISO Fuels Director/Lead

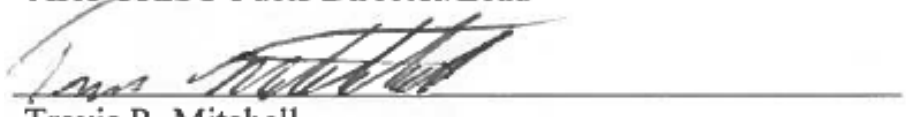

Travis R. Mitchell

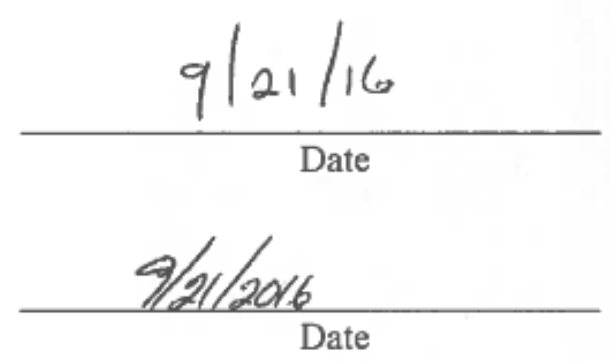

Relationship Manager, ART TDO Fuels
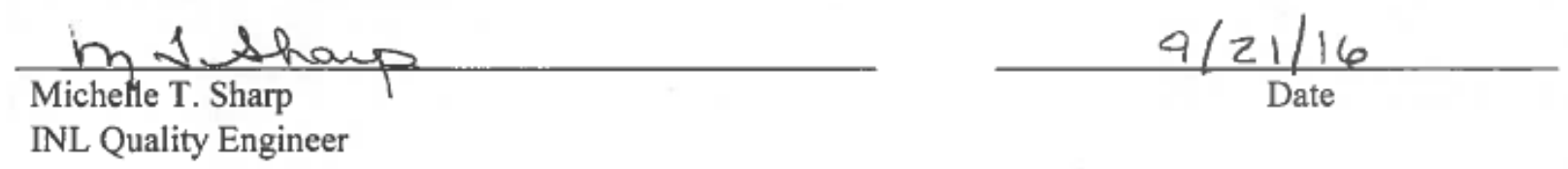



\section{SUMMARY}

The Advanced Gas Reactor (AGR)-3/4 experiment was designed to study fission product transport within graphitic matrix material and nuclear-grade graphite. To this end, this experiment consisted of 12 capsules, each fueled with 4 compacts containing uranium oxycarbide (UCO) tri-structural isotropic (TRISO)-coated particles as driver fuel and 20 UCO designed-to-fail (DTF) fuel particles in each compact. The DTF fuel was fabricated with a thin pyrocarbon layer that was intended to fail during irradiation and provide a known source of fission products. These fission products could then migrate through the compact and into the surrounding concentric rings of graphitic matrix material and/or nuclear-grade graphite. Through post-irradiation examination (PIE) of the rings (including physical sampling and gamma scanning) fission product concentration profiles within the rings can be determined. These data can be used to elucidate fission product transport parameters (e.g., diffusion coefficients within the test materials) which will be used to inform and refine models of fission product transport.

After irradiation in the Advanced Test Reactor (ATR) had been completed in April 2014, the AGR-3/4 experiment was shipped to the Hot Fuel Examination Facility (HFEF) at the Materials and Fuels Complex (MFC) for inspection, disassembly, and metrology. The AGR-3/4 test train was received at MFC in two separate shipments between February and April 2015. Visual examinations of the test train exterior did not indicate dimensional distortion, and only two small discolored areas were observed at the bottom of Capsules 8 and 9. Despite slight external discoloration, no corresponding discoloration was found on the inside of these capsules. Prior to disassembly, the two test train sections were subject to analysis via the Precision Gamma Scanner (PGS), which did not indicate that any gross fuel relocation had occurred.

A series of specialized tools, including clamps, cutters, and drills, had been designed and fabricated to carry out test train disassembly and recovery of capsule components (graphite rings and fuel compacts). This equipment performed well for separating each capsule in the test train and extracting the capsule components. Only a few problems were encountered. In one case, the outermost ring (the sink ring) was cracked during removal of the capsule through tubes. Although the sink ring will be analyzed to obtain a mass-balance of fission products in the experiment, these cracks do not pose a major concern because the sink ring will not be analyzed for its fission product spatial distribution. In Capsules 4 and 5, the compacts could not be removed from the inner rings using standard methods. An arbor press was modified and used to successfully remove the compacts from the inner rings without damaging the rings.

Dimensional measurements were made on the compacts, inner rings, outer rings, and sink rings. The diameters of all compacts decreased by 0.5 to $2.0 \%$. Generally, the extent of compact diametric shrinkage increased with increasing neutron fluence until exhibiting a turn-around at fluences above about $4.2 \times 10^{25} \mathrm{n} / \mathrm{m}^{2}$. Most compact lengths also decreased. Compact lengths decreased with increasing fluence, reaching maximum shrinkage of about $0.9 \%$ at a fast fluence of $4.0 \times 10^{25} \mathrm{n} / \mathrm{m}^{2}(\mathrm{E}>0.18 \mathrm{MeV})$. Above this fluence, the extent of length reduction appeared to turn around and decrease as fluence increased. Most compacts from Capsules 4 and 5 and two compacts from Capsule 7 had length increases between $0.1 \%$ and $0.5 \%$ after a fluence of $4.8 \times 10^{25} \mathrm{n} / \mathrm{m}^{2}$.

The inner rings exhibited a decrease in the outer diameter (OD) and an increase in the inner diameter (ID) with increasing fluence. This indicates that the ring wall thickness decreased with fluence. A nearzero change was observed for the lowest-fluence capsules (Capsules 1 and 12 at a fluence of approximately $\left.1.5 \times 10^{25} \mathrm{n} / \mathrm{m}^{2}\right)$. For Capsule 7 , the highest fast fluence capsule $\left(5 \times 10^{25} \mathrm{n} / \mathrm{m}^{2}\right)$, the ID increased by $2.3 \%$, and the OD decreased by $2.8 \%$. A subtle turn-around in the direction of the dimensional change may exist, beginning at a fluence of $4.8 \times 10^{25} \mathrm{n} / \mathrm{m}^{2}$. 
The outer rings exhibited the same trend in diametric change as the inner rings in that the IDs increased and the ODs decreased; however, a turn-around in the dimensional change appears to occur at a fast fluence of $4.0 \times 10^{25} \mathrm{n} / \mathrm{m}^{2}$. This is the same fluence at which an apparent turn-around occurred in the compact lengths. The extent of ID increase and OD decrease increases with increasing fluence up to $4.0 \times 10^{25} \mathrm{n} / \mathrm{m}^{2}$. Above this fluence, the extent of diametric change decreases with increasing fluence.

Generally, the sink rings exhibited shrinkage of both the IDs and ODs with the IDs shrinking more than the ODs. The extent of OD shrinkage increased with fluence. Two exceptions were noted. In Capsules 1 and 3, the IDs were measured to have increased while the ODs decreased. Oddly, the extent of ID shrinkage decreased with increasing fluence. This indicates unusually rapid ID shrinkage at low fluences.

Revision 0 of the thermal model used to calculate temperatures in the experiment assumed that the IDs and ODs of the inner, outer, and sink rings would all decrease with fluence. This is not what was observed for the inner and outer rings. While both the IDs and ODs of the sink rings decreased in most cases, the rapid shrinkage of the IDs was not expected. The information obtained from metrology has been used to update the thermal calculations and issue Revision 1 to ECAR-2807, "AGR-3/4 Daily As-Run Thermal Analyses." 


\section{ACKNOWLEDGEMENTS}

The authors wish to extend their appreciation to Process Engineers Cad Christensen and Katelyn Wachs, Technicians Nick Ingle and Jake Maupin, and Mechanical Technician Tom Morgan at the Idaho National Laboratory's

Materials and Fuels Complex. Their competence, cooperation, care, and patience were indispensable in completing the post-irradiation examinations described in this report. 


\section{CONTENTS}

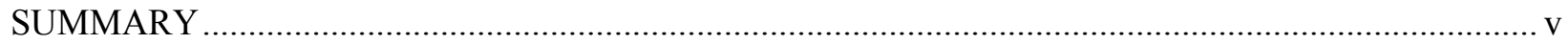

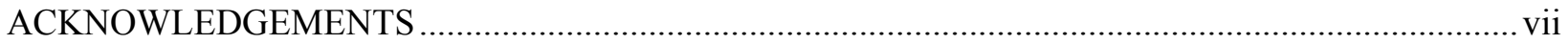

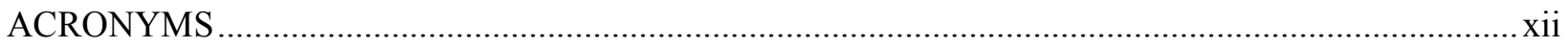

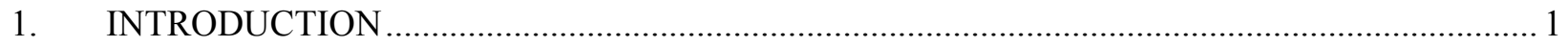

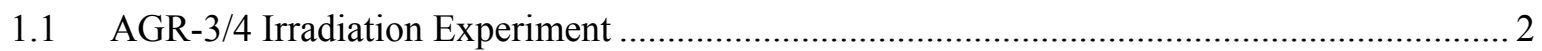

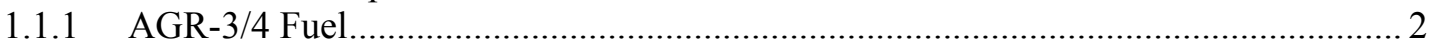

1.1.2 AGR-3/4 Capsule Types and Ring Materials....................................................... 3

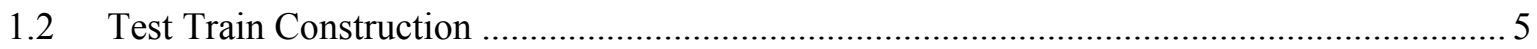

1.3 As-Run Neutron Fluence Data and Irradiation Temperatures ............................................. 6

2. RECEIPT AND INSPECTION OF AGR-3/4 TEST TRAIN AT MFC ......................................... 7

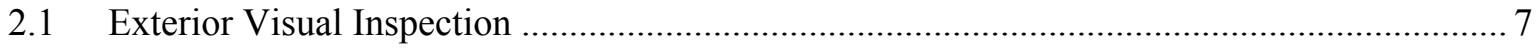

2.2 Gamma Scanning Results Prior to Test Train Disassembly .............................................. 9

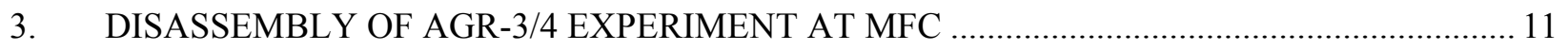

3.1 Test Train Disassembly: Procedures and Observations ................................................... 11

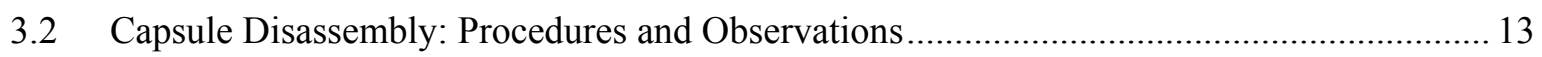

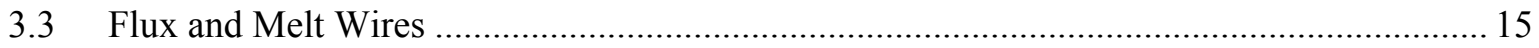

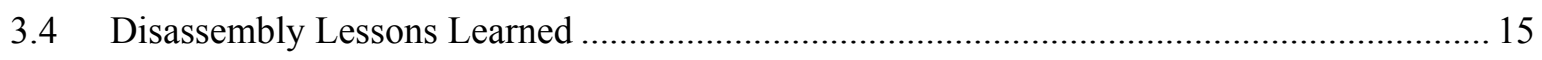

4. VISUAL INSPECTION AND NOTES FROM CAPSULE DISASSEMBLY ............................. 16

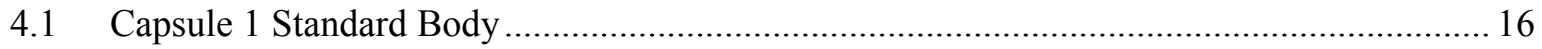

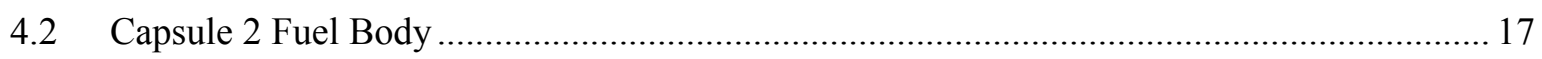

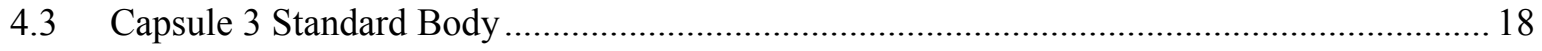

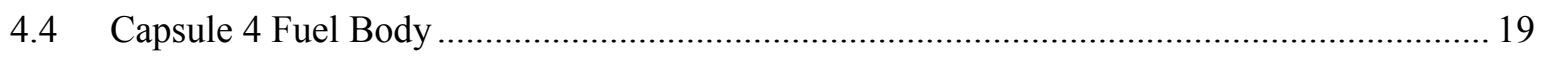

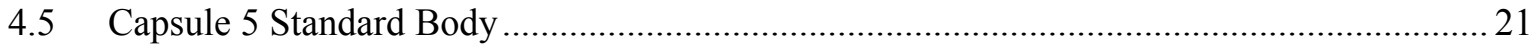

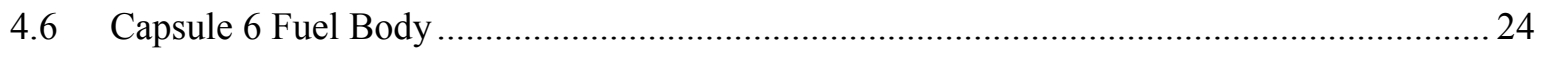

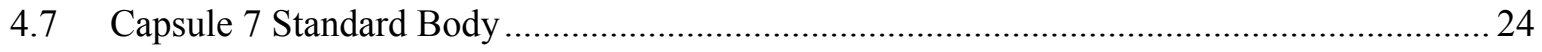

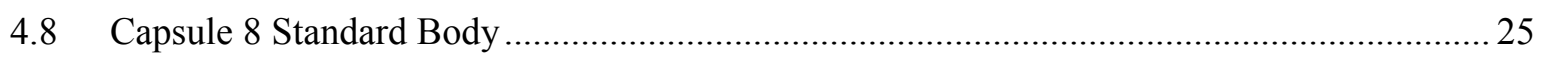

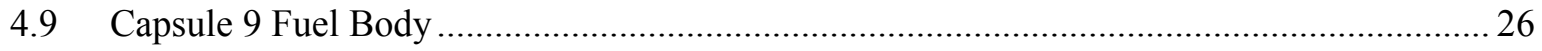

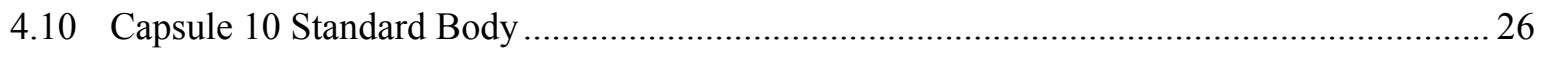

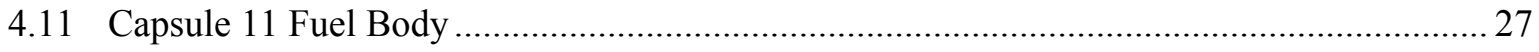

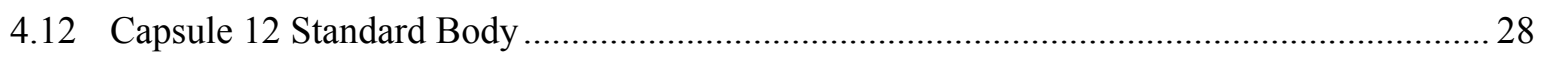

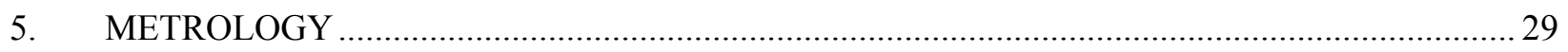

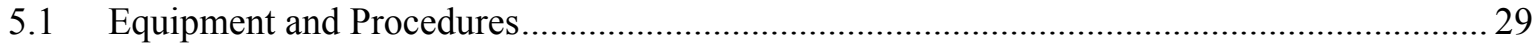

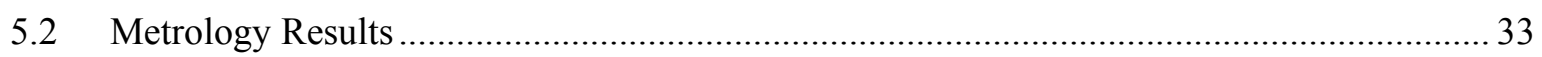

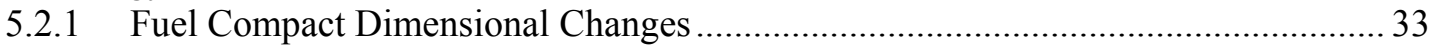

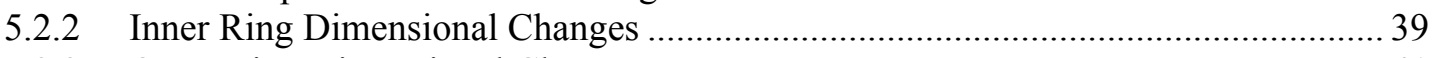

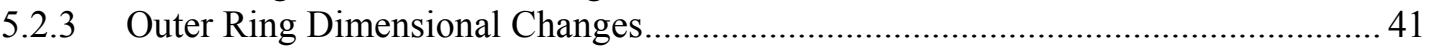




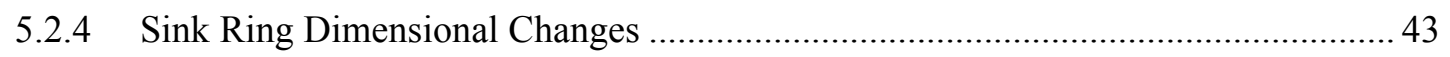

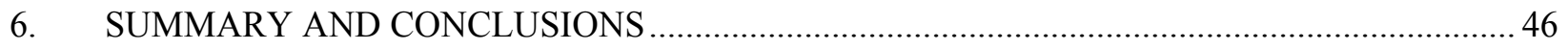

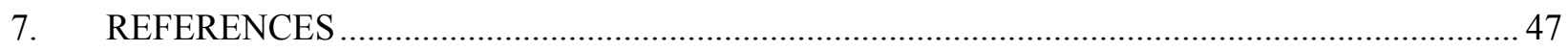

\section{FIGURES}

Figure 1. Axial schematic of AGR-3/4 test train of 12 capsules and axial cross-section of capsules. 3

Figure 2. Radial and axial cross section of an AGR-3/4 capsule.. 4

Figure 3. AGR-3/4 fuel compact (left) and x-ray side-view image (right) (Hunn et al. 2011). DTF particles are highlighted with red dots in the x-ray image. 4

Figure 4. Calculated fast fluence and TAVA temperature for each of the four compacts in each capsule. ... 6

Figure 5. TAVA temperature versus fast fluence for each of the four compacts in each capsule............... 7

Figure 6. Bottom of AGR-3/4 test train (top). Entire section A of AGR-3/4 test train (bottom)................ 7

Figure 7. Typical capsule-to-capsule weld on the AGR-3/4 test train.................................................... 8

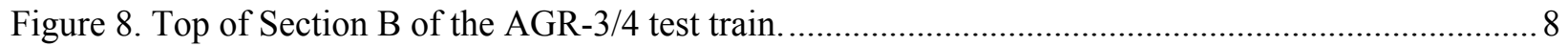

Figure 9. Discoloration at the bottom of Capsule 8 (left) and the bottom of Capsule 9 (right)................. 9

Figure 10. AGR-3/4 test train gamma scans of first section (Capsules 6 to 1 from left to right).............. 10

Figure 11. AGR-3/4 test train gamma scans of second section (Capsules 12 to 7 from left to right).

Figure 12. Pipe cutter showing a capsule lid cut with thermocouples and gas lines protruding to the left. Only one cutter is shown. 12

Figure 13. Disassembly table base with pipe cutter, clamps, and drill press......................................... 13

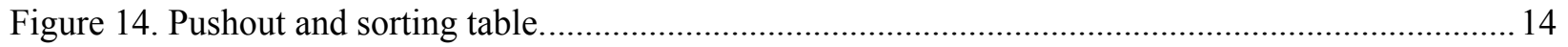

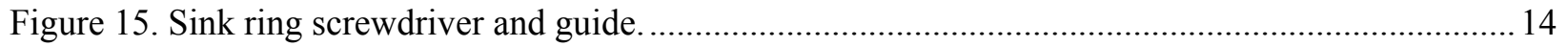

Figure 16. Sink ring being pushed out of Capsule 1 shell. ................................................................... 16

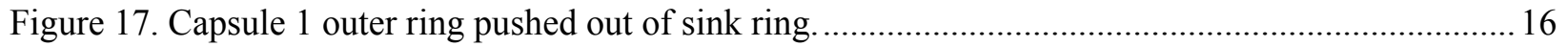

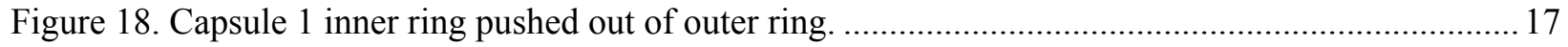

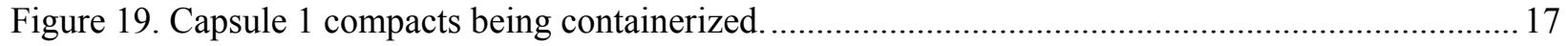

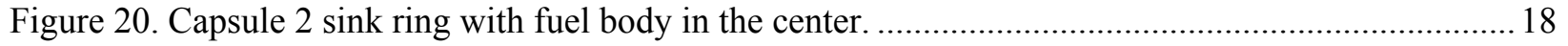

Figure 21. Capsule 3 compacts with damage visible in the right-most compact (Compact 3-4)............... 18

Figure 22. Three compacts from Capsule 3. Compact 3-4 fractured during removal. Fractured corner piece held by tweezers. 19

Figure 23. Arbor press used to push compacts out of the inner rings from Capsules 4 and 5 . 20 
Figure 24. Compact 4-1 fractured during pushout from the inner ring using the apparatus in Figure 23.

Figure 25. Capsule 5 lid being separated from capsule body. .............................................................. 21

Figure 26. End of Capsule 5 with burr that prevented sink ring removal with capsule lid.......................22

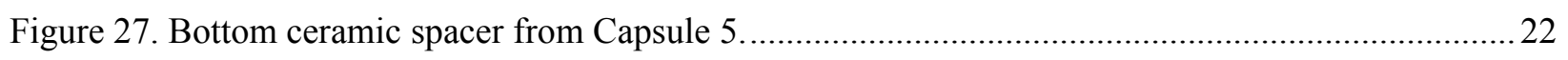

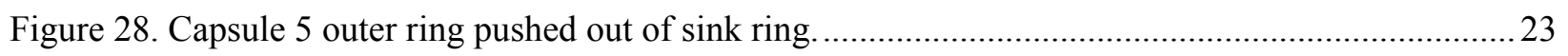

Figure 29. Attempting to push out Capsule 5 compacts on pushout and sorting table (Figure 14)........... 23

Figure 30. Compact 5-4 shown partially removed from Capsule 5 inner ring.........................................2 24

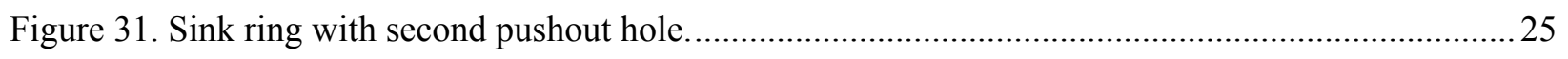

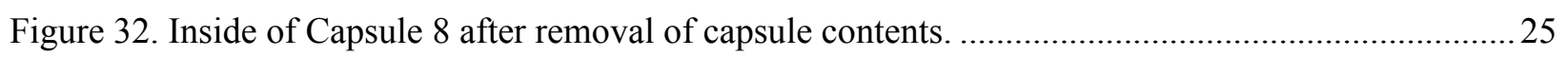

Figure 33. Inside of Capsule 9 shell containing fragment of broken spacer. ...........................................26

Figure 34. Manual removal of compacts from Capsule 10 ..................................................................26

Figure 35. Capsule 10 inner ring showing blackening of ends...........................................................2 27

Figure 36. Cutting through tubes to separate sink ring from capsule lid. ...............................................2

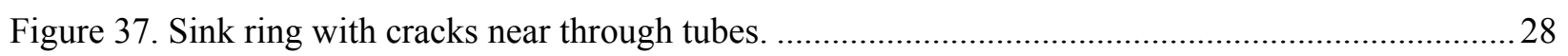

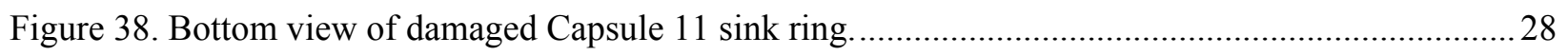

Figure 39. Capsule 12 sink ring (left) with stuck through tube and outer ring (right)...........................29

Figure 40. Diagram showing compact measurement locations. ............................................................ 31

Figure 41. Ring inner and outer diameter measurement locations. Each location is at approximately the same axial elevation as the center of each compact.................................... 31

Figure 42. AGR-1 compact metrology system used for AGR-3/4 compacts............................................ 32

Figure 43. Outer diameter metrology system used for inner, outer, and sink rings................................. 32

Figure 44. Inner diameter bore gauge metrology system used for inner, outer, and sink rings................. 33

Figure 45. Relative change in compact diameter by compact and capsule. Error bars shows

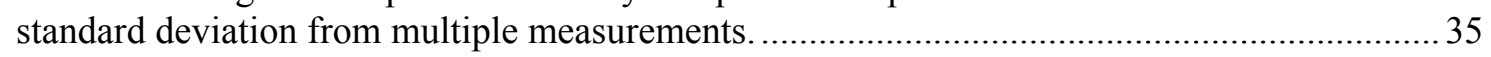

Figure 46. Relative change in compact length by compact and capsule................................................. 35

Figure 47. Compact length change versus compact diameter change....................................................... 36

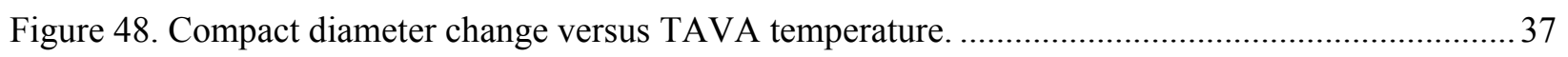

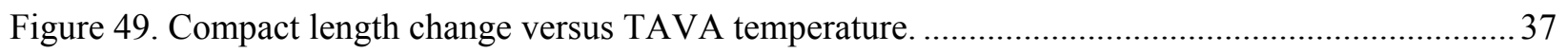

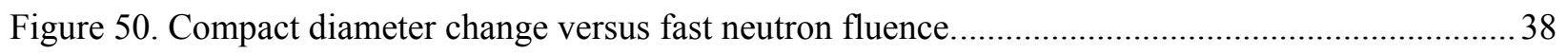

Figure 51. Compact length change as a function of fast neutron fluence. ................................................ 38

Figure 52. Percent change in the inner (ID) and outer (OD) diameters of the inner rings........................ 39

Figure 53. Percent change in inner ring dimensions as a function of inner ring irradiation temperature. Temperatures from ECAR-2807 Rev. 1 (Hawkes 2016).................................... 40

Figure 54. Possible orientation of compacts within Capsules 4 and 5 inner rings................................... 41

Figure 55. Percent change for the inner (ID) and outer (OD) diameters of the outer rings...................... 42 
Figure 56. Outer ring dimensional changes as a function of TAVA irradiation temperature.

Temperatures from ECAR-2807 Rev. 1 (Hawkes 2016). 42

Figure 57. Percent change in the inner (ID) and outer (OD) diameters of the sink rings.

Figure 58. Percent change in sink ring diameters as a function of TAVA irradiation temperature.

Temperatures from ECAR-2807 Rev. 1 (Hawkes 2016).

\section{TABLES}

Table 1. AGR-3/4 capsule type, ring material and thickness, and INL drawing numbers......................... 5

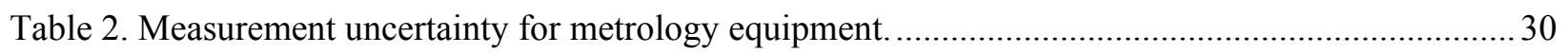

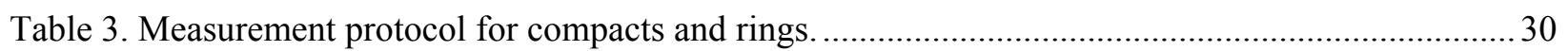

Table 4. Dimensional changes and standard deviations for all AGR-3/4 compacts measured...................34

Table 5. Summary of inner ring inner diameter (ID) and outer diameter (OD) dimensions before and after irradiation.

Table 6. Summary of outer ring inner diameter (ID) and outer diameter (OD) dimensions before and after irradiation.

Table 7. Summary of sink ring inner diameter (ID) and outer diameter (OD) dimensions before and after irradiation. 


\section{ACRONYMS}

AGR Advanced Gas Reactor

ART Advanced Reactor Technologies

ATR Advanced Test Reactor

BWXT BWX Technologies

DTF designed-to-fail

FGMS fission gas monitoring system

FIMA fissions per initial heavy metal atom

HFEF Hot Fuel Examination Facility

HTGR high temperature gas-cooled reactor

ID inner diameter

INL Idaho National Laboratory

IPyC inner pyrolytic carbon

MFC Materials and Fuels Complex

OD outer diameter

OPyC outer pyrolytic carbon

PGS precision gamma scanner

PIE post-irradiation examination

$\mathrm{SiC} \quad$ silicon carbide

TAVA time-average volume-average

TC thermocouple

TDO Technology Development Office

TRISO tristructural isotropic

UCO uranium oxycarbide 


\section{AGR-3/4 Irradiation Test Train Disassembly and Component Metrology First Look Report 1. INTRODUCTION}

The Advanced Gas Reactor (AGR) Fuel Development and Qualification Program was established to perform the requisite research and development on tristructural isotropic (TRISO) coated particle fuel to support deployment of a high temperature gas-cooled reactor (HTGR) (Petti et al. 2010). The work continues as part of the Advanced Reactor Technologies (ART) TRISO Fuel Program. The overarching program goal is to provide a baseline fuel qualification data set to support licensing and operation of an HTGR. To achieve these goals, the program includes the elements of fuel fabrication, irradiation, postirradiation examination (PIE) and safety testing, fuel performance, and fission product transport (INL 2015c).

A series of fuel irradiation experiments has been planned and completed in the Advanced Test Reactor (ATR) at the Idaho National Laboratory (INL). Additional experiments are being planned or are in various stages of PIE. These experiments will provide data on fuel performance under irradiation, support fuel fabrication process development, qualify the fuel for normal operating conditions, provide irradiated fuel for safety testing, and support the development of fuel performance and fission product transport models.

The first of these tests, designated AGR-1, began irradiation in the ATR in December 2006 and ended in November 2009. This experiment was conducted primarily to act as a shakedown test of the multicapsule test train design and provide early data on fuel performance for use in fuel fabrication process development. The AGR-1 uranium oxycarbide (a mixture of uranium carbide and uranium oxide referred to as UCO) TRISO-coated particles were fabricated using a 2-in. laboratory scale coater. The AGR-1 test train included six independent capsules containing fuel compacts made from baseline fuel fabrication parameters and three variants of the parameters. It also provided samples for post-irradiation safety testing so that fission product retention in the fuel at high temperatures could be experimentally measured.

The second experiment, AGR-2, began irradiation in June 2010 and ended on October 16, 2013. The AGR-2 irradiation experiment was designed to provide fuel performance data for coated particles fabricated on an engineering-scale pilot line using a 150-mm (6-in.) diameter coater. The AGR-2 test train included six independent capsules containing fuel compacts made from particles with kernels of either $\mathrm{UCO}$ or uranium oxide (UO2).

AGR-3/4 combined the third and fourth experiments in the AGR series to test TRISO-coated lowenriched uranium oxycarbide fuel. This experiment was intended to support the refinement of fission product transport models and to assess the effects of sweep gas impurities on fuel performance and fission product transport (Collin 2015a, Collin 2015b). The experiment featured fuel compacts loaded with TRISO-coated particles having UCO kernel diameters similar to those in AGR-1 and TRISO coating thicknesses similar to those in AGR-2. A known quantity of designed-to-fail (DTF) fuel particles was also included in each compact. These compacts were placed at the center of concentric rings of fuel-compact graphitic matrix material and nuclear-grade (fuel-element) graphite. Upon failure of the DTF fuel particles, fission products were released, and migrated into the surrounding rings. The fission product distribution within the rings is currently being measured with gamma scanning and will be compared to fission product concentrations determined from future physical sampling of the ring material. These data can then be used to determine the diffusion coefficients and other transport parameters for the fission products within graphitic matrix and nuclear-grade graphite. 
AGR-3/4 fuel compacts were irradiated to the targeted burnup and fast fluence ranges, despite termination of the experiment slightly before its initial target of 400 effective full power days (Collin 2015a, Collin 2015b). Out of 48 AGR-3/4 compacts, 42 achieved the specified burnup of at least $6 \%$ fissions per initial heavy metal atom (FIMA). Three capsules had a maximum fuel compact average burnup of less than 10\% FIMA, and one capsule had a higher burnup than originally specified. The maximum fuel compact average burnup was less than 19\% FIMA for the remaining capsules, as specified. Fast neutron fluence fell in the expected range of 1.0 to $5.5 \times 1025 \mathrm{n} / \mathrm{m}^{2}(\mathrm{E}>0.18 \mathrm{MeV})$ for all compacts (Collin 2015a).

\subsection{AGR-3/4 Irradiation Experiment}

\subsubsection{AGR-3/4 Fuel}

Goals of the AGR-3/4 experiment are to observe fission product transport in HTGR materials and to determine relevant fission product transport parameters (e.g., diffusion coefficients). The fuel used in AGR-3/4 functioned as driver fuel and a source of fission products. Typical AGR-specification TRISO-coated particles were used for the driver fuel, but DTF particles were also incorporated into the fuel compacts to provide a known source of fission products for the experiment.

As shown in the axial and radial schematics (Figure 1 and Figure 2, respectively), four fuel compacts were stacked vertically in the center of each of the 12 individual capsules in the AGR-3/4 test train. Fuel compacts are numbered in the $X-Y$ format where $X$ is the capsule number and $Y$ is the level of the compact within Capsule $X$. Within each capsule, compacts are numbered from bottom to top such that the compact at Level 1 is at the bottom of the capsule, and the compact at Level 4 is at the top of the capsule fuel stack.

The AGR-3/4 TRISO-coated particles contained low-enriched (U-235 enrichment was 19.7\%) UCO kernels. These kernels, approximately $350 \mu \mathrm{m}$ in diameter, were manufactured at BWX Technologies (formerly Babcock \& Wilcox Nuclear Operations Group - Lynchburg, VA). Driver fuel particles were fabricated by applying TRISO coatings to the kernels, with the following average thicknesses for each layer:

- $\quad$ Buffer: $109.7 \mu \mathrm{m}$

- Inner pyrolytic carbon (IPyC): $40.4 \mu \mathrm{m}$

- Silicon carbide (SiC): $33.5 \mu \mathrm{m}$

- Outer pyrolytic carbon (OPyC): $41.3 \mu \mathrm{m}$.

The DTF particles were fabricated by applying a single $20-\mu \mathrm{m}$-thick pyrolytic carbon coating to the kernels. This layer was intentionally fabricated with a high anisotropy such that it would be likely to fail during the irradiation (Collin 2015b).

The AGR-3/4 fuel compacts were fabricated at Oak Ridge National Laboratory. The compacts are nominally $12.3 \mathrm{~mm}$ in diameter and $12.5 \mathrm{~mm}$ long (in contrast to the AGR-1 and AGR-2 compacts, which were approximately $25 \mathrm{~mm}$ long). Figure 3 shows an AGR-3/4 compact. Each compact contains approximately 1872 driver fuel particles and precisely $20 \mathrm{DTF}$ particles. The DTF particles were aligned in each compact roughly along the compact axial centerline (Figure 3). The DTF particles tended to slump toward the bottom of the compact during fabrication, leaving roughly the top quarter of the compact without DTF particles. 


\subsubsection{AGR-3/4 Capsule Types and Ring Materials}

Figure 1 and Figure 2 show that an "inner ring" surrounds the central fuel stack in each capsule. Earlier drawings and documents labeled this ring as the "matrix" ring; however, several of these inner rings were made of nuclear-grade graphite (PCEA or IG-110) rather than graphitic matrix material. Therefore, this ring is simply referred to as the "inner ring." The graphitic matrix material used in the inner rings was made at Oak Ridge National Laboratory using the same graphite/resin composition that will be used to fabricate the AGR-5/6/7 compacts. The function of the inner ring was to allow adsorption and diffusion of metallic fission products released from the DTF particles. During PIE, these rings will be analyzed to determine the fission product distribution in the rings and determine a diffusion coefficient for the fission products within that ring material. Surrounding the inner ring is the outer ring that was made from nuclear-grade graphite (PCEA or IG-110). Fission products which transport through the inner ring will encounter the outer ring which can also be analyzed for relevant transport parameters during PIE. Post-irradiation heating may also be used in order to determine the extent of fission product migration in the inner and outer rings at temperatures exceeding the irradiation temperatures. Surrounding the outer ring is the sink ring, made from nuclear-grade graphite (PCEA), which was kept at much cooler temperatures in order to act as a sink to prevent further radial diffusion of fission products. Table 1 summarizes the inner and outer ring materials and thicknesses. Gas gaps between rings were used to control the temperatures in the experiment. This accounts for the different ring wall thicknesses.

Two types of capsule configurations were used: (1) A "standard capsule" (shown in Figure 2), in which the rings were open on the top and bottom ends, and (2) a "fuel body" in which the outer ring itself acts as a capsule (with a floor and a cap) in order to contain the compacts and inner ring within the fuel body. After irradiation, a fission product migration experiment could be performed by heating a fuel body in a furnace as a single piece. Table 1 denotes the standard and fuel body capsules.

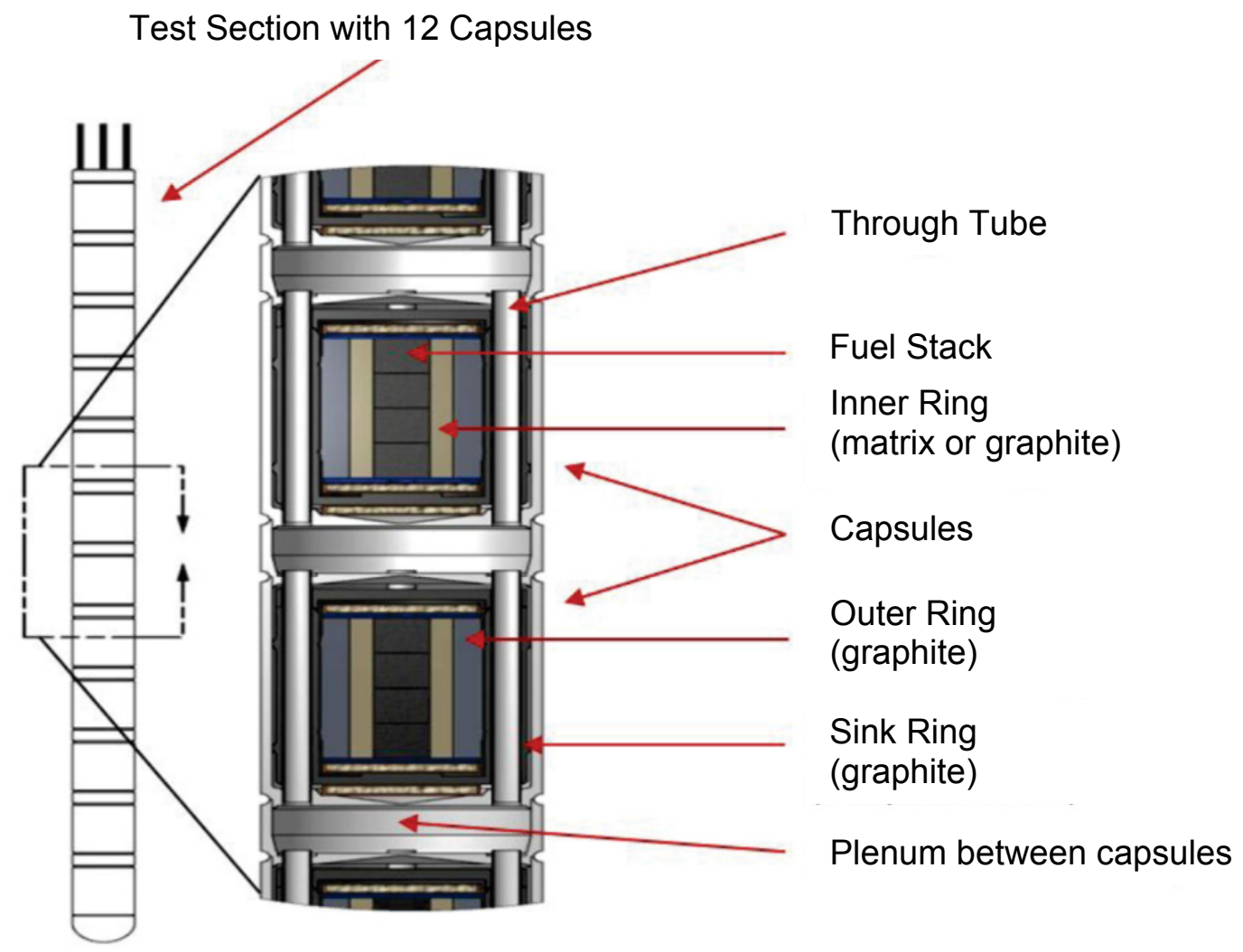

Figure 1. Axial schematic of AGR-3/4 test train of 12 capsules and axial cross-section of capsules. 


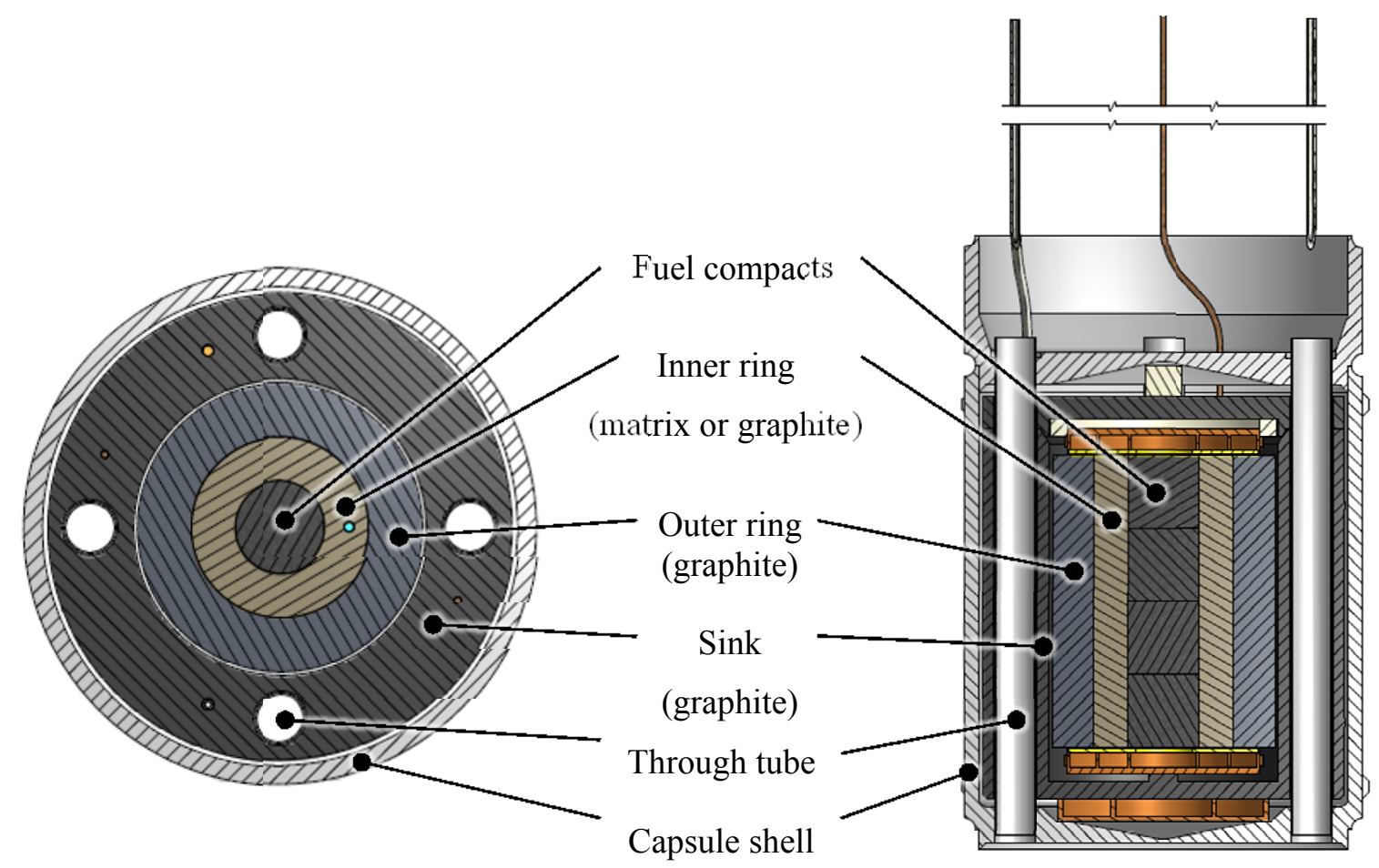

Figure 2. Radial and axial cross section of an AGR-3/4 capsule.
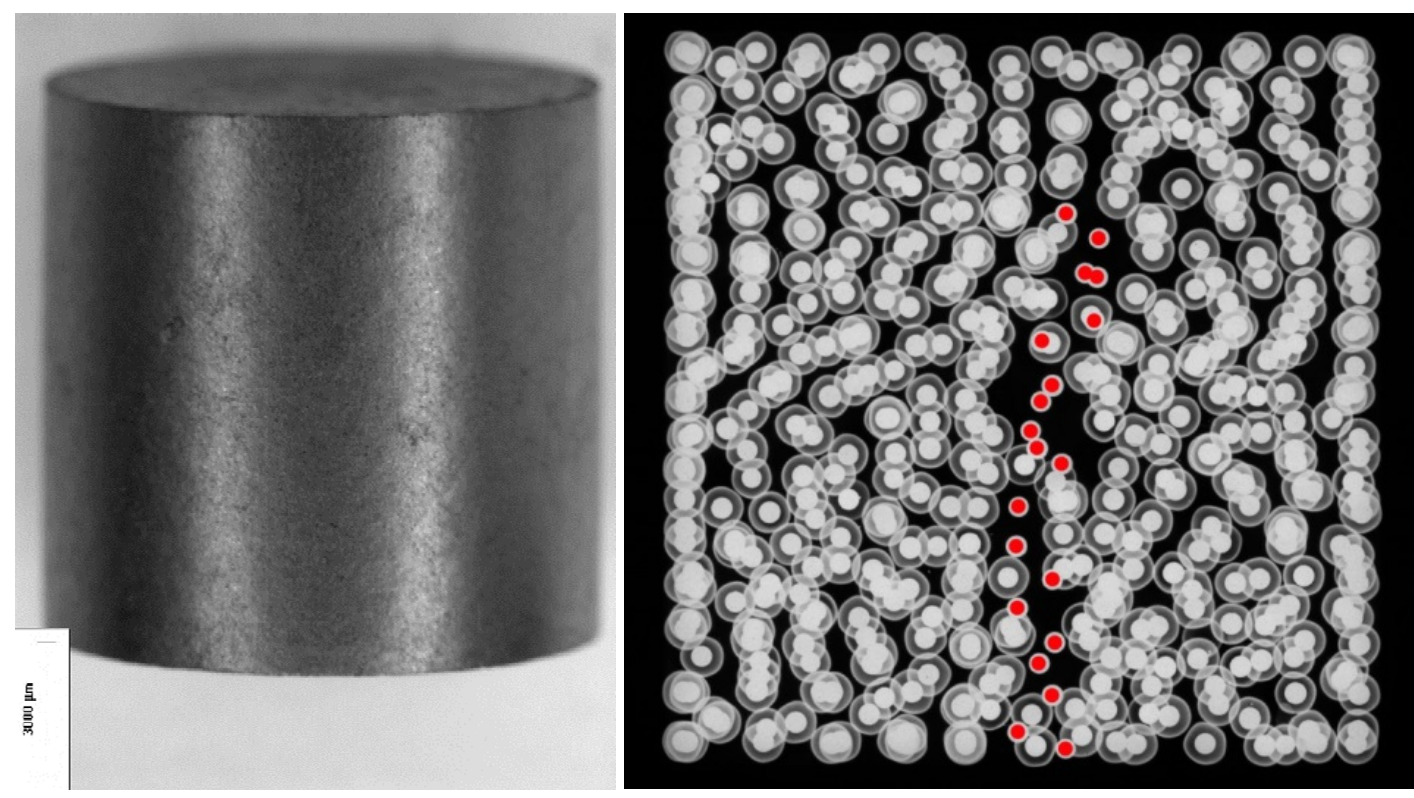

Figure 3. AGR-3/4 fuel compact (left) and x-ray side-view image (right) (Hunn et al. 2011). DTF particles are highlighted with red dots in the x-ray image. 
Table 1. AGR-3/4 capsule type, ring material and thickness, and INL drawing numbers.

\begin{tabular}{|c|c|c|c|c|c|c|}
\hline \multirow[b]{2}{*}{ Capsule } & \multirow[b]{2}{*}{ Type } & \multicolumn{2}{|c|}{ Material } & \multicolumn{2}{|c|}{$\begin{array}{l}\text { Thickness } \\
(\mathrm{mm})\end{array}$} & \multirow[b]{2}{*}{ Drawing No. } \\
\hline & & Inner Ring & Outer Ring & Inner Ring $^{\mathrm{a}}$ & Outer Ring & \\
\hline 12 & Standard & Matrix & PCEA & 5.96 & 5.22 & DWG-602712 (INL 20111) \\
\hline 11 & Fuel body & Matrix & PCEA & 5.02 & 4.50 & DWG-602711 (INL 2011k) \\
\hline 10 & Standard & PCEA & PCEA & 5.96 & 6.73 & DWG-602710 (INL 2011j) \\
\hline 9 & Fuel body & Matrix & IG-110 & 5.96 & 7.49 & DWG-602709 (INL 2011i) \\
\hline 8 & Standard & IG-110 & IG-110 & 5.96 & 7.23 & DWG-602708 (INL 2011h) \\
\hline 7 & Standard & Matrix & PCEA & 5.96 & 6.72 & DWG-602707 (INL 2011g) \\
\hline 6 & Fuel body & Matrix & PCEA & 5.96 & 7.56 & DWG-602706 (INL 2011f) \\
\hline 5 & Standard & Matrix & PCEA & 5.96 & 7.56 & DWG-602705 (INL 2011e) \\
\hline 4 & Fuel body & Matrix & PCEA & 5.96 & 7.49 & DWG-602704 (INL 2011d) \\
\hline 3 & Standard & PCEA & PCEA & 5.96 & 4.50 & DWG-602703 (INL 2011c) \\
\hline 2 & Fuel body & Matrix & PCEA & 5.96 & 6.22 & DWG-602702 (INL 2011b) \\
\hline 1 & Standard & Matrix & PCEA & 5.65 & 4.51 & DWG-602701 (INL 2011a) \\
\hline
\end{tabular}

\subsection{Test Train Construction}

The AGR-3/4 test train was designed for insertion in the northeast flux trap of the ATR. Unlike the Large B positions used for the AGR-1 and AGR-2 irradiations, the northeast flux trap minimizes the radial neutron flux gradient, provides a high neutron flux, and features a larger diameter (Collin 2015a).

Figure 1 shows the test train stack of 12 sample capsules containing different types of graphite. Capsules are numbered from the bottom up, where Capsule 1 is at the bottom and Capsule 12 is at the top. This test train contains gas lines for controlling the capsule temperature by varying the neon/helium ratio in the gas and sweeping fission gases to the fission gas monitoring system (FGMS) and thermocouples (TCs) for temperature measurements. The through tubes (shown in Figure 1 and Figure 2) were used for passing gas lines and TC leads to capsules throughout the test train. Type N TCs with Inconel 600 sheath material were used. Two TCs are located in the sink ring in each capsule. In addition, a single TC is located in the inner ring in three capsules (Capsules 5, 10, and 12). Each capsule had an independent gas supply, fission product monitoring, and temperature monitoring. Either zirconia or zirconium thermal insulators were placed at the top and bottom of each capsule. In addition, gas impurities were injected into the sweep gas mixture in Capsule 11 during several ATR cycles to assess the effect of impurities that may be found in the primary coolant circuit of an HTGR. ECAR-2457 (Scates 2015) details the gas impurity flow history in Capsule 11.

Neutron fluence monitors (flux wires) were also included in the test train. Each capsule contained three separate flux wires intended to measure the thermal and fast neutron fluences. Each wire was individually encapsulated in a small (1.27-mm outer diameter [OD], 0.79-mm inner diameter [ID]) vanadium tube. The wires used were (1) $\mathrm{V}+0.1 \% \mathrm{Co}$, (2) Fe, and (3) $\mathrm{Nb}$. These fluence wire packages ranged from about 5 to $9 \mathrm{~mm}$ in length, and were placed inside the graphite sink in each capsule (specific locations can be found in the capsule drawings). 
Melt wires were installed in each capsule in order to verify the peak temperatures achieved in each capsule. Several different types of melt wires were used, with each melt wire contained inside a small ( 1.25-mm OD) vanadium tube ranging from approximately 8 to $11 \mathrm{~mm}$ in length. Each capsule contained between 1 and 3 melt wire packages, selected based on the expected capsule temperatures and wire melting points. The melt wire packages were embedded in the inner ring (specific locations can be found in the capsule drawings). PLN-3867 (Collin 2015b) details the specific melt wire compositions used in each capsule.

\subsection{As-Run Neutron Fluence Data and Irradiation Temperatures}

INL/EXT-15-35550 (Collin 2015a) thoroughly describes the as-run experiment. Here, the fast fluence, from ECAR-2753 (Sterbentz 2015), and the time-average volume-average (TAVA) irradiation temperature, from ECAR-2807 Rev. 1 (Hawkes 2016), for each of the four compacts in each of the 12 capsules are summarized. This thermal analysis was updated based on the metrology data collected. These plots are included here in order to compare the axial temperature and flux profiles to the axial dimensional change profiles discussed in Section 4. Figure 4 shows the TAVA temperature and fast fluence for each compact in each capsule. The sine-shape of the axial fluence profile is clearly visible, but the axial variation in the TAVA temperature is flatter. Figure 5 shows that the TAVA temperature increases loosely with increasing fast fluence.

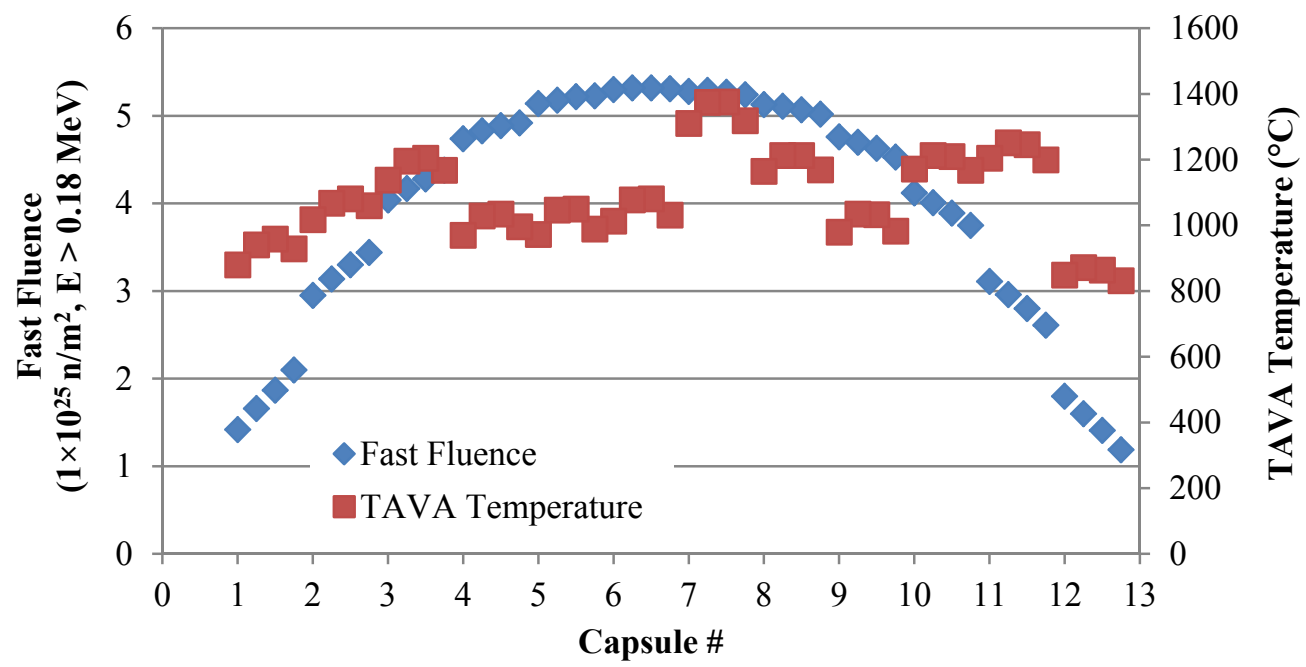

Figure 4. Calculated fast fluence and TAVA temperature for each of the four compacts in each capsule. 


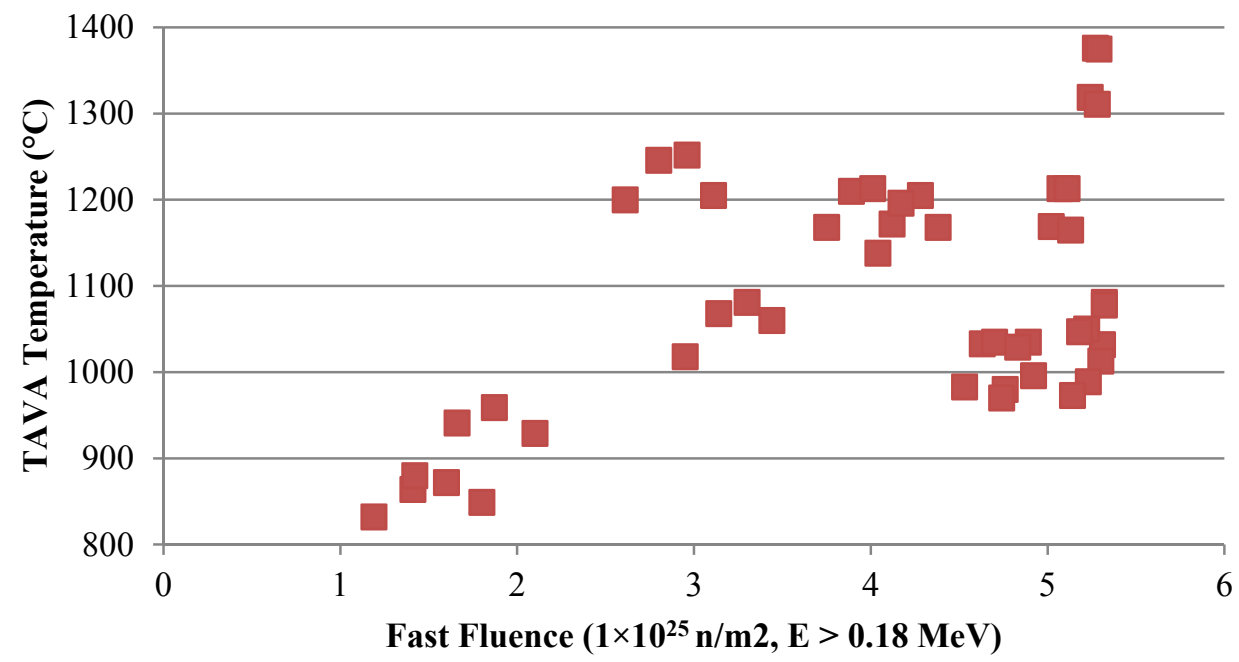

Figure 5. TAVA temperature versus fast fluence for each of the four compacts in each capsule.

\section{RECEIPT AND INSPECTION OF AGR-3/4 TEST TRAIN AT MFC}

The AGR-3/4 test train was cut into two sections for shipment from ATR to the Materials and Fuels Complex (MFC). Section A of the AGR-3/4 test train (containing Capsules 1 through 6) was received in the Hot Fuel Examination Facility (HFEF) main cell on February 25, 2015, and Section B (containing Capsules 7 through 12) was received on April 13, 2015.

\subsection{Exterior Visual Inspection}

Generally, visual examination showed negligible discoloration and no visible dimensional distortion. Figure 6 shows Section A (Capsules 1 through 6) of the AGR-3/4 test train. Typical capsule-to-capsule welds appeared as shown in the example in Figure 7. Figure 8 shows the top of Section B (Capsules 7 through 12) of the AGR-3/4 test train. Figure 9 shows the two discolored areas that were noted at the bottom of Capsules 8 and 9. Each of these discolorations appeared to center on one of the nubs. It was conjectured that these discolorations may have been due to a higher-than-normal temperature at these locations; however, no evidence exists to support this hypothesis. Visual examination of the contents of Capsules 8 and 9 did not exhibit any unusual coloring.
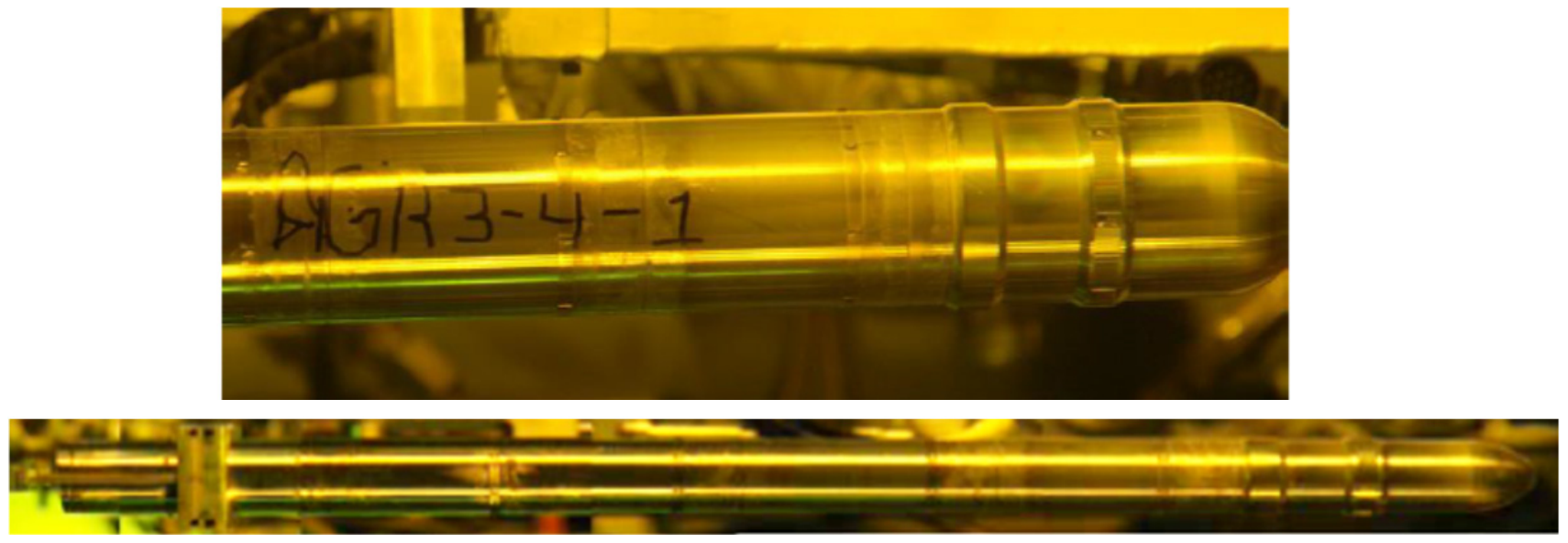

Figure 6. Bottom of AGR-3/4 test train (top). Entire section A of AGR-3/4 test train (bottom). 


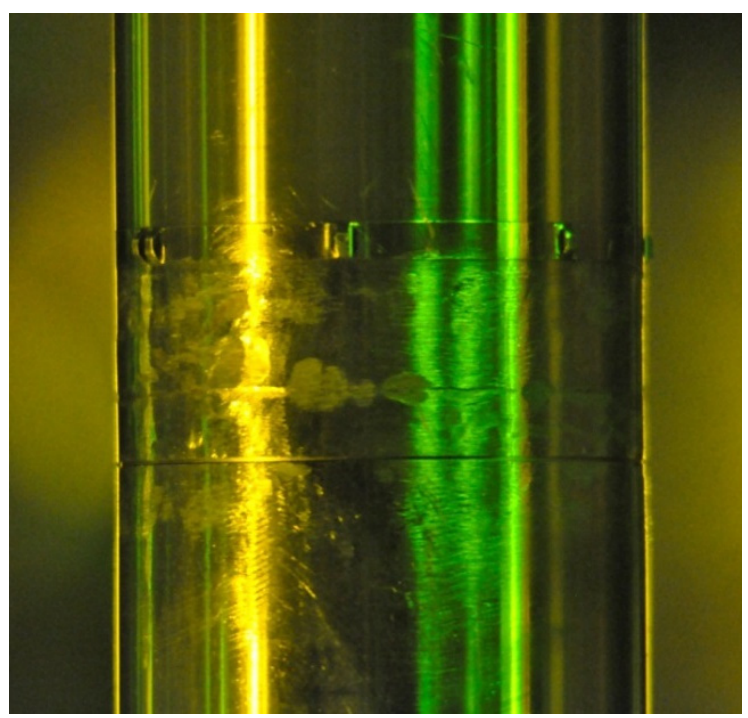

Figure 7. Typical capsule-to-capsule weld on the AGR-3/4 test train.

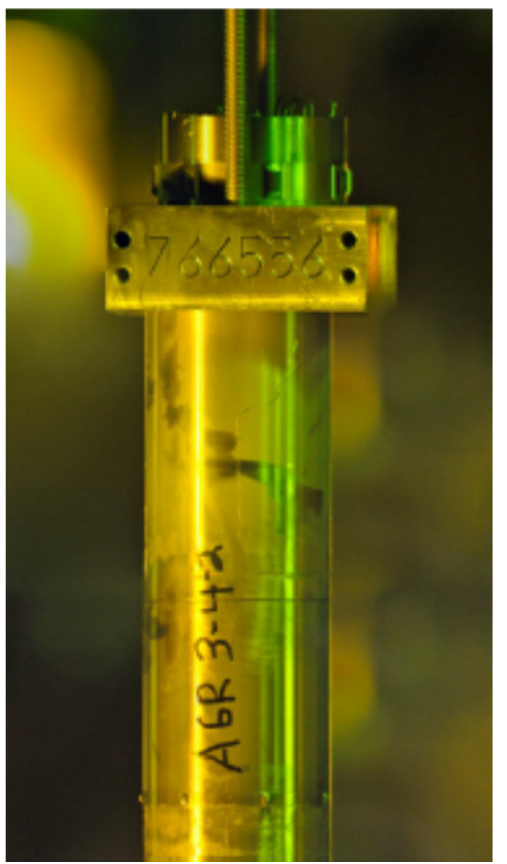

Figure 8. Top of Section B of the AGR-3/4 test train. 


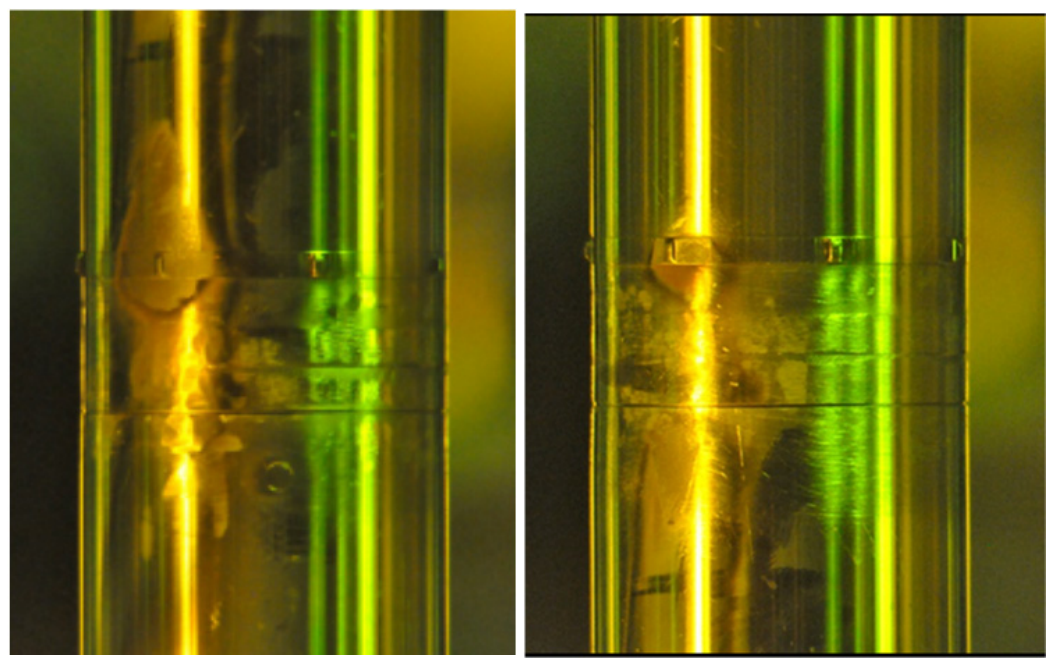

Figure 9. Discoloration at the bottom of Capsule 8 (left) and the bottom of Capsule 9 (right).

\subsection{Gamma Scanning Results Prior to Test Train Disassembly}

After visual inspection at HFEF, each section of the AGR-3/4 test train was gamma scanned using the HFEF Precision Gamma Scanner (PGS). The test train gamma scan was used to verify that the fuel had not shifted during irradiation and shipping. Detection of Co-60 was used to identify the location of the test train structural components, and detection of Cs-137 was used to identify the location of the fuel. The test train was scanned in $0.127 \mathrm{~cm}(0.050$ in.) steps and collimator heights at the centerline of the test train. The PGS collimator is $2.2225 \mathrm{~cm}$ ( 0.875 in.) wide. This allowed capture of all the compacts and a large portion of the test train in a single, vertical sweep along the test train. Additional sweeps were not necessary to fulfill the goal of the scans. Gamma scanning did not indicate that any gross fuel relocation had occurred.

Figure 10 shows the Co-60 and Cs- 137 net count rate for the first section of the AGR-3/4 test train (Section A), which was the lower portion of the test train (Capsules 6 to 1). The counts diminish with the axial variation in fluence as the test train was scanned from top to bottom (left to right in the Figure 10). There is an area of reduced counts near a PGS scan height of $75 \mathrm{~cm}$ that is caused by shielding from the clamping fixture used to suspend the test train in front of the PGS collimator. This area is outlined in black Figure 10.

For the second section of the AGR-3/4 test train (Section B), gamma scan results for the top six test train capsules (Capsules 12 to 7) are shown in Figure 11. Co-60 was used to identify the location of the structural components and Cs-137 was used to identify the location of the fuel. The test train was again scanned in $0.127-\mathrm{cm}(0.050-\mathrm{in}$.) steps and collimator widths along the centerline of the test train. There was no indication of gross fuel relocation in the test train gamma scan. Small drops in the Cs-137 intensity indicate scans where the collimator was positioned between two compacts. 


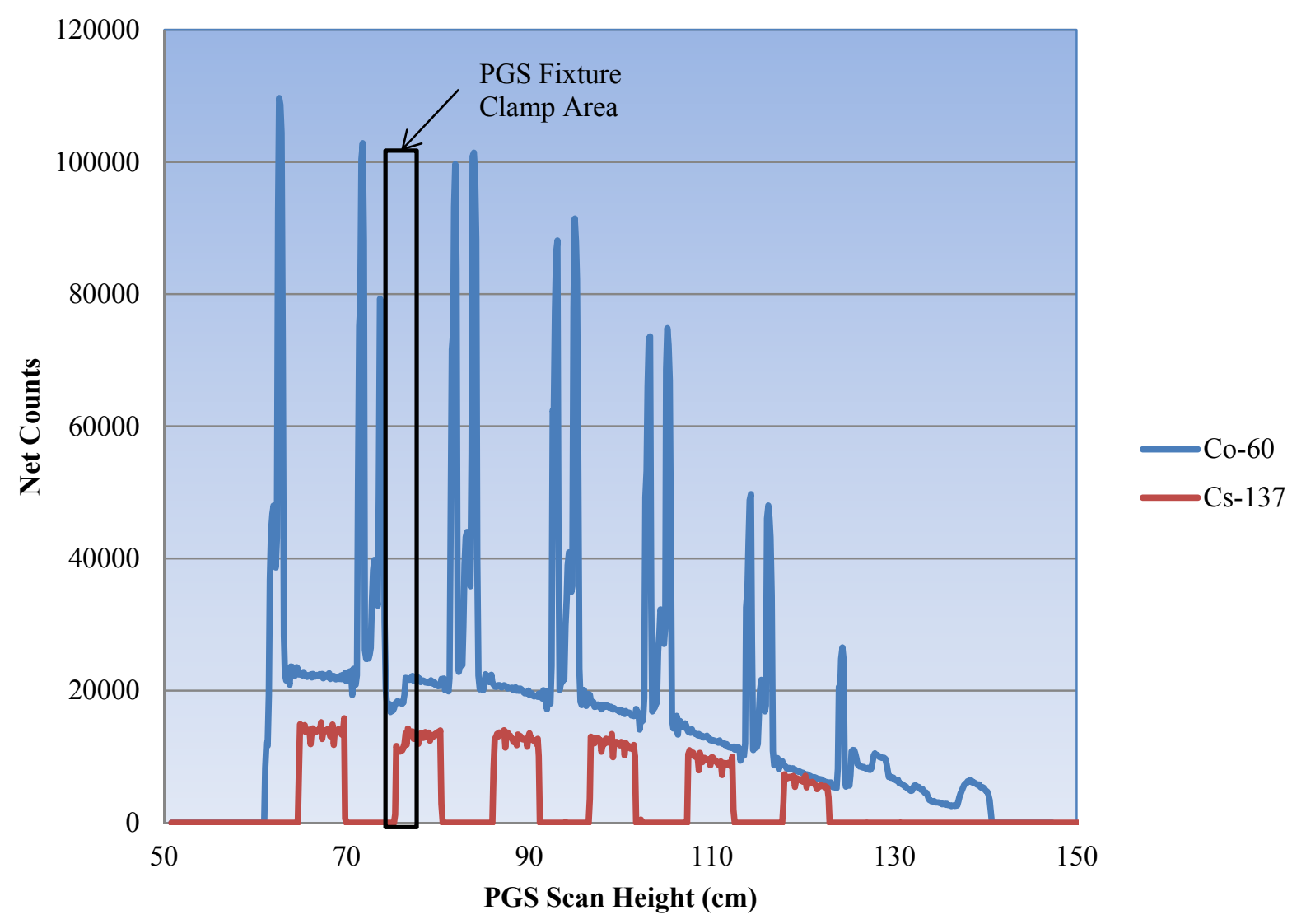

Figure 10. AGR-3/4 test train gamma scans of first section (Capsules 6 to 1 from left to right). 


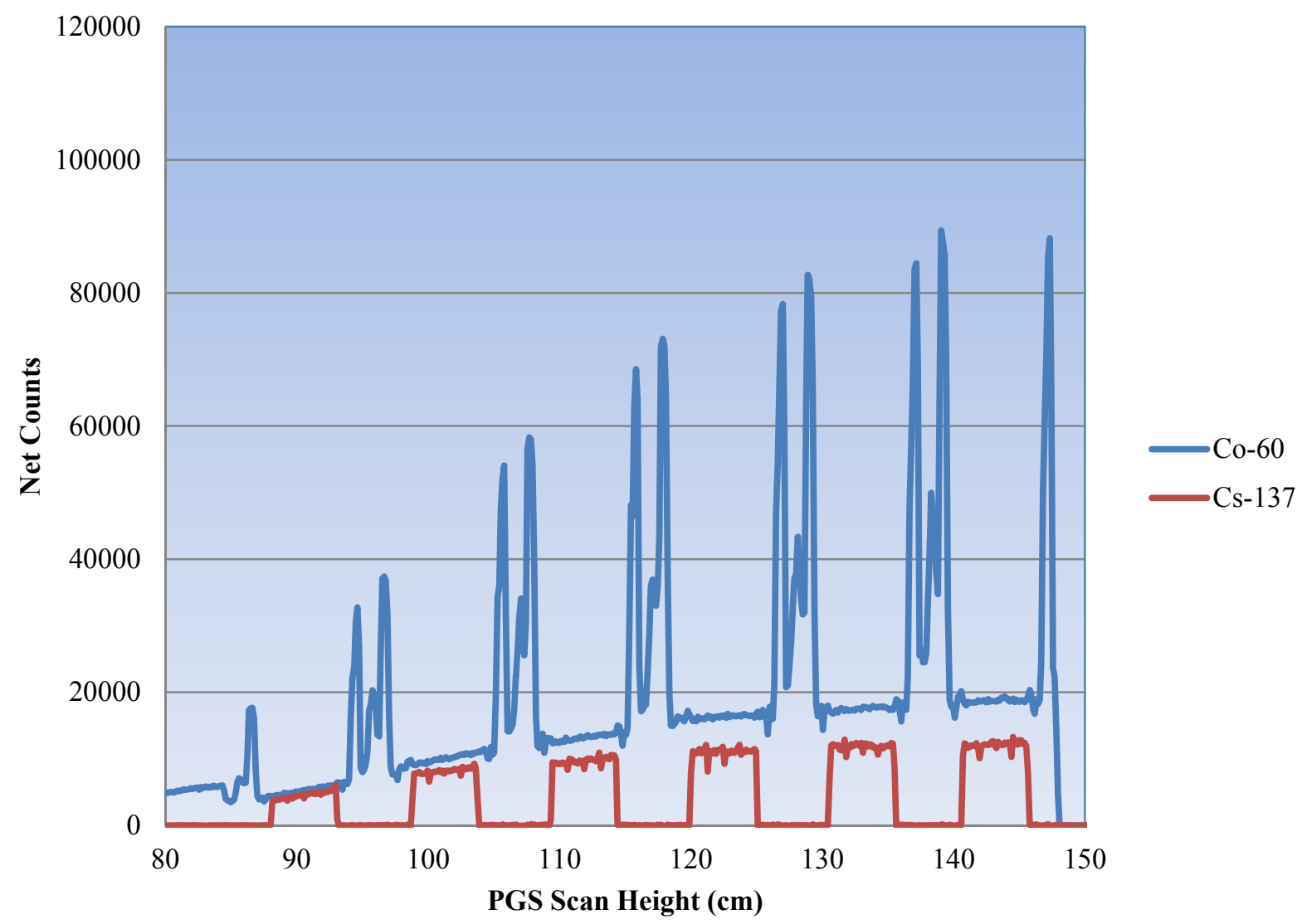

Figure 11. AGR-3/4 test train gamma scans of second section (Capsules 12 to 7 from left to right).

\section{DISASSEMBLY OF AGR-3/4 EXPERIMENT AT MFC}

Separation of the individual AGR-3/4 capsules was completed in late June 2015, and removal of the sink rings, outer and inner rings, and compacts began June 30, 2015 with Capsule 1. Unlike AGR-1 and AGR-2, removal of the capsule lid allowed the through tubes to slide out of the graphite sink ring with minimal resistance.

\subsection{Test Train Disassembly: Procedures and Observations}

The equipment that was developed to disassemble the test train primarily consists of a structural base with V-rail alignment tracks that the components are mounted on in the horizontal and vertical sections of the base. A modified E.H. Wachs compact split-frame pipe cutter is secured to the rail and the test train capsules are aligned so that circumferential capsule-to-capsule and capsule head cuts can be made (see Figure 12). The Wachs cutter is basically a lathe tool that is driven around the pipe circumference with incremental depth changes to complete the cut. The split-frame aspect of the unit allows separation of the unit into two halves for installation on or removal from the pipe. The unit was modified to use a reversible pneumatic drive to simplify inter-cut reset of the cutters. The pipe cutter had several problems with cutter breakage (it is fitted with two cutters, one on either side), which according to the vendor was partly due to inadequate tightening of the test train in the clamping collet. 
Figure 13 shows the horizontal rail on the base of the disassembly table fitted with a carriage that has split clamps that are used to secure the test train section during cutting and separation. The horizontal carriage is driven laterally by a leadscrew that allows capsule components to be pulled apart by clamping one piece in a fixed clamp and the other in the moveable carriage clamp to pull it apart. It also includes a drill press that is mounted to the back plane rail, which was intended to do center and through-tube counterbore drilling.

The disassembly procedure involves separating the capsules, making a cut to free the capsule head from its body, and then drilling a center hole through the capsule bottom to enable pushout of the capsule internals. The capsule head was clamped in the fixed clamp and the body pulled away from the head and through tubes. The initial plan assumed that the through tubes would resist the head separation to a degree that would require counterboring where the through tubes penetrated the top and bottom of the capsule. Because the tubes were swaged into place in the capsule bottom and brazed into place in the capsule head, it was determined that a direct pull may be sufficient to pull the head free from the capsule.

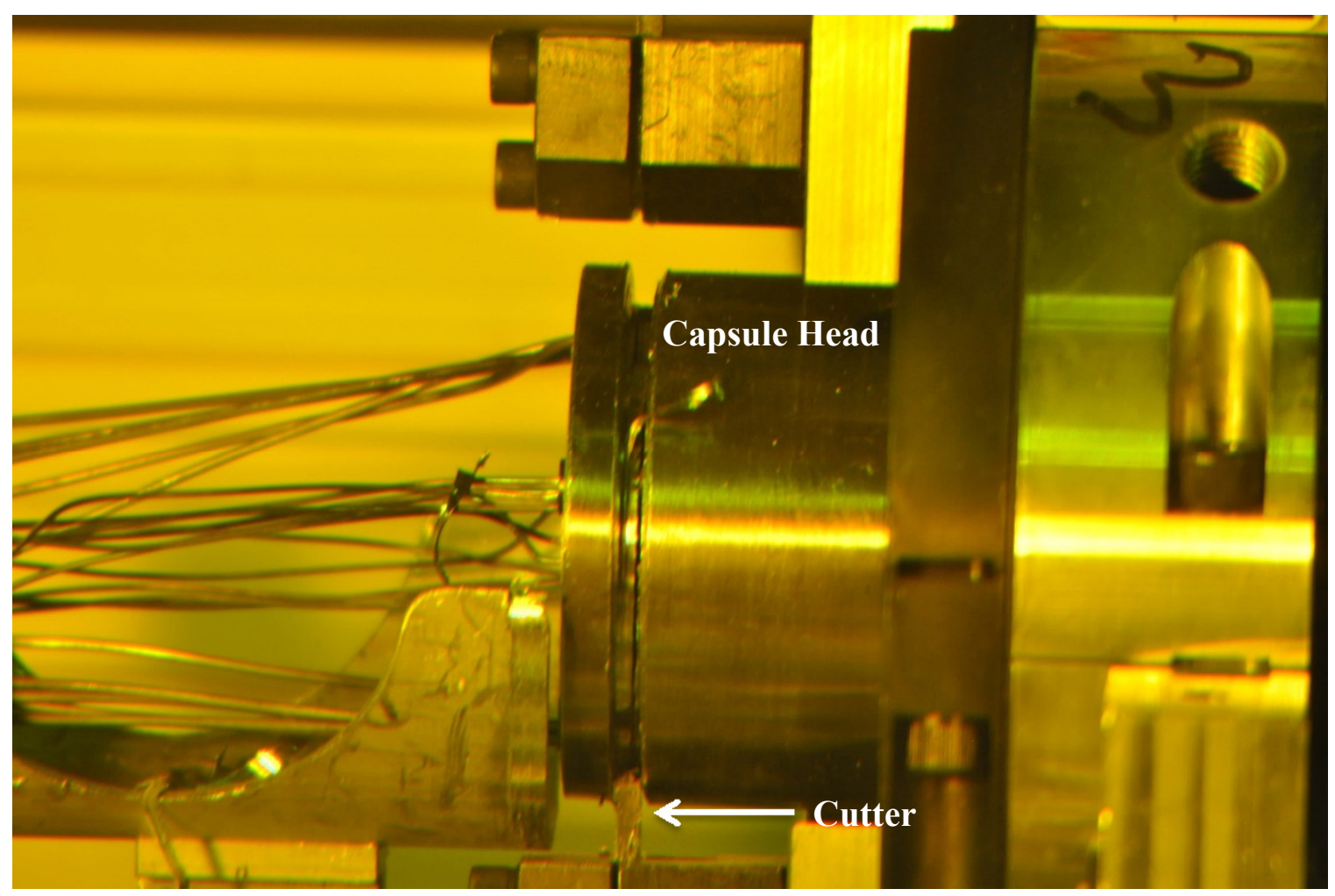

Figure 12. Pipe cutter showing a capsule lid cut with thermocouples and gas lines protruding to the left. Only one cutter is shown. 


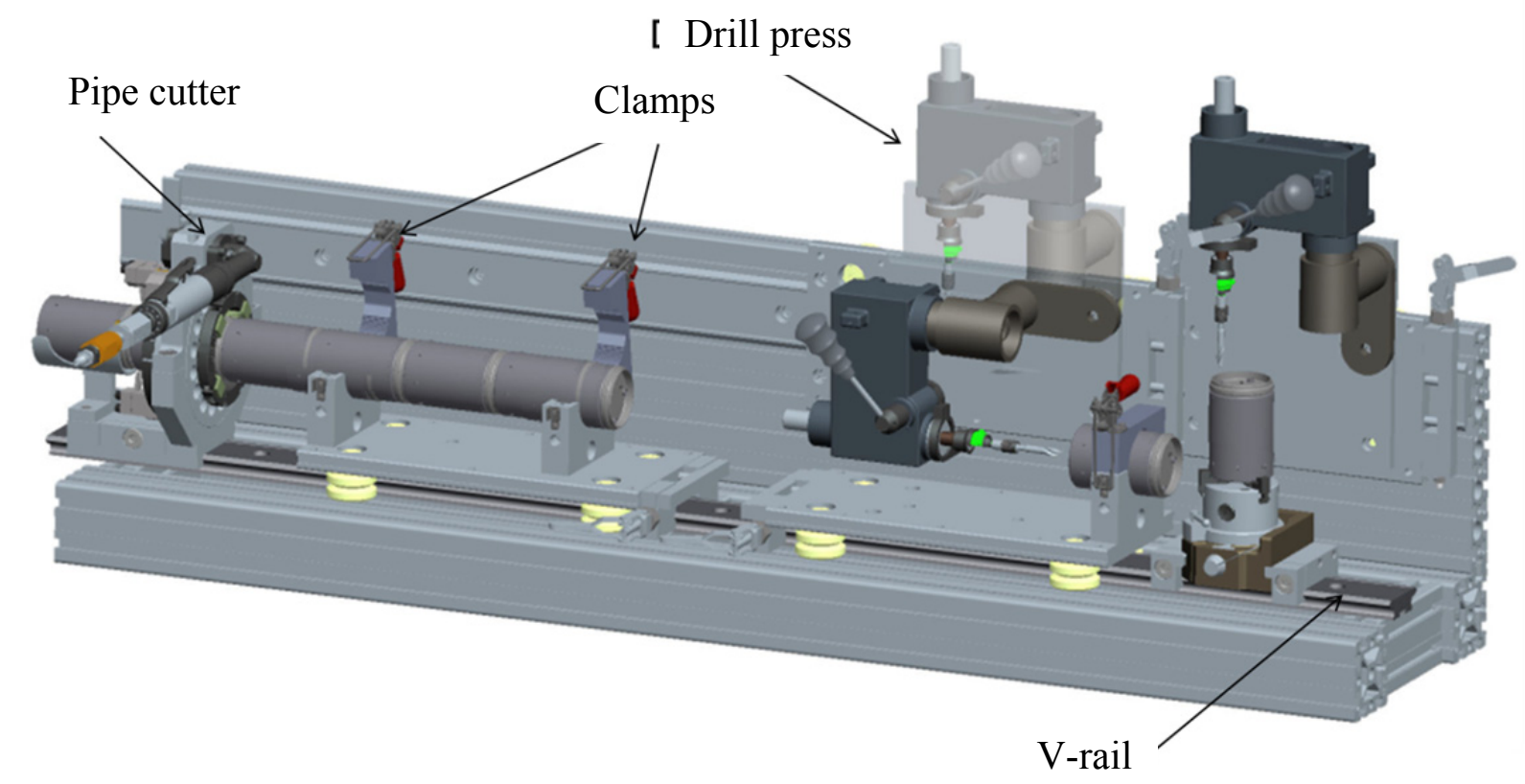

Figure 13. Disassembly table base with pipe cutter, clamps, and drill press.

\subsection{Capsule Disassembly: Procedures and Observations}

Once the graphite sink ring was freed from the capsule head, it was apparent that the outer and inner rings in Capsule 1 could slide within the sink ring with very little force. In some instances, slightly tipping the capsule during handling indicated that either the outer or inner rings had minimal friction, allowing the component to slide out to a distance that allowed use of tweezers to pull it out of the sink ring without drilling the pushrod hole. When the rings required pushing for removal, in order to enable pushing the outer ring out of the sink ring, a nominal $0.635-\mathrm{cm}(0.25$-in.) diameter hole was drilled in the bottom of the sink ring to accommodate the pushrod. The graphite rings and fuel components were pushed out laterally using the pushrod table that mounted on the moveable carriage in place of the test train section clamp. Component-specific trays were installed to receive and transfer each of the outer and inner rings and compacts into their specific containers. An illustration of the sorting table is shown in Figure 14.

Due to suggestions that the inner and outer rings fabricated of graphitic matrix material might be friable, and thus, unable to retain their annular configuration, cylindrical "void fillers" fabricated from acetyl plastic were used to push the annular components while filling their IDs to improve the probability they would retain their shapes inside the handling containers. The void fillers were fabricated to be $0.254-\mathrm{mm}(0.010 \mathrm{in}$.) smaller than the design-specified ID of the rings.

An additional tool was designed and fabricated to facilitate removal of the graphite screws from the sink rings. It amounts to a guide that aligns to the through tube holes and a remote screwdriver that fits in the guide at the positions of the screws. The tool is shown in Figure 15 where the screwdriver is labeled "18." 


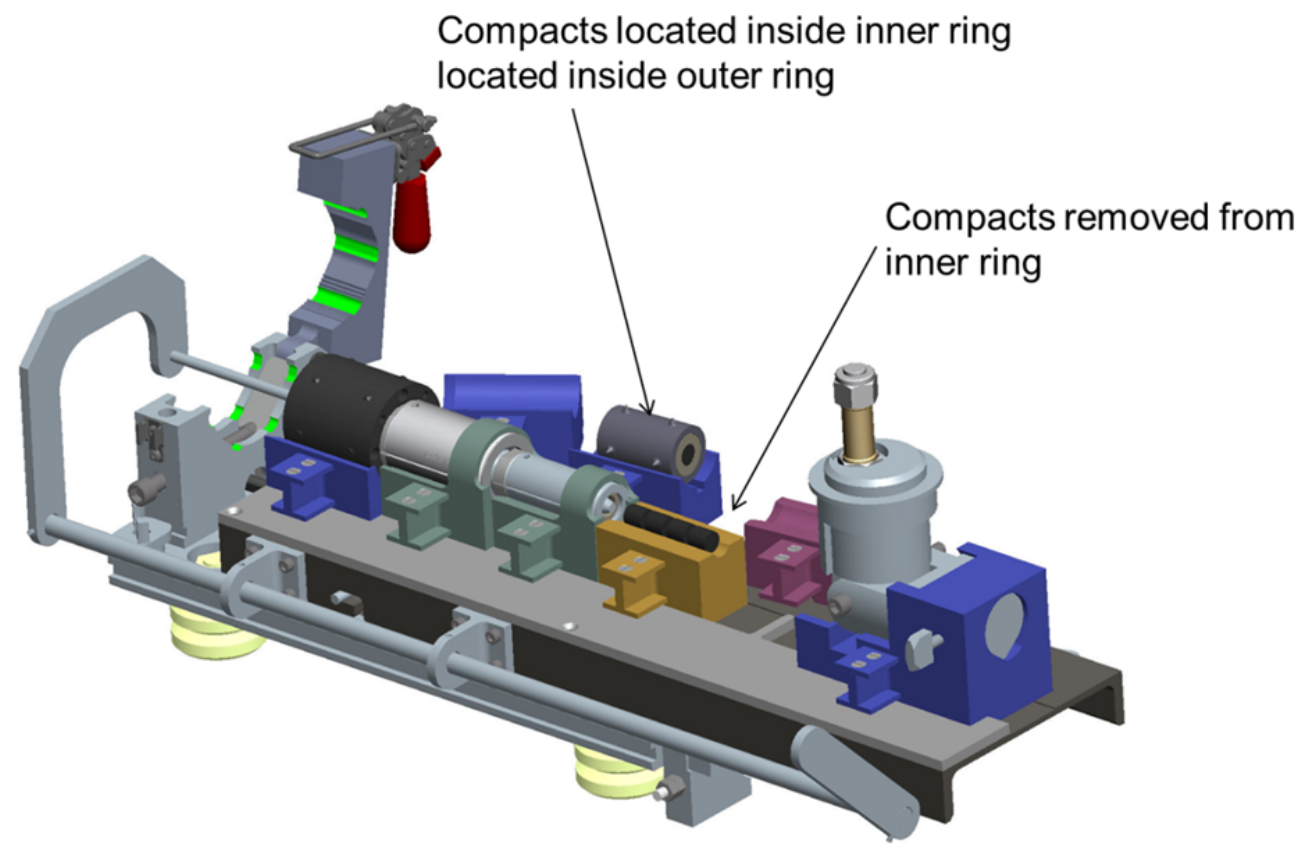

Figure 14. Pushout and sorting table.

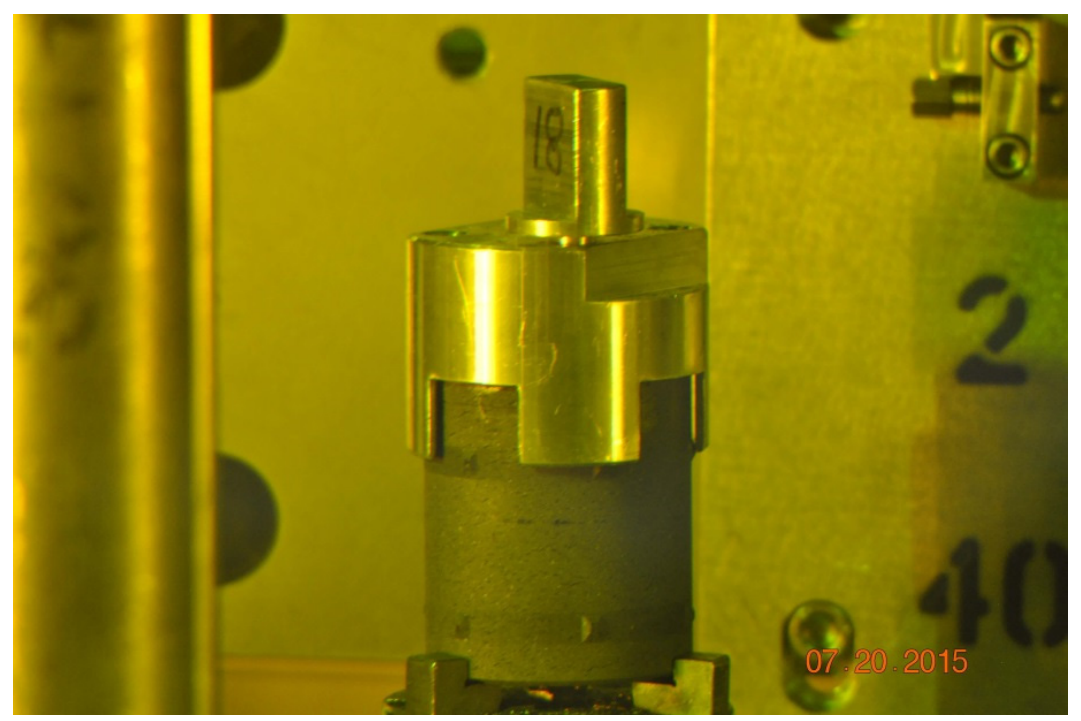

Figure 15. Sink ring screwdriver and guide.

Capsule 3 compacts resisted being pushed out, and Compact 3-4 seemed to adhere to the inner ring. This adhesion resulted in a nominal 5-mm square layer of the graphitic matrix being broken off of Compact 3-4 as it was removed (see Subsection 4.3 for pictures of the fractured compact). Particles were visible on the compact at the location where this piece originated. It appeared that the inner ring ID had decreased based on the inability to fit the void filler pushout rod into the inner ring following compact removal. Metrology results (see Subsection 5.2.2), however, report that the inner ring ID had, in fact, increased. It is possible that the void filler was being inserted at an angle that prevented it from fitting easily into the inner ring. 
Rather than keeping the Capsule 4 fuel body intact, it was selected to be disassembled. Removal of compacts from the inner rings of the Capsule 4 fuel body and Capsule 5 standard body was not initially successful using the equipment on the pushout and sorting table. An alternative method, discussed in Section 4.4 and Section 0, employed a press to successfully remove the compacts from the inner rings of Capsules 4 and 5. This enabled metrology and PGS activities to proceed for components of all standard bodies and the Capsule 4 fuel body. All intact fuel bodies were also staged for metrology (where only the outer ring ODs of these fuel bodies were measured) and PGS analysis.

The Capsule 11 sink ring was damaged while the capsule lid was being removed. A split on the lower end of the ring occurred due to the through tubes resisting pull-out during separation of the lid from the ring. It appeared that the tubes may have been distorted during thermocouple removal. The through tubes were separated from the capsule lid using a small reciprocating saw, allowing removal of the outer and inner rings.

Generally, no exceptional discoloration was observed on any of the graphite components during removal from the test train capsules. The standard body zirconia and zirconium spacers were observed to have collected what appeared to be fine carbon black "soot" that loosely adhered to the spacers.

Discoloration identified on the external surfaces of the test train capsules was initially thought to be correlated to a darkened surface on the exterior of the associated sink ring. A more careful evaluation indicated that there was no correlation between the two.

\subsection{Flux and Melt Wires}

All fluence wire packages (flux wires) were recovered from the sink rings and containerized for transfer to the MFC Analytical Laboratory for gamma counting. The three flux wires that were installed in the sink rings of each capsule were recovered and placed together in a polyethylene cryo-vial for transfer. The plug that retained them in the sink ring was typically easy to remove following sink ring lid removal. The flux wires and soot accumulations from Capsule 2 had fallen out during lid and outer ring removal and were caught together in a Teri-towel. Those flux wires were then recovered after sorting through the soot. Based on the possibility that the rings might be damaged during melt wire removal, melt wires were retained in their respective rings so that the rings could first undergo analysis with the PGS and metrology.

\subsection{Disassembly Lessons Learned}

For future operations of this type, an improved hold-down configuration for components that resist being pushed apart should be designed and implemented.

If a multiple-orientation drill press is used, the mounting structure needs to be more rigid so as to be more precise in positioning where holes are drilled. Use of a conventional drill chuck should be considered unless a quick hex chuck can be acquired that consistently holds the drill bits in a predictable manner.

If a pipe cutter of the E.H. Wachs compact split frame type is used in a configuration like the one used in this system, it should be noted that securing the workpiece in the collet is important to ensure that the cutters are less likely to fracture due to vibration. It may be possible to shorten the tail end of the cutters to keep them from being fully extended during operations. 


\section{VISUAL INSPECTION AND NOTES FROM CAPSULE DISASSEMBLY}

\subsection{Capsule 1 Standard Body}

The sink ring lid was fractured at the through tube holes during removal from the capsule body. The capsule lid and through tubes pulled directly out of the sink ring, leaving the lid exposed. This amount of exposed material did not allow pulling the sink ring out of the capsule body. A through tube insert tool was fabricated that allowed rotation of the sink ring and pushout of the sink ring by inserting the tool through the bottom of the capsule. No significant scratches or abrasions on the sink ring were observed. Figure 14 and Figure 15 show generalized schematics of the pushout of capsule components and the removal of sink ring lid screws. Figure 16 through Figure 19 show the push-out of successive Capsule 1 rings and compacts.

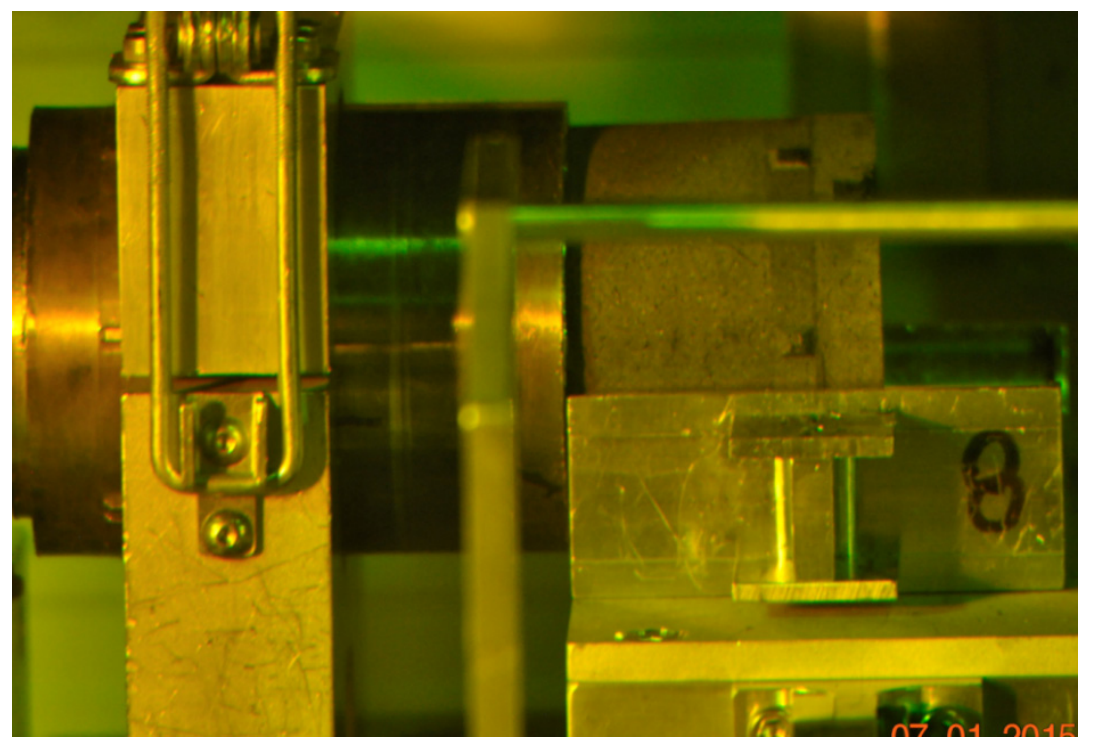

Figure 16. Sink ring being pushed out of Capsule 1 shell.

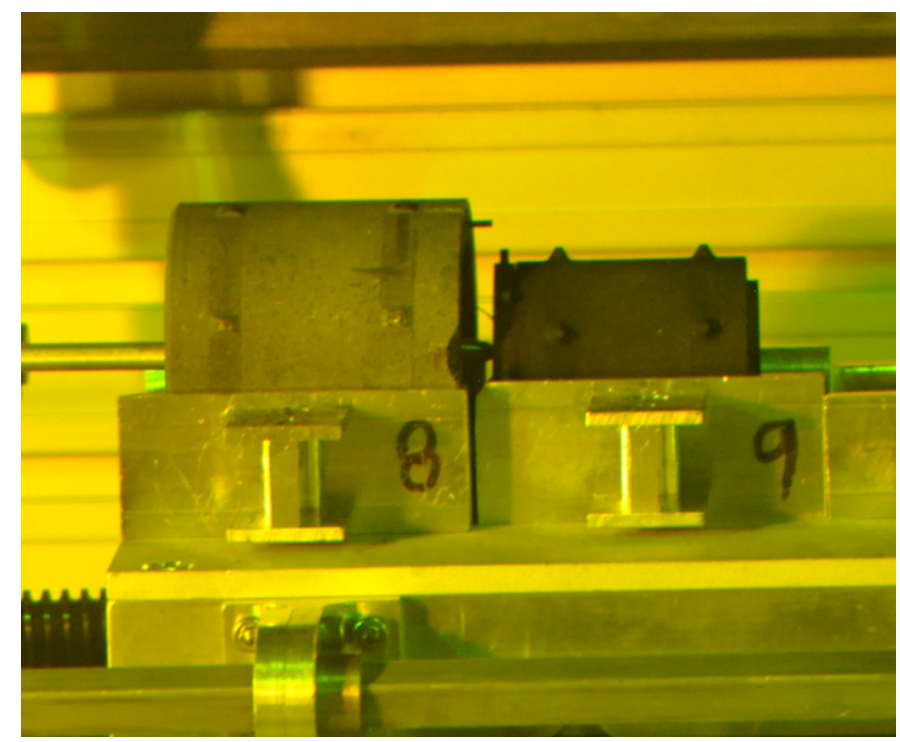

Figure 17. Capsule 1 outer ring pushed out of sink ring. 


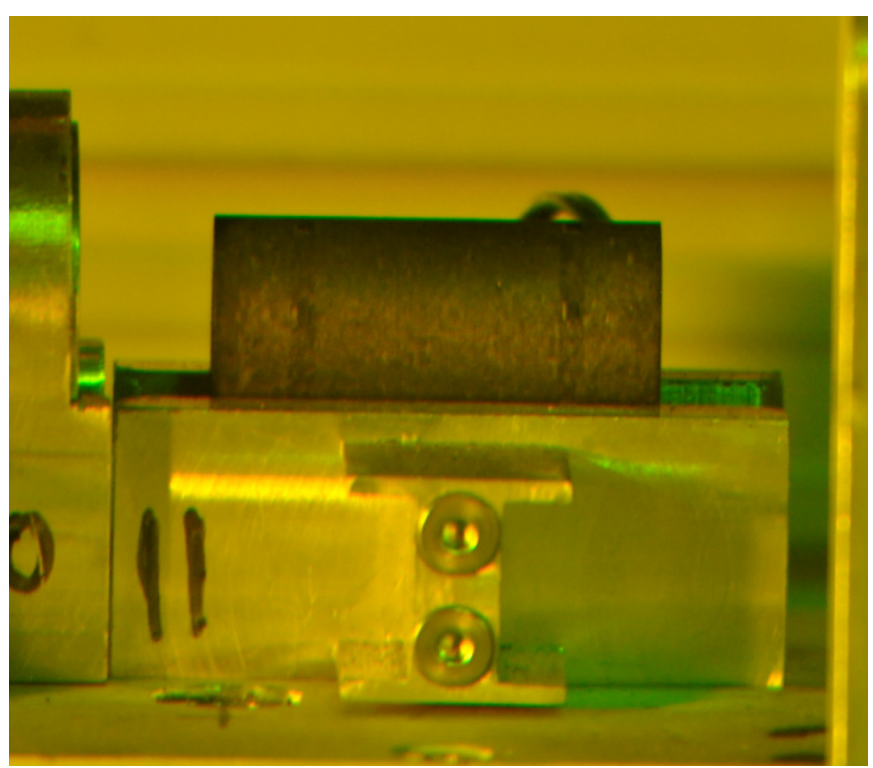

Figure 18. Capsule 1 inner ring pushed out of outer ring.

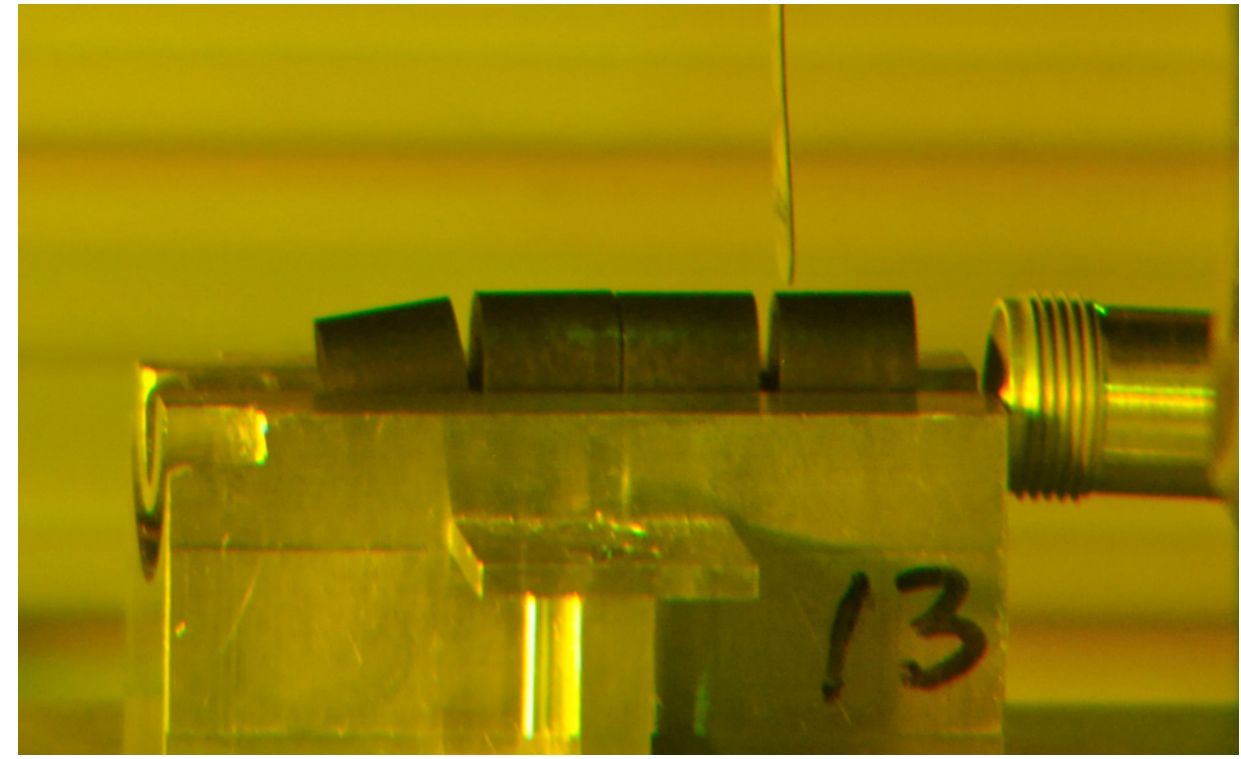

Figure 19. Capsule 1 compacts being containerized.

\subsection{Capsule 2 Fuel Body}

The sink ring lid came off during capsule separation. Figure 20 shows the sink ring with the lid removed. The fuel body is located at the center of the sink ring in Figure 20. The body of the sink ring was uniform in color with no noticeable damage. The underside of the top spacer was covered with black soot. When removing the fuel body, an exceptional amount of fine, black soot-like material came out of the bottom of the capsule. Soot and debris were collected in a paper Teri-towel for later analysis. The fuel body surface was darker grey/black than the surface of the sink ring. This fuel body was not disassembled. 


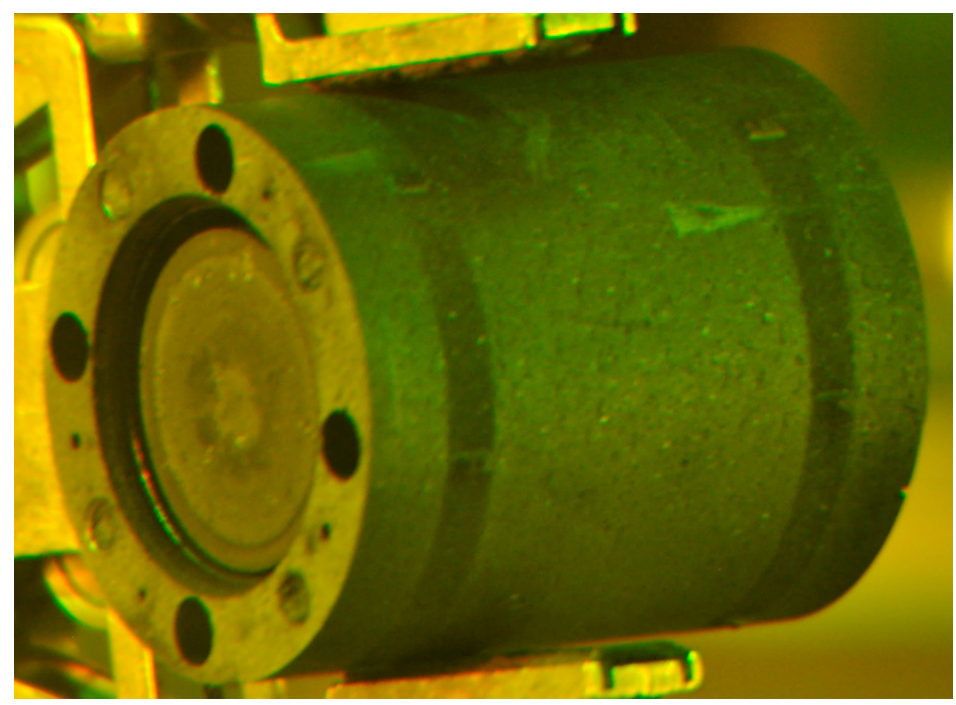

Figure 20. Capsule 2 sink ring with fuel body in the center.

\subsection{Capsule 3 Standard Body}

The sink ring lid was held in place by four screws, two of which unscrewed, and two of which broke off during disassembly. When pushing out the inner ring, it appeared that the outer ring ID was smaller than the design value, preventing insertion of the void filler. A void-filler with $0.254-\mathrm{mm}(0.01-\mathrm{in}$.) reduced diameter was fabricated, and inserted into the outer ring. Metrology results indicate that the Capsule 3 outer ring ID actually increased. It is not clear why the initial void-filler did not fit. If the void filler had been inserted at an angle to the ring, this could have prevented it from sliding into the ring. As discussed in Subsection 3.2, a corner of the top compact (Compact 3-4) was sheared off during push-out. This fractured compact is shown below in Figure 21.

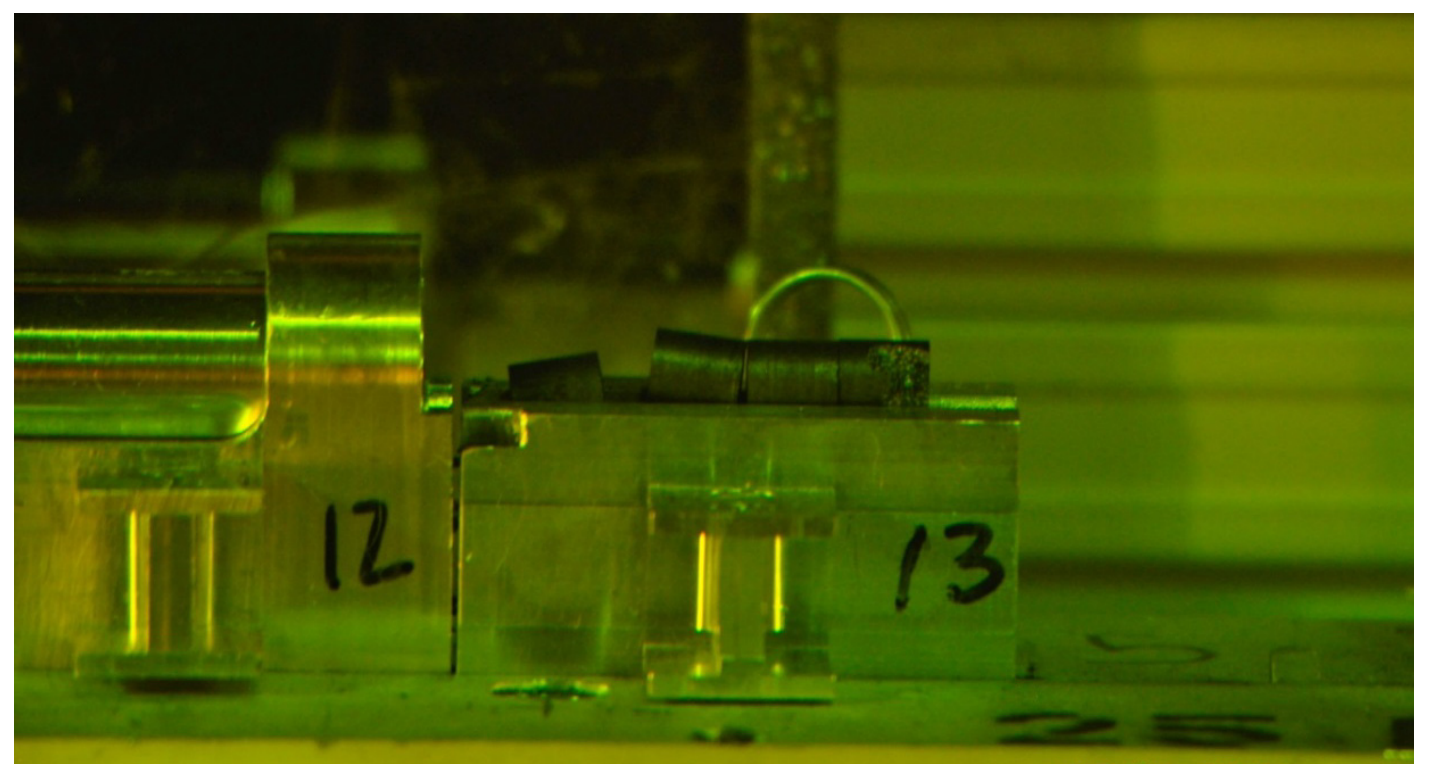

Figure 21. Capsule 3 compacts with damage visible in the right-most compact (Compact 3-4). 


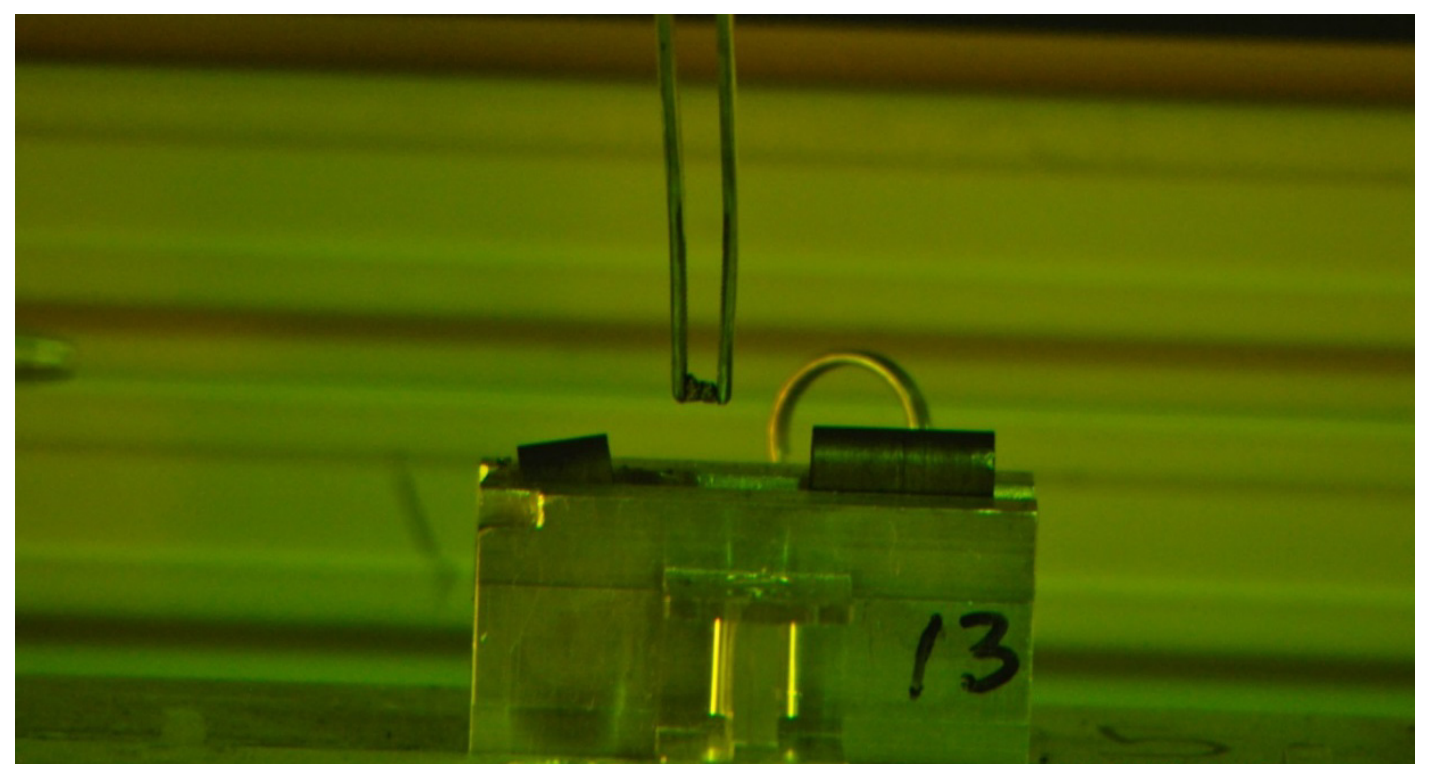

Figure 22. Three compacts from Capsule 3. Compact 3-4 fractured during removal. Fractured corner piece held by tweezers.

\subsection{Capsule 4 Fuel Body}

The sink ring lid was secured with four screws. Two of these lid screws were unscrewed, and the other two screws sheared off during pull-out of the through tubes. Upon pushing with the pushrod, the fuel body presented strong resistance to pushout; however, the fuel body slid directly out into the catch tray when the sink ring was tipped up. As with other internals, the fuel body surface was darker than the sink ring external surface. No abrasions were observed on the external surface of the fuel body.

This fuel body had been selected for disassembly. The fuel body lid unscrewed freely, but the compacts did not drop out of the fuel body into the catch container. The tool designed for receipt of fuel body compacts was a Lexan annulus that screwed onto the fuel body so that when inverted, the compacts would drop into the annulus for transfer to the sorting table and pushout into the compact containers. In this instance, use of gravity was insufficient for removing the compacts. A $0.635 \mathrm{~cm}(0.25 \mathrm{in})$ diameter hole was drilled through the fuel body bottom. Using the pushrod, compact pushout was attempted when the body was clamped down, but the compacts resisted removal via the pushrod.

Figure 23 shows the press devised to push the compacts out of the inner ring. This press features a 3:1 ram-to-applied force ratio. At HFEF, moderate force was applied with the manipulators until movement of the ram stopped. The ring was rotated and force was again applied until ram displacement ceased. This alternating pressing and turning was repeated until the compacts were removed from the ring into the Lexan compact catcher. The inner ring did not have any visible damage. Figure 24 shows that the last compact to be pushed from the inner ring, Compact 4-1, fractured during push out. The other compacts did not have any visible damage. 


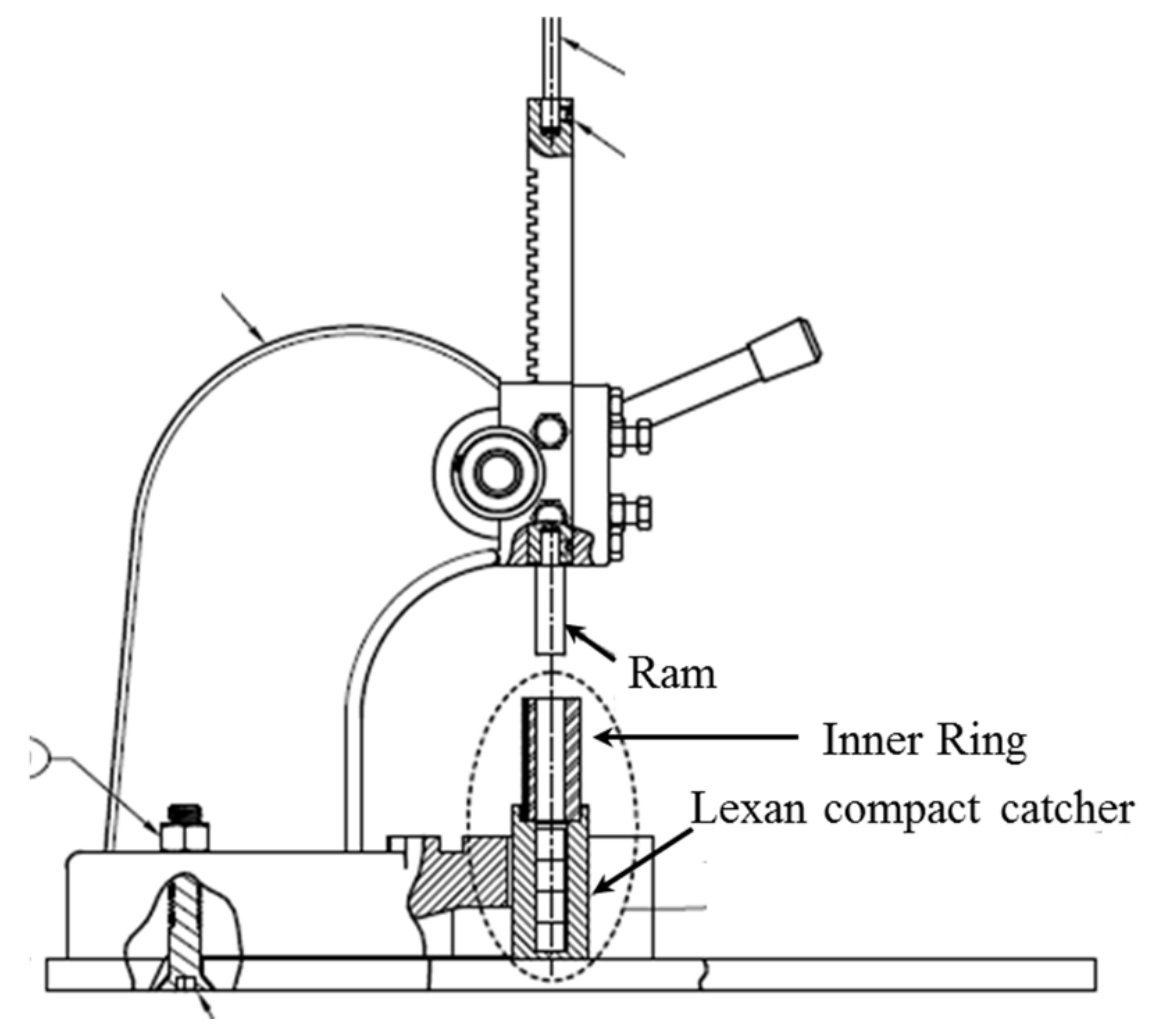

Figure 23. Arbor press used to push compacts out of the inner rings from Capsules 4 and 5.

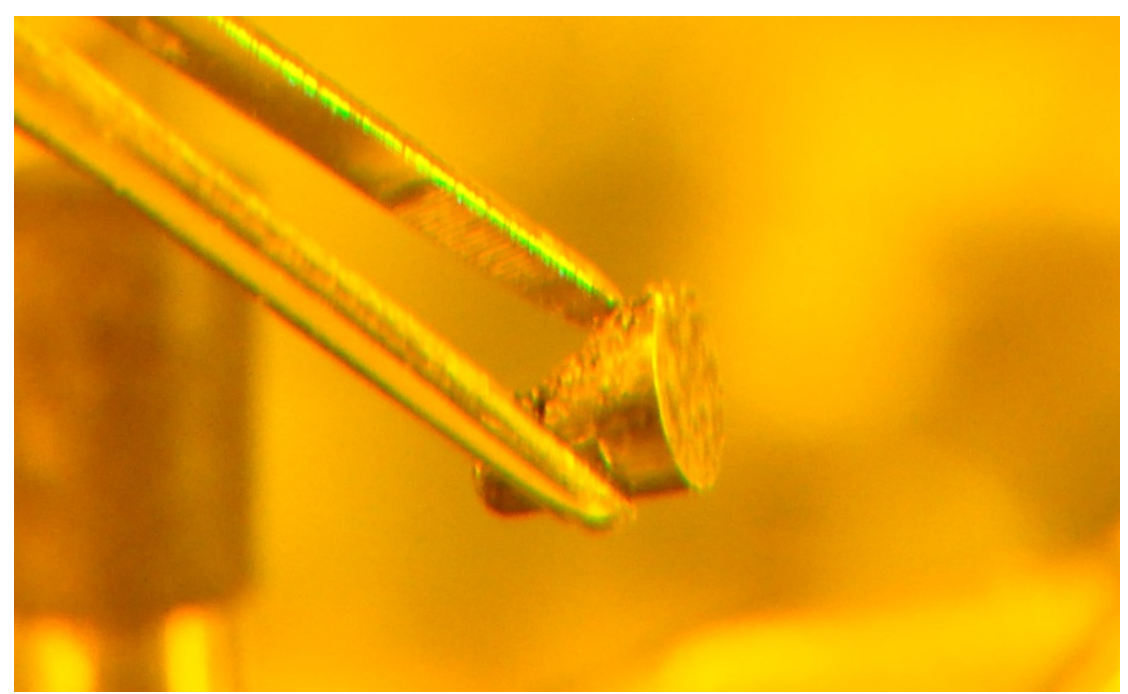

Figure 24. Compact 4-1 fractured during pushout from the inner ring using the apparatus in Figure 23. 


\subsection{Capsule 5 Standard Body}

The lid was removed from the capsule with no significant resistance from the bottom-swaged through tubes. Figure 25 shows removal of the capsule lid. The stationary rail clamp is on the left and the moveable clamp is on the right, holding the capsule body. The through tubes are visible between the capsule body and the left clamp. Note that the sink ring is not visible, because it is still retained inside the capsule body.

Removal of the sink ring from the capsule was hindered by a burr that remained after completion of the capsule lid-to-body cut. Figure 12 shows the pipe cutter used to make the cut, where only one cutter blade is visible at the bottom of the figure. The burr which resulted from the cut and hindered sink ring removal is shown in Figure 26. As with other capsules, there was a significant amount of sooty material present on the ceramic spacers, as can be seen in Figure 27. Figure 28 shows the outer ring which was pushed out of the sink ring with minimal effort and no damage to the ceramic spacer. The inner ring was also pushed out with no notable issues. The compacts, however, resisted removal when pushed with the void filler shown in Figure 29.

The same apparatus pictured in Figure 23 was used to push the Capsule 5 compacts out of the Capsule 5 inner ring. Figure 30 shows the top compact, Compact 5-4, partly removed from the Capsule 5 inner ring. By repeatedly pressing, turning the ring, and pressing, all Capsule 5 compacts were removed from the Capsule 5 inner ring. The inner ring was not damaged; however, some scratching and chipping of the final compact (Compact 5-1) was noted.

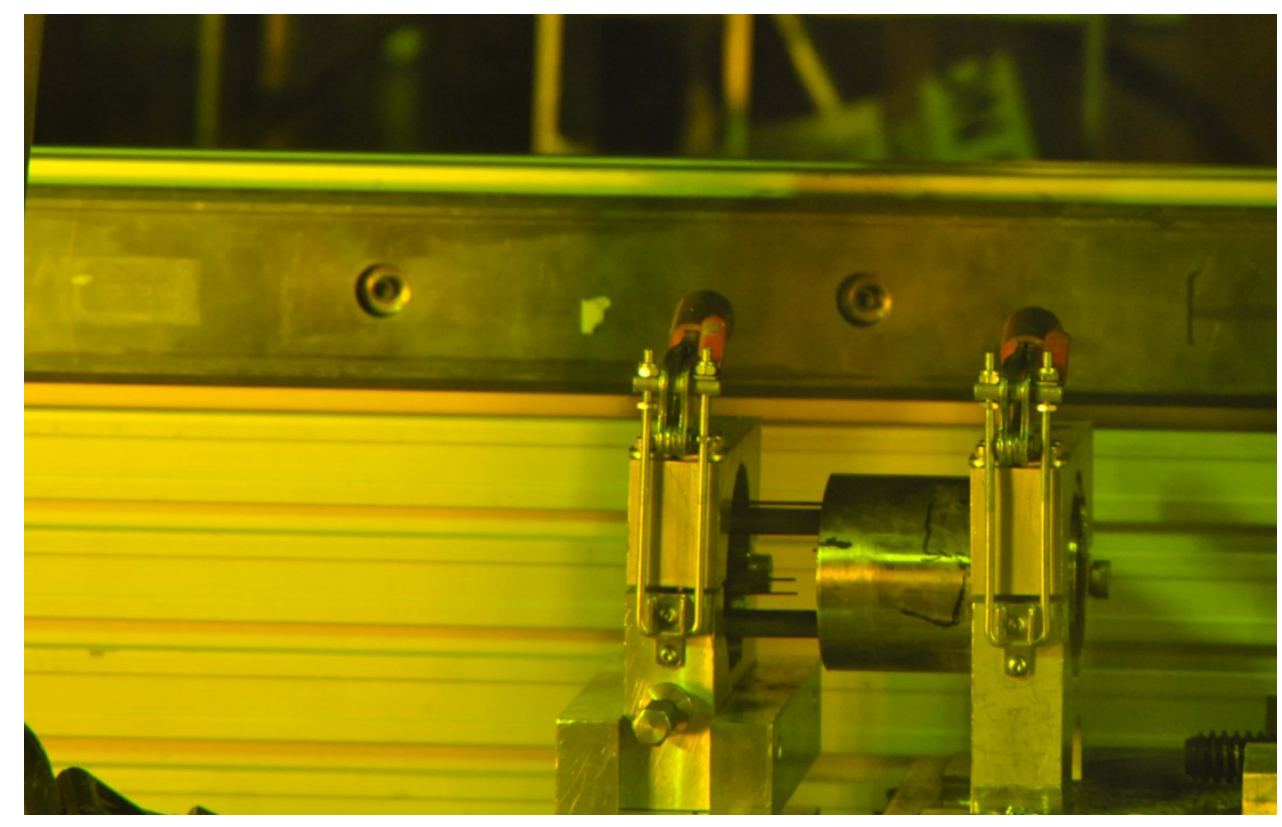

Figure 25. Capsule 5 lid being separated from capsule body. 


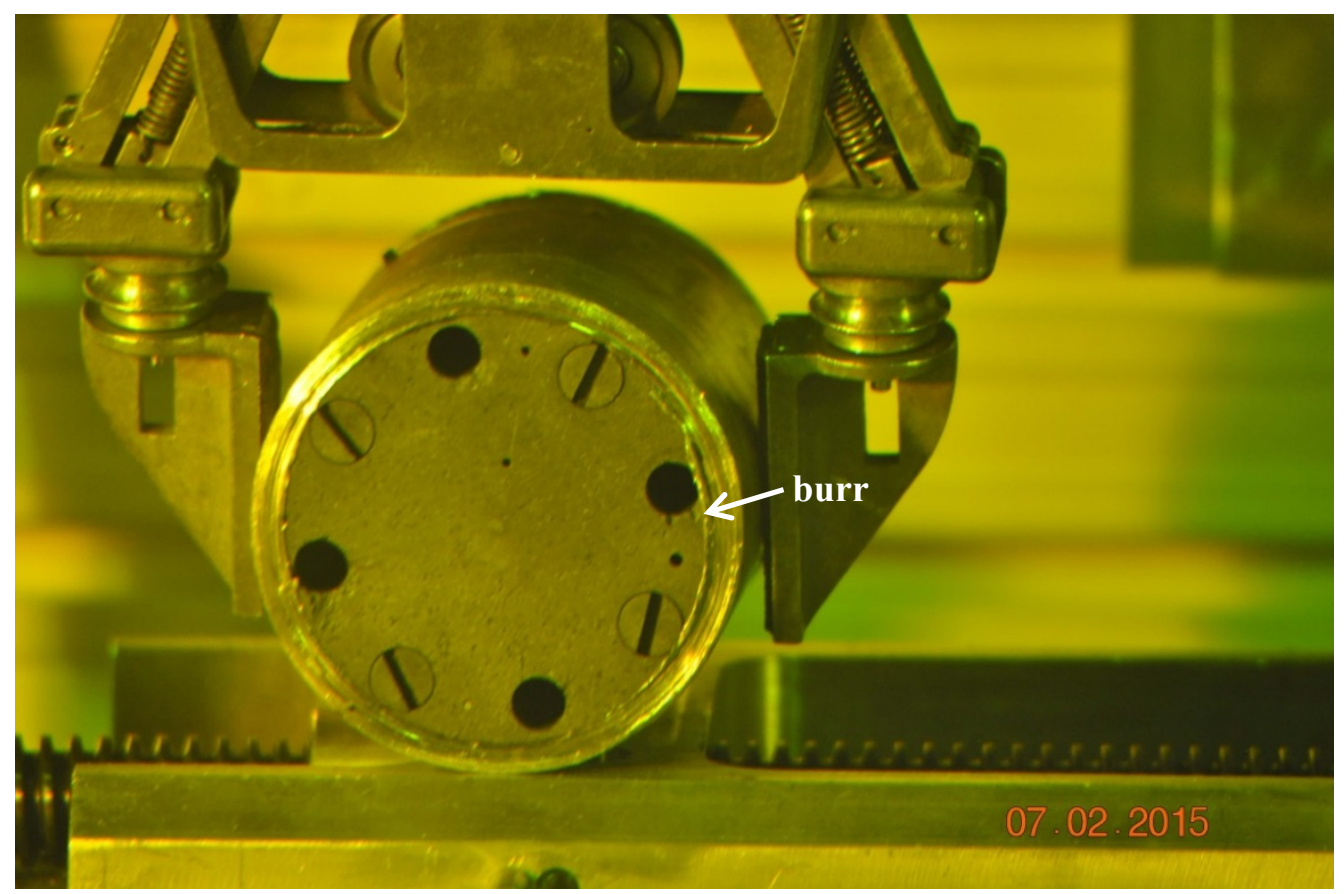

Figure 26. End of Capsule 5 with burr that prevented sink ring removal with capsule lid.

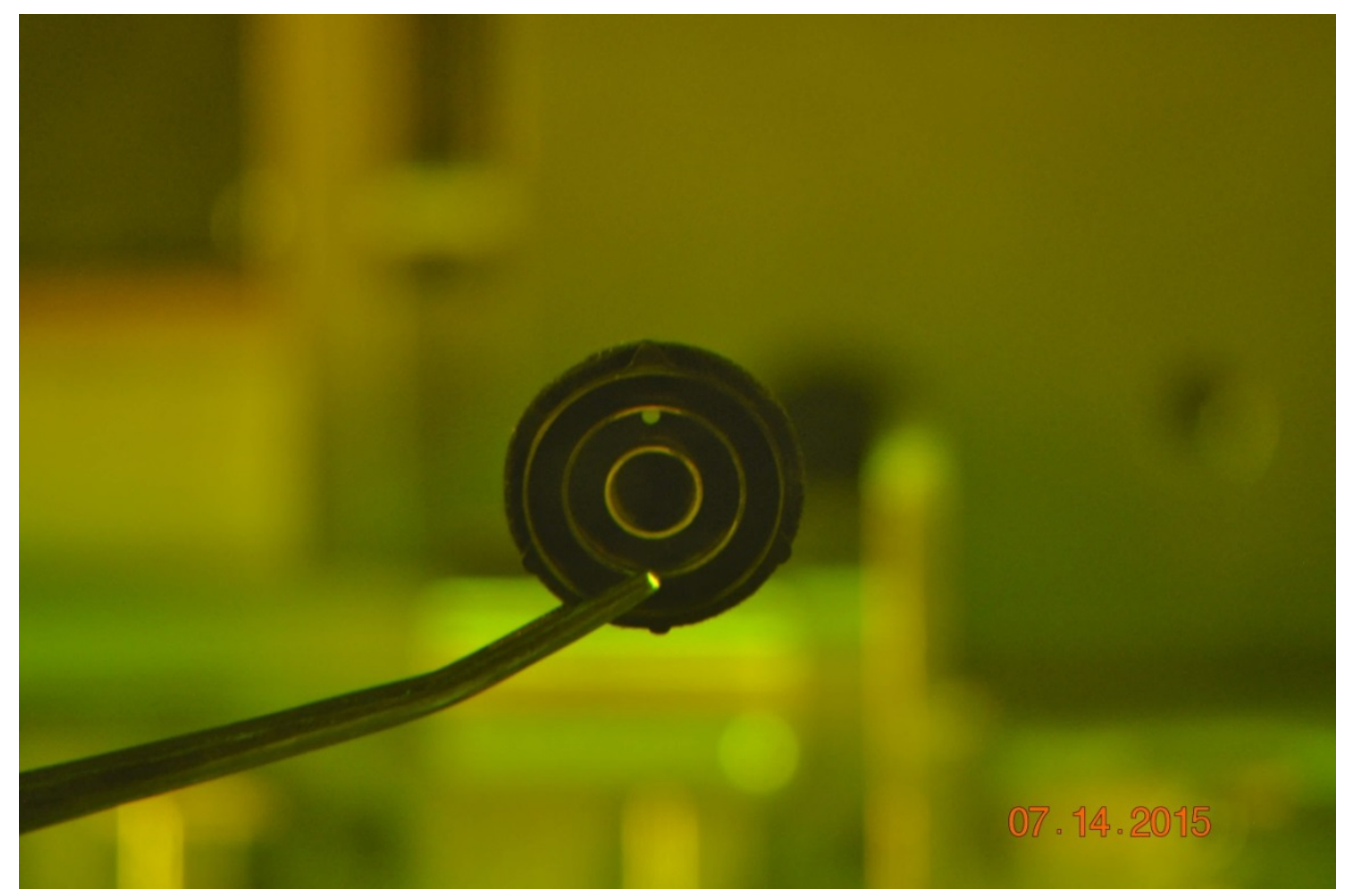

Figure 27. Bottom ceramic spacer from Capsule 5. 


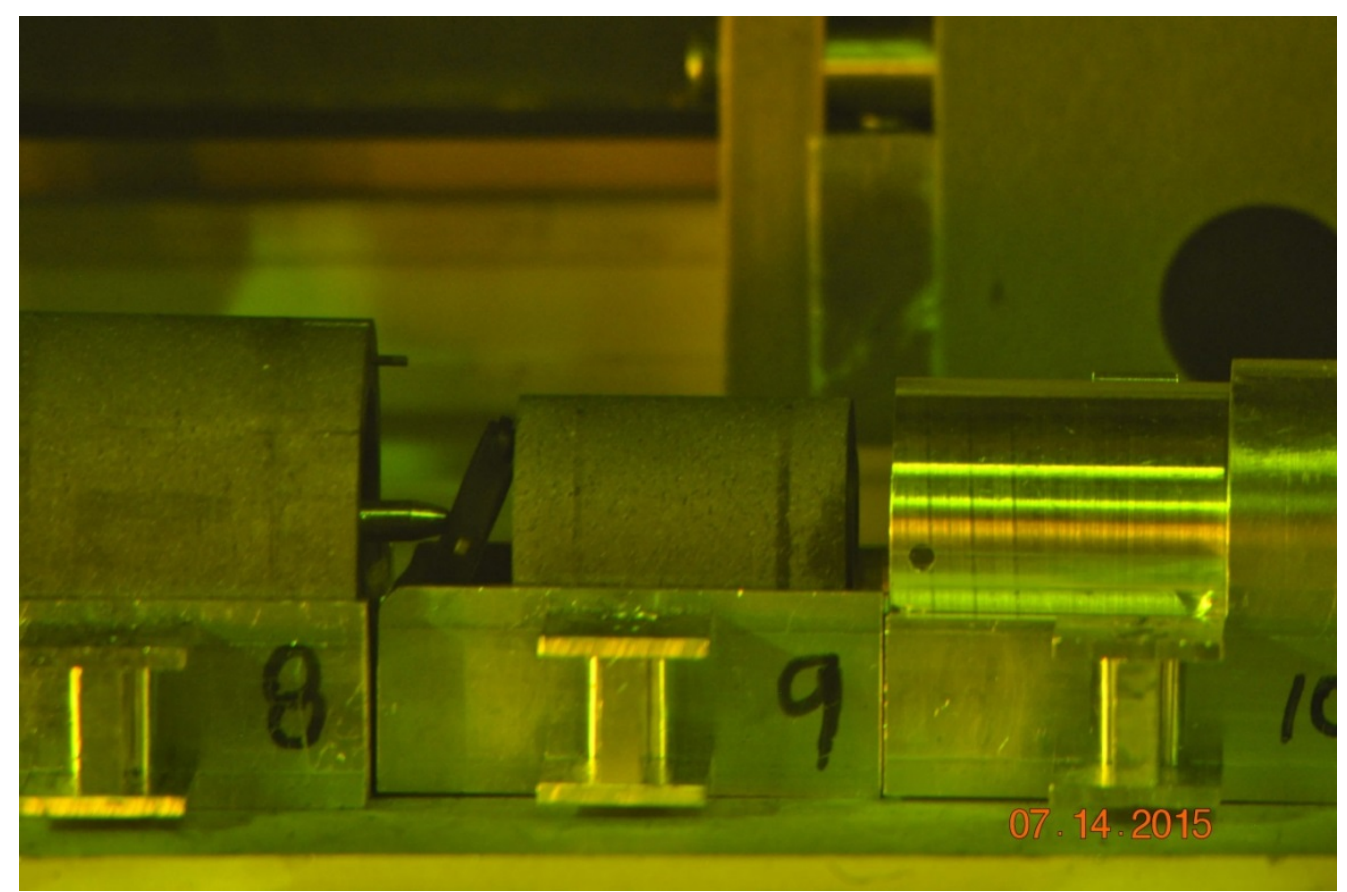

Figure 28. Capsule 5 outer ring pushed out of sink ring.

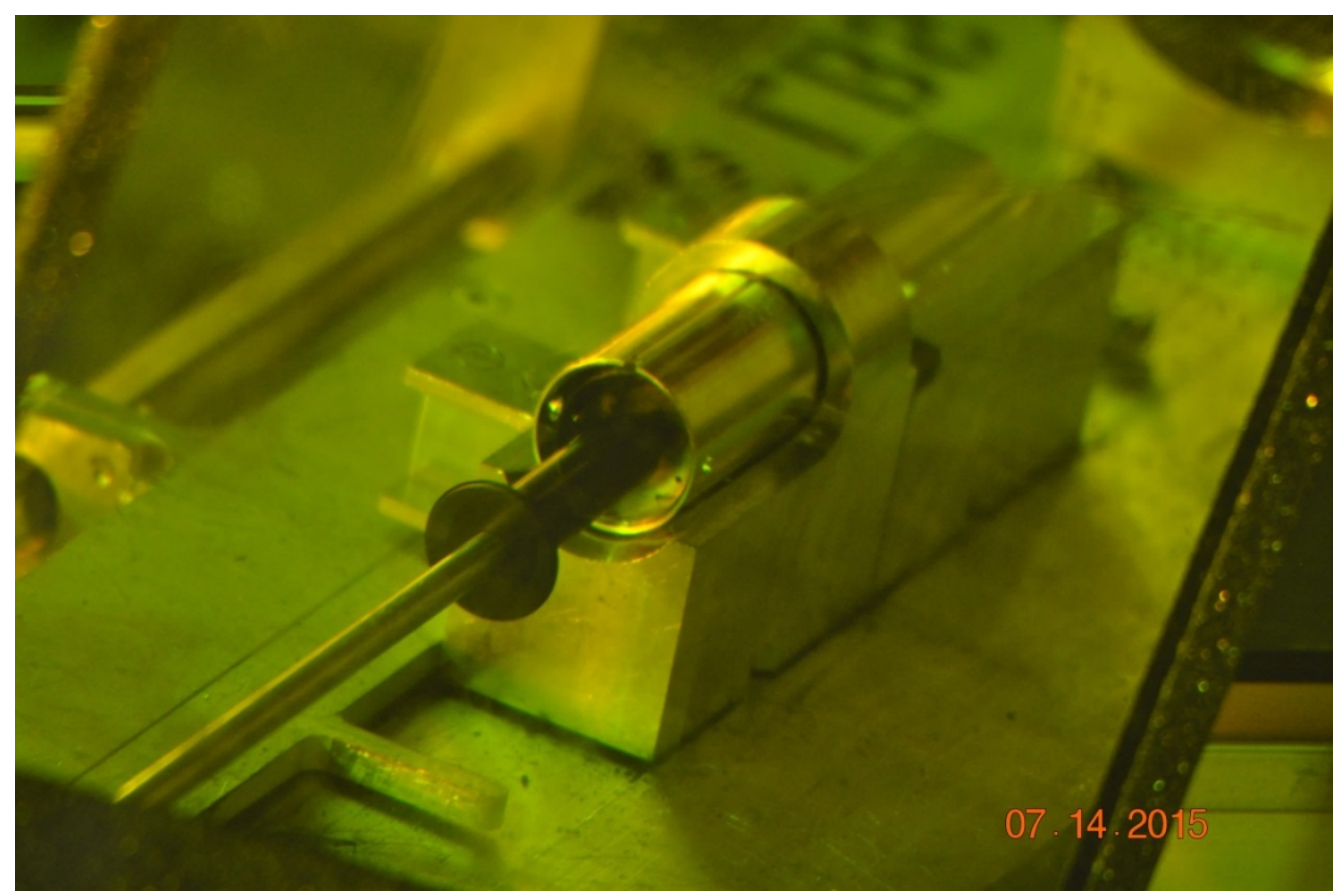

Figure 29. Attempting to push out Capsule 5 compacts on pushout and sorting table (Figure 14). 


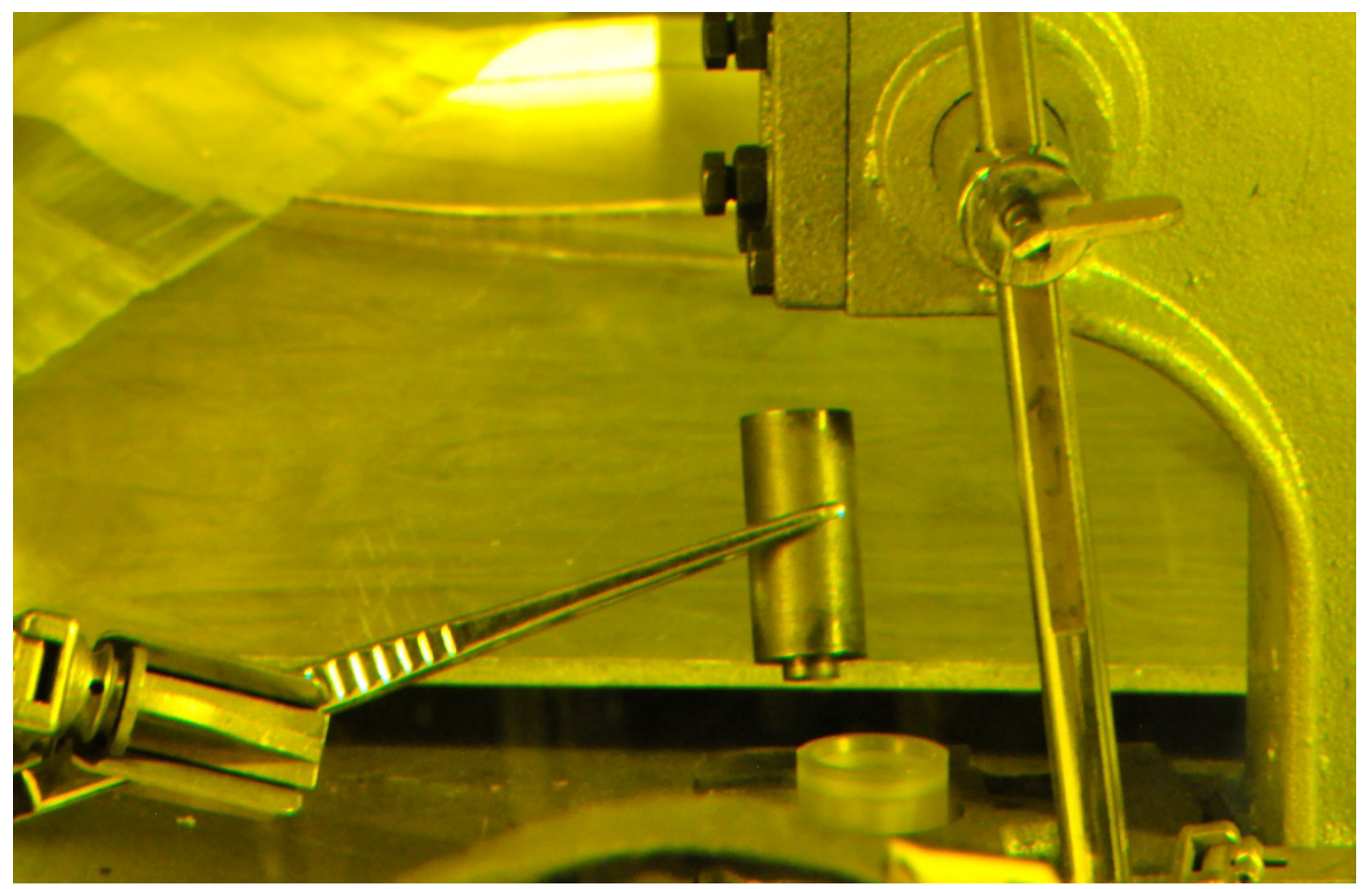

Figure 30. Compact 5-4 shown partially removed from Capsule 5 inner ring.

\subsection{Capsule 6 Fuel Body}

The sink ring was removed without incident, and the fuel body tipped out without drilling through the bottom of the sink ring. This fuel body was not disassembled.

\subsection{Capsule 7 Standard Body}

The sink ring was removed from the capsule without incident. The sink ring lid fractured around the screws, eliminating the need to remove them. The top ceramic spacer was broken approximately into two $60-40 \%$ pieces. The inner ring with the compacts was pushed directly out, while the outer ring remained in the sink ring.

The compacts pushed out with some resistance. The number 2 compact appeared to have a point at which it may have fused to the inner ring. The outer ring did not tip out despite prying with a palette knife. So a hole was drilled in the sink ring at the diameter of the outer ring (shown in Figure 31); however, the pushrod was unsuccessful in pushing out the ring. After being able to achieve a small movement, the sink ring was tipped back vertically, and then the outer ring was tipped out. It is assumed that a part of the broken zirconia bottom spacer had wedged itself in such a way as to interfere with outer ring movement. There were no significant marks or abrasions on the outer ring other than a slightly shiny spot on its lower end. The outer ring void filler would not readily fit into the outer ring. No void filler was inserted in this outer ring because the inner ring and compacts had already been removed. It is possible that insertion of the void filler was attempted with the component at an angle that prevented it fitting into the interior diameter of the ring. Despite the fact that the void filler did not fit within the outer ring, metrology results (see Figure 55) show that the Capsule 7 outer ring ID actually increased. 


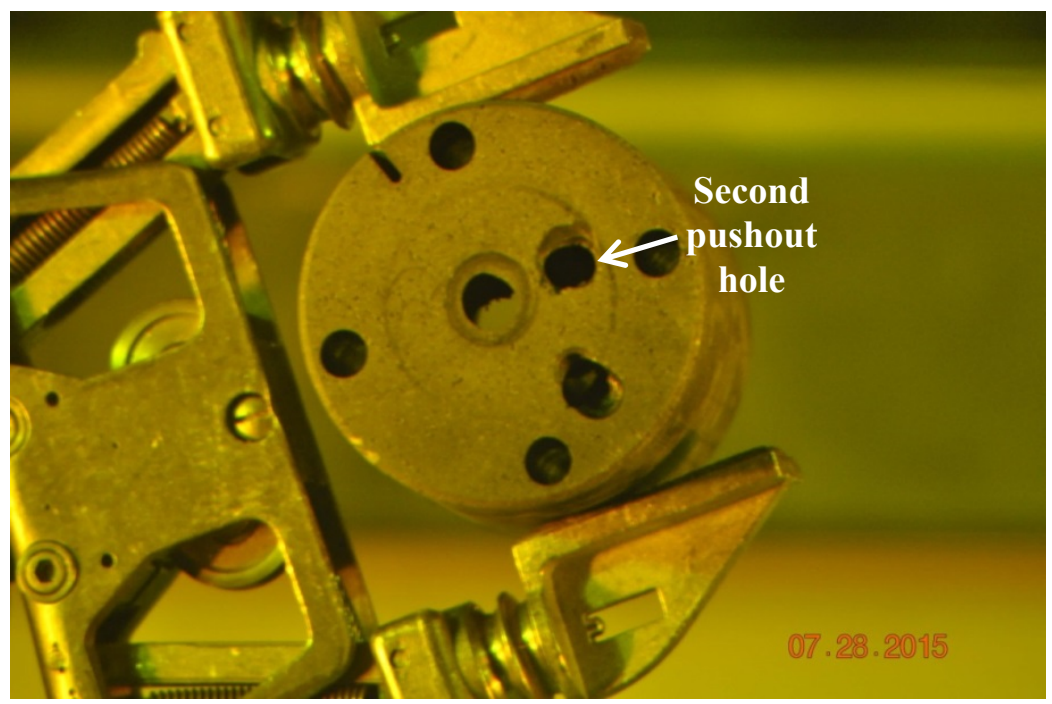

Figure 31. Sink ring with second pushout hole.

\subsection{Capsule 8 Standard Body}

The sink ring came out of the capsule with no particular incident. The sink ring lid was removed without removal of the screws. The outer ring was removed with little resistance. The outer ring was largely black, noticeably darker than the uniform gray of the sink ring. The spacers were also black with soot, and the bottom ceramic spacer was broken. There were no problems with insertion of the void filler for the outer or inner ring. The inner ring was blackened on both axial ends for approximately $10 \mathrm{~mm}$. The compacts slid out with very little resistance.

An area of discoloration was observed surrounding a nub on the outside of Capsule 8 (see Figure 9); however, there was no corresponding discoloration on the inside of the capsule shell (see Figure 32), nor was any unusual discoloration apparent on the capsule contents. No soot was observed to adhere to the inside of the capsule shell.

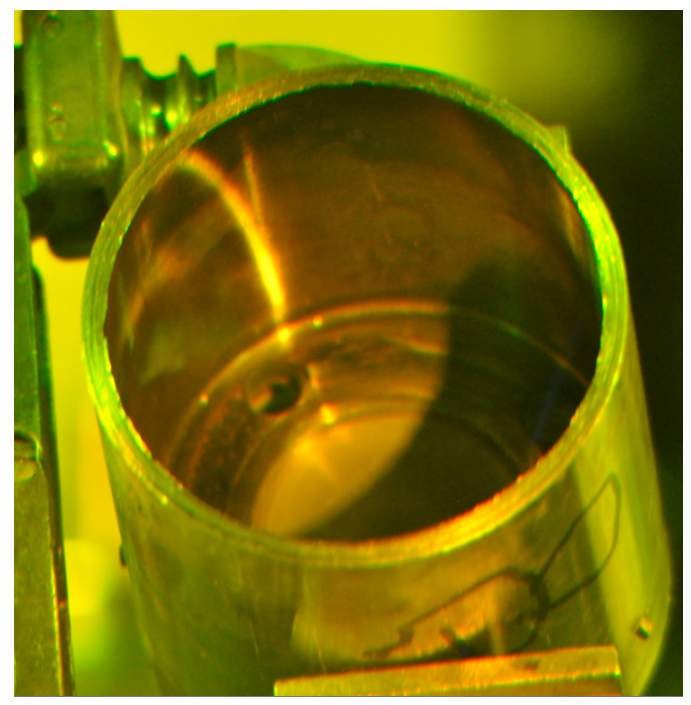

Figure 32. Inside of Capsule 8 after removal of capsule contents. 


\subsection{Capsule 9 Fuel Body}

The sink ring was readily removed from the capsule and the fuel body was tipped out without the need to drill a hole in the sink ring. This fuel body was not disassembled. Figure 33 shows the inside of Capsule 9 along with a piece of the cracked spacer. Neither the spacer nor the inside of the capsule shell appeared to have soot deposits. As with Capsule 8, an area of discoloration was also observed surrounding a nub on the outside of Capsule 9 (see Figure 9); however, no discoloration was observed inside the Capsule 9 shell.

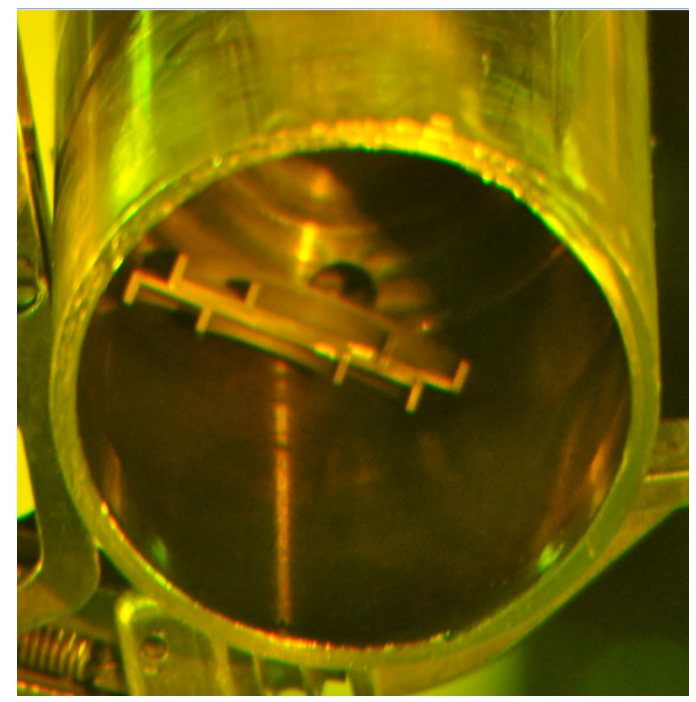

Figure 33. Inside of Capsule 9 shell containing fragment of broken spacer.

\subsection{Capsule 10 Standard Body}

The sink ring was removed from the capsule without incident and the sink ring lid came off without unscrewing the screws. When drilling through the bottom of the sink ring, it became apparent that the bottom zirconia spacer was broken through, meaning that the pushout rod contacted the compacts, pushing them out first. The compacts were retrieved manually (see Figure 34) and containerized, followed by manual removal of the inner ring. As observed in other capsules, the ends of the inner ring showed distinct darkening of the ends (see Figure 35); however, there was no excessive amount of soot present.

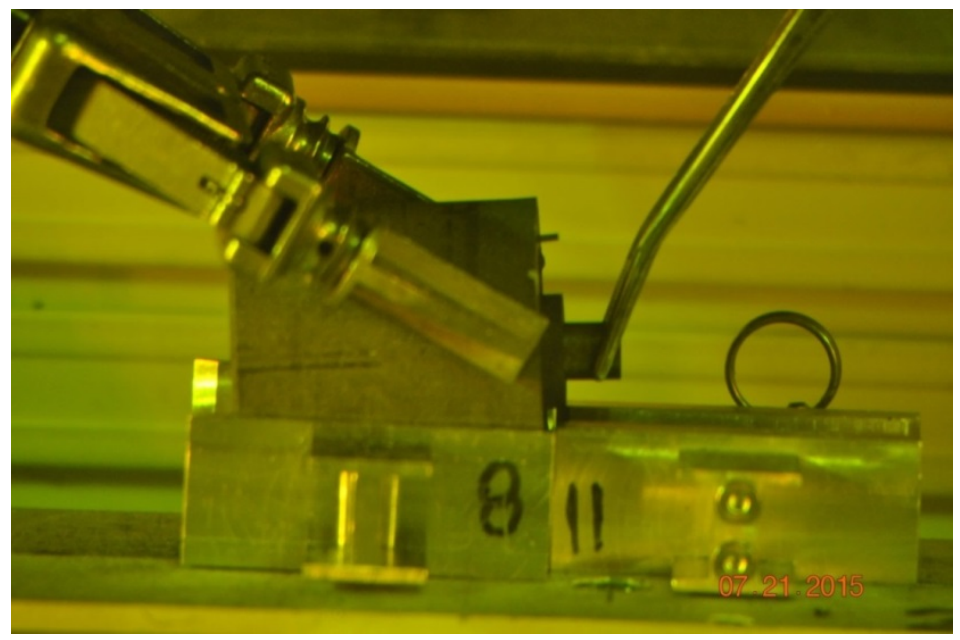

Figure 34. Manual removal of compacts from Capsule 10. 


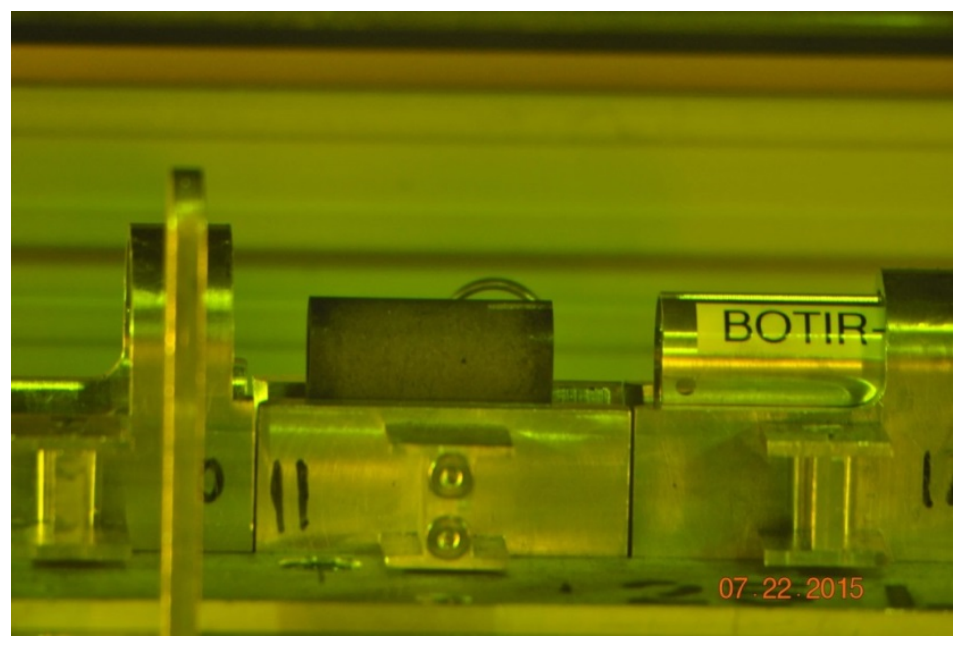

Figure 35. Capsule 10 inner ring showing blackening of ends.

\subsection{Capsule 11 Fuel Body}

Following removal of the capsule lid from the body, the through tubes remained stuck in the sink ring and attached to the capsule lid, making sink ring lid removal impossible. An attempt was made to pull the through tubes out by clamping the capsule lid in the fixed clamp and putting the sink ring in the carriage clamp and pulling laterally. The result was longitudinal cracking of the sink ring at the bottom of the ring where the through tubes were located. It appeared that the tubes may have been splayed radially in that the bottom ends of the tubes were splitting the ring. Figure 36 shows a small pneumatic reciprocating saw that was used to cut the through tubes and enable removal of the sink ring from the capsule lid. The longitudinal cracks caused by the attempt to pull the through tubes out of the sink are shown in Figure 37 and Figure 38. In Figure 38, one of the stuck through tubes is clearly visible in the sink ring. The Capsule 11 fuel body was not disassembled.

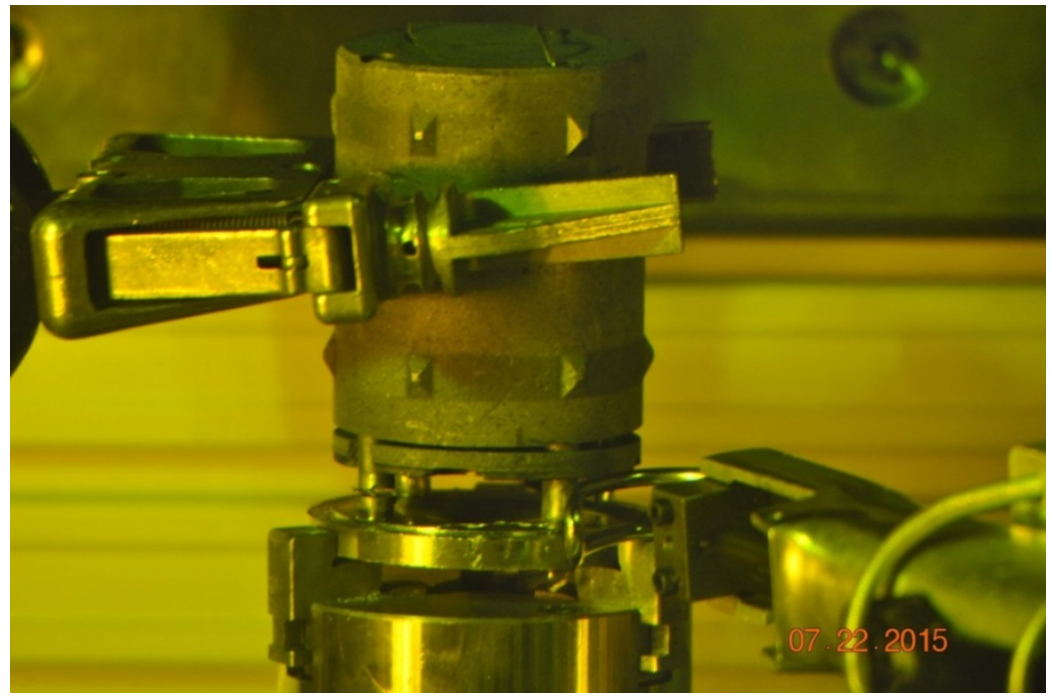

Figure 36. Cutting through tubes to separate sink ring from capsule lid. 


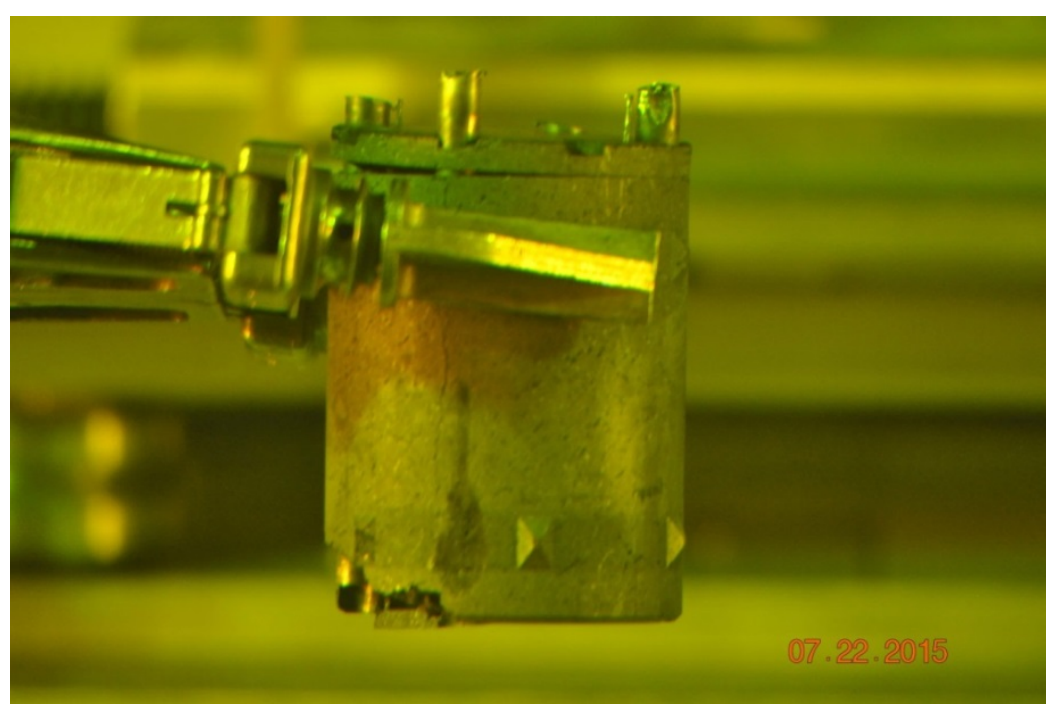

Figure 37. Sink ring with cracks near through tubes.

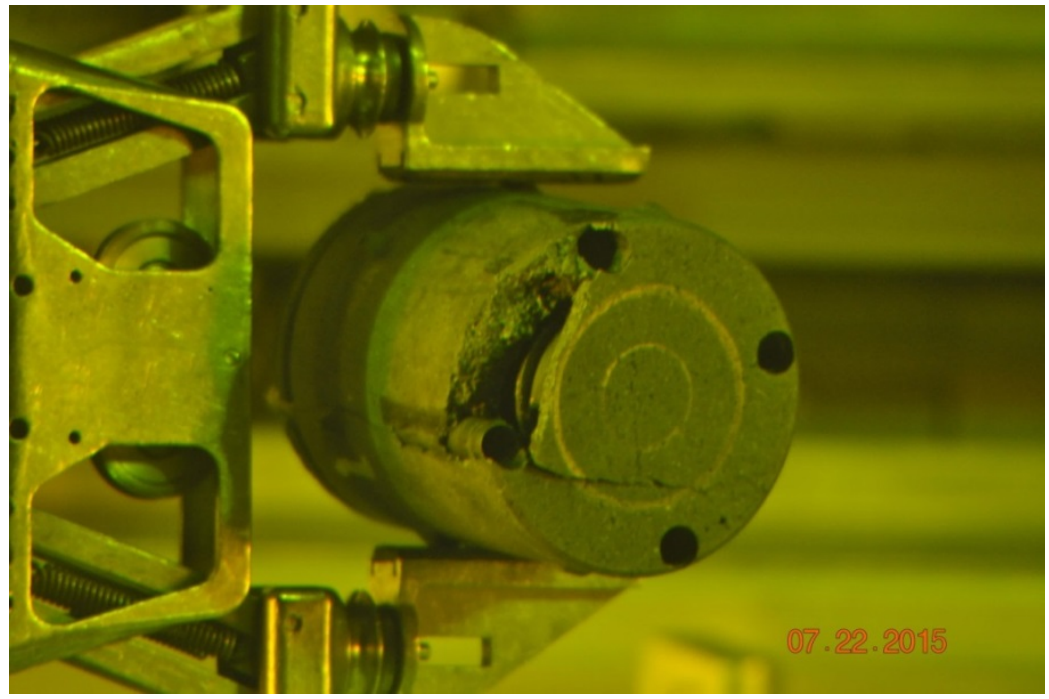

Figure 38. Bottom view of damaged Capsule 11 sink ring.

\subsection{Capsule 12 Standard Body}

Separating the lid from the capsule required clamping the head in the fixed position, using an adjustable knife-edge clamp, and pulling the capsule body off with the leadscrew-driven carriage clamp. As depicted in Figure 39, the separation resulted in two through tubes pulling out and two remaining in the sink ring initially. The remaining through tubes were drilled out of the lid using a conventional 2-flute drill bit, as the 4-flute bit made minimal progress.

The outer ring was pushed out using the 0.635 -cm (0.2-in.) pushrod against the bottom zirconia spacer with minimal force. It was placed in its container, and the inner ring was pushed out using the void filler, which fit easily. The compacts were, in turn, pushed out without incident. The surface of the zirconia spacers oriented toward the experiment appeared sooty. Darkening of the inner ring was seen to extend approximately $5 \mathrm{~mm}$ from each end longitudinally. The compacts appeared to have slight mottling and circumferential lines, but otherwise were uniform in color. 


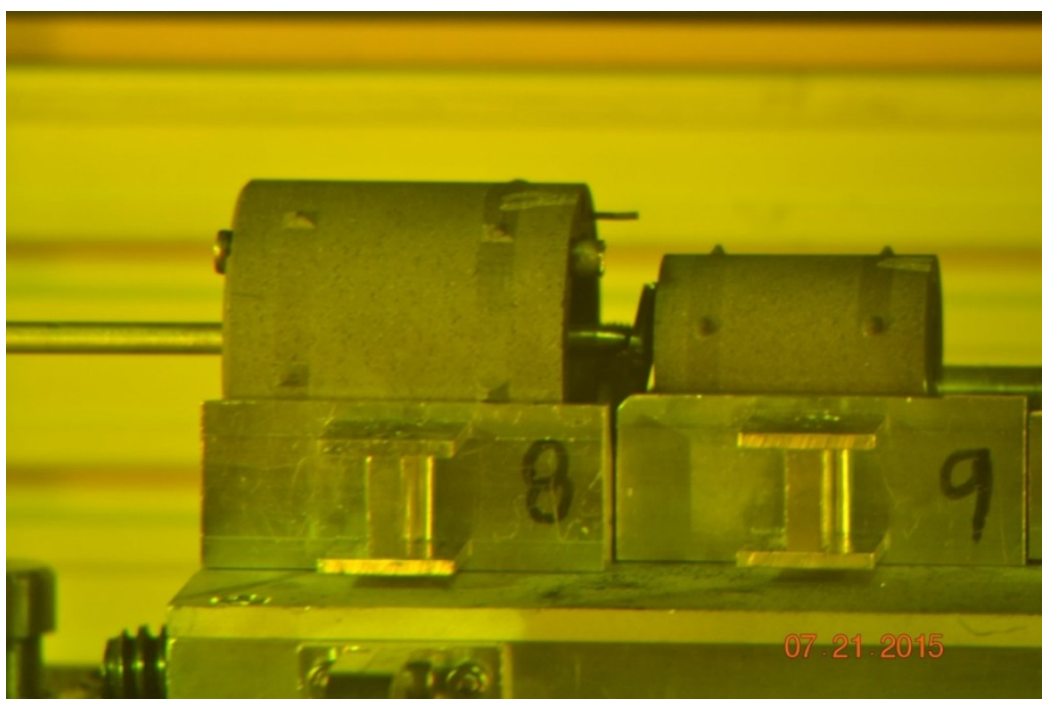

Figure 39. Capsule 12 sink ring (left) with stuck through tube and outer ring (right).

\section{METROLOGY}

\subsection{Equipment and Procedures}

All dimensional measurements were performed in the HFEF main cell according to laboratory instructions manual HFEF-LI-0072 (INL 2015a). All metrology equipment was evaluated prior to qualification per TEV-1665 (INL 2012). Performance of the metrology systems ${ }^{\mathrm{a}}$ used for AGR-3/4 was evaluated and qualified for remote handling and proper function in the mock-up facility at MFC per MFC-EQP-0068 (INL 2010e), MFC-EQP-0163 (INL 2014b), and MFC-EQP-0182 (INL 2014c). Prior to qualification, all equipment was calibration-verified at the INL calibration laboratory using National Institute of Standards and Technology traceable standards and per LWP-13455 (INL 2015b).

Due to the hot-cell environment in which the metrology equipment was located, annual calibrations were not possible; however, reference standards were used to quantify any drift and proper function of the equipment. Compact reference standards were fabricated to resemble the AGR-3/4 fuel compacts according to INL drawing SK-JDW-5/7/15 (INLa) and dimensionally inspected to verify they met drawing specifications per LWP-13410 (INL 2014a). Outer diameter reference standards for the rings were fabricated according to INL drawings SK-JDW-10/31/13-001 (INLb), SK-JDW-10/31/13-002 (INLc), and SK-JDW-10/31/13-003 (INLd) and dimensionally inspected to verify they met drawing specifications per LWP-13410 (INL 2014a). Reference standards for inner ring measurements were acquired commercially, complete with National Institute of Standards and Technology traceable certifications.

Measurement uncertainties associated with each metrology system are summarized in Table 2. Note that in some cases, the dials were graduated in inches, and other dials were graduated in $\mathrm{mm}$. All measurements taken in inches were converted to $\mathrm{mm}$ for this report. Table 3 summarizes the location and number of measurements taken at each location on the different AGR-3/4 capsule components. The measurement locations for the compacts and rings are illustrated in Figure 40 and Figure 41. HFEF-LI-0072 (INL 2015a) provides detailed instructions used to complete each measurement.

a The compact measuring system used for AGR-3/4 compacts was originally designed and qualified for the AGR-1 compacts metrology as a backup system should the camera system used for this purpose fail during that measurement campaign. This equipment was repurposed for AGR-3/4 metrology, and it functioned acceptably for the AGR-3/4 campaign with the reference standards fabricated for AGR-3/4. 
Figure 42 shows metrology equipment used for compact measurements. The metrology equipment for the AGR-3/4 compact was originally designed for measuring the AGR-1 compacts. Since the AGR-3/4 compacts are 1.27-cm (0.5-in.) shorter than those for AGR-1, a 1.27-cm (0.5-in.) shim/reference standard was used to allow proper function of the micrometer without modifying the equipment. The ODs of the rings were measured using the apparatus shown in Figure 43. Ring ID measurements were taken using the bore gauge apparatus shown in Figure 44.

Table 2. Measurement uncertainty for metrology equipment.

\begin{tabular}{|c|c|c|c|}
\hline $\begin{array}{l}\text { Metrology System / Units }{ }^{*} / \\
\text { (Reference Drawings) }\end{array}$ & $\begin{array}{c}\text { Calibration } \\
\text { Tolerance }\end{array}$ & $\begin{array}{c}\text { System Resolution/ } \\
\text { Uncertainty }\end{array}$ & $\begin{array}{c}\text { Reference Standard Tolerances } \\
\text { (Units) }\end{array}$ \\
\hline $\begin{array}{l}\text { Compact metrology /inches/ } \\
\text { (DWG-768117 [2010a], } \\
\text { DWG-768118 [2010b], } \\
\text { DWG-768119 [2010c], and } \\
\text { DWG-768120 [2010d]) } ¥, \infty\end{array}$ & $1 \mathrm{E}-4$ & $1 \mathrm{E}-4 / 5 \mathrm{E}-5$ & $1 \mathrm{E}-4$ \\
\hline $\begin{array}{l}\text { Ring outer diameter metrology/mm/ } \\
\text { (DWG-774612 [2013a], } \\
\text { DWG-774616 [2013b], } \\
\text { DWG-774620 [2013c], } \\
\text { SK-JDW-10/31/13-001 [INLb], } \\
\text { SK-JDW-10/31/13-002 [INLc], and } \\
\text { SK-JDW-10/31/13-003 [INLd]) }\end{array}$ & $2 \mathrm{E}-3$ & $1 \mathrm{E}-4 / 5 \mathrm{E}-5$ & $\begin{array}{l}\text { 2E-3/2E-3/1E-3 (per } \\
\text { SK-JDW-10/31/13-001 [INLb], } \\
\text { SK-JDW-10/31/13-002 [INLc], } \\
\text { and } \\
\text { SK-JDW-10/31/13-003 [INLd], } \\
\text { respectively) }\end{array}$ \\
\hline $\begin{array}{l}\text { Ring inner diameter metrology } \\
\text { /inches/ (none) })^{\#, \uparrow}\end{array}$ & Not applicable & $5 \mathrm{E}-4 / 5 \mathrm{E}-5$ & $4 \mathrm{E}-5$ \\
\hline \multicolumn{4}{|c|}{$\begin{array}{l}\text { ¥ http://ecatalog.mitutoyo.com/Digital-Outside-Micrometers-Series-193-C1099.aspx } \\
\infty \mathrm{http} / / / \text { ecatalog.mitutoyo.com/Micrometer-Heads-Series-250-with-Digit-Counter-C1565.aspx } \\
\text { \# https://www.dorseymetrology.com/traditional-dial-indicators/group-2 } \\
\dagger \text { http://pmcmercury.com/cylindrical-gages/cylindrical-plain-ring-gages/ } \\
\text { * Some dials were graduated in inches and some dials were graduated in } \mathrm{mm} \text {. All measurements taken in inches } \\
\text { were converted to mm for this report. }\end{array}$} \\
\hline
\end{tabular}

Table 3. Measurement protocol for compacts and rings.

\begin{tabular}{|l|l|l|}
\hline $\begin{array}{l}\text { Experiment } \\
\text { Component }\end{array}$ & \multicolumn{1}{|c|}{$\begin{array}{c}\text { Number of } \\
\text { Measurement Locations }\end{array}$} & \multicolumn{1}{|c|}{ Number of Measurements Taken at Location } \\
\hline $\begin{array}{l}\text { Inner rings } \\
\text { OD }\end{array}$ & $\begin{array}{l}\text { Two diameter (upper middle and lower } \\
\text { middle), one length }\end{array}$ & $\begin{array}{l}\text { Two at upper middle, two at lower middle, and } \\
\text { one length. }\end{array}$ \\
\hline $\begin{array}{l}\text { Inner rings } \\
\text { ID }\end{array}$ & Four (top, upper-middle, lower-middle, bottom) & $\begin{array}{l}\text { Four at each location with three rotations of } \\
\text { 45 degrees. }\end{array}$ \\
\hline $\begin{array}{l}\text { Outer rings } \\
\text { OD }\end{array}$ & Four (top, upper-middle, lower-middle, bottom) & $\begin{array}{l}\text { Four at each location with three rotations of } \\
\text { 45 degrees as permitted by nubs. } \\
\text { gzimuthal rotation degrees were adjusted on } \\
\text { outer ring when nub interference occurred. }\end{array}$ \\
\hline $\begin{array}{l}\text { Outer rings } \\
\text { ID }\end{array}$ & Four (top, upper-middle, lower-middle, bottom) & $\begin{array}{l}\text { Two at each location. Location of bore gauge } \\
\text { was static at each elevation. }\end{array}$ \\
\hline $\begin{array}{l}\text { Sink rings } \\
\text { OD }\end{array}$ & Four (top, upper-middle, lower-middle, bottom) & $\begin{array}{l}\text { Four at each location with three rotations of } \\
\text { 45 degrees. }\end{array}$ \\
\hline $\begin{array}{l}\text { Sink rings } \\
\text { ID }\end{array}$ & Four (top, upper-middle, lower-middle, bottom) & $\begin{array}{l}\text { Two at each location. Location of bore gauge } \\
\text { was static at each elevation. }\end{array}$ \\
\hline
\end{tabular}




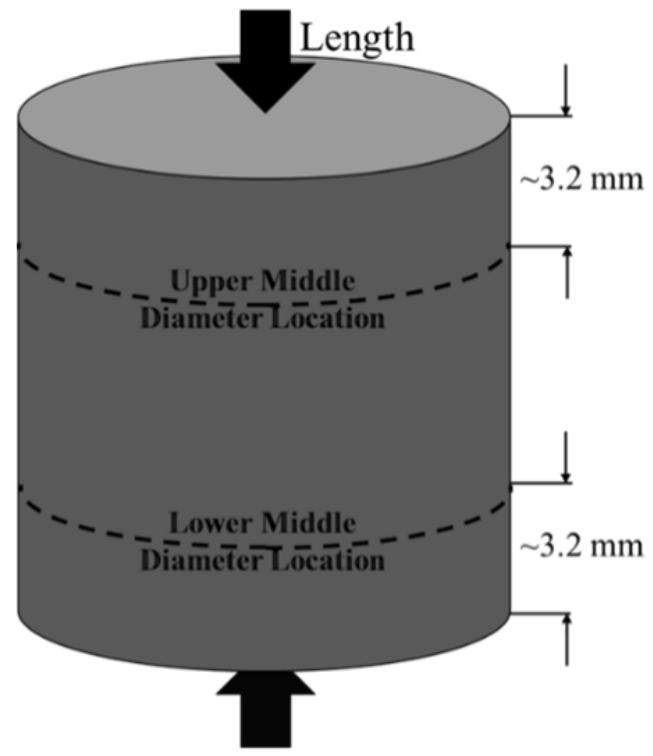

Figure 40. Diagram showing compact measurement locations.

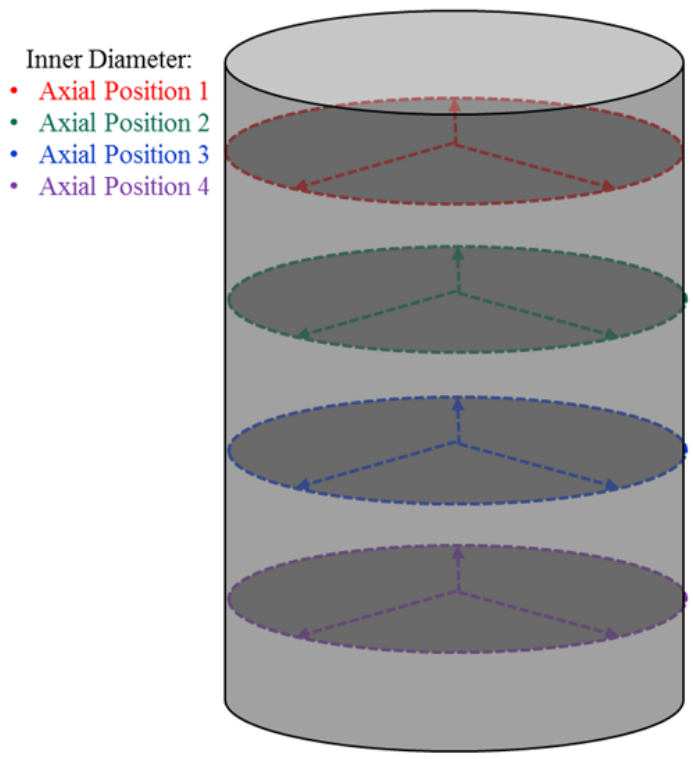

\section{Outer Diameter:}

- Axial Position

- Axial Position 2

- Axial Position 3

- Axial Position 4

- Azimuthal Position 1

- Azimuthal Position 2

- Azimuthal Position 3

- Azimuthal Position 4

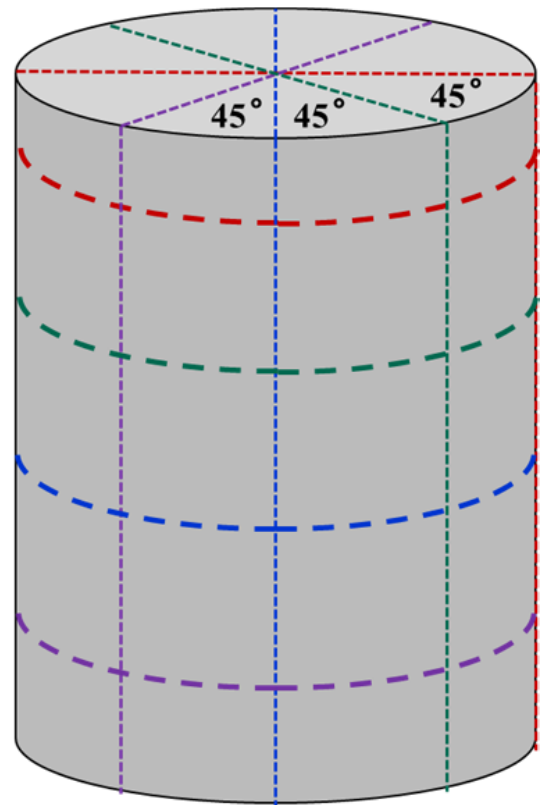

Figure 41. Ring inner and outer diameter measurement locations. Each location is at approximately the same axial elevation as the center of each compact. 


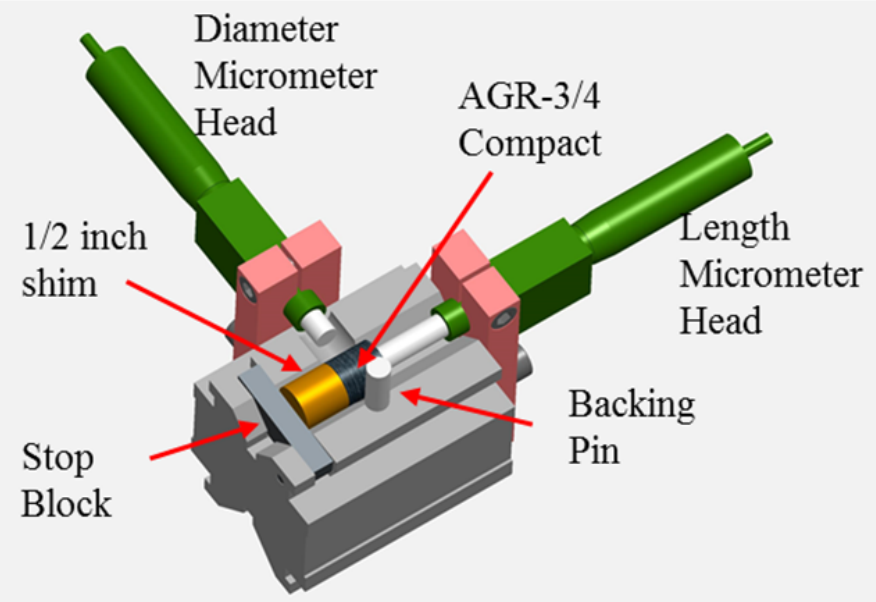

Figure 42. AGR-1 compact metrology system used for AGR-3/4 compacts.

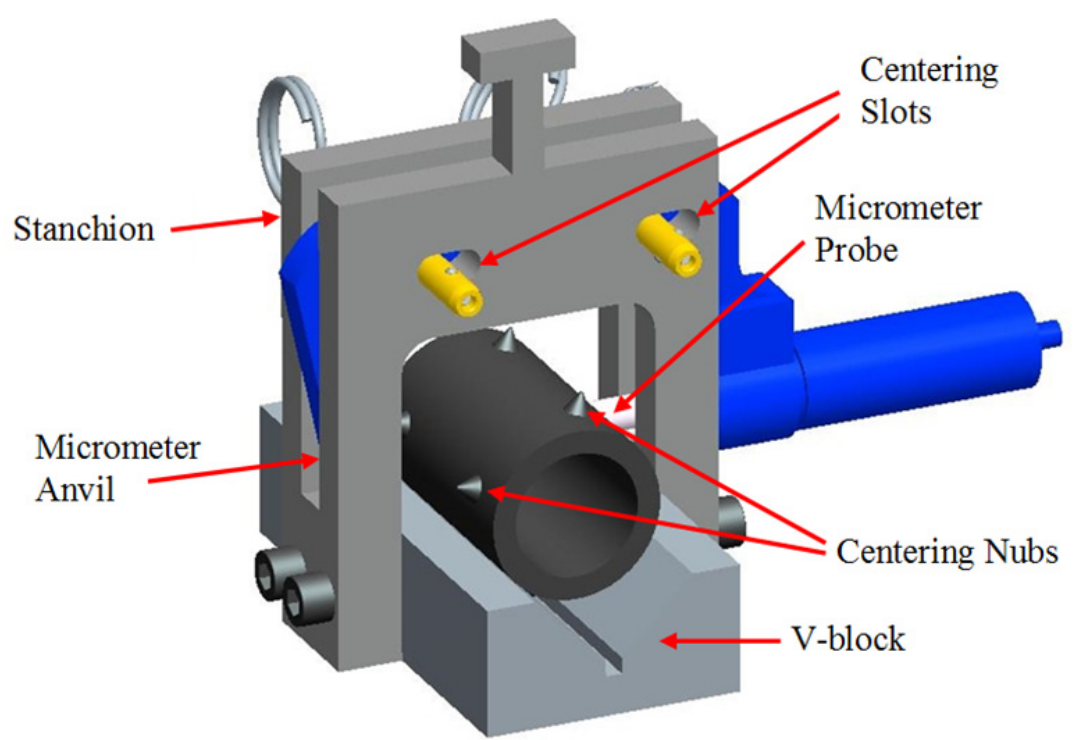

Figure 43. Outer diameter metrology system used for inner, outer, and sink rings. 


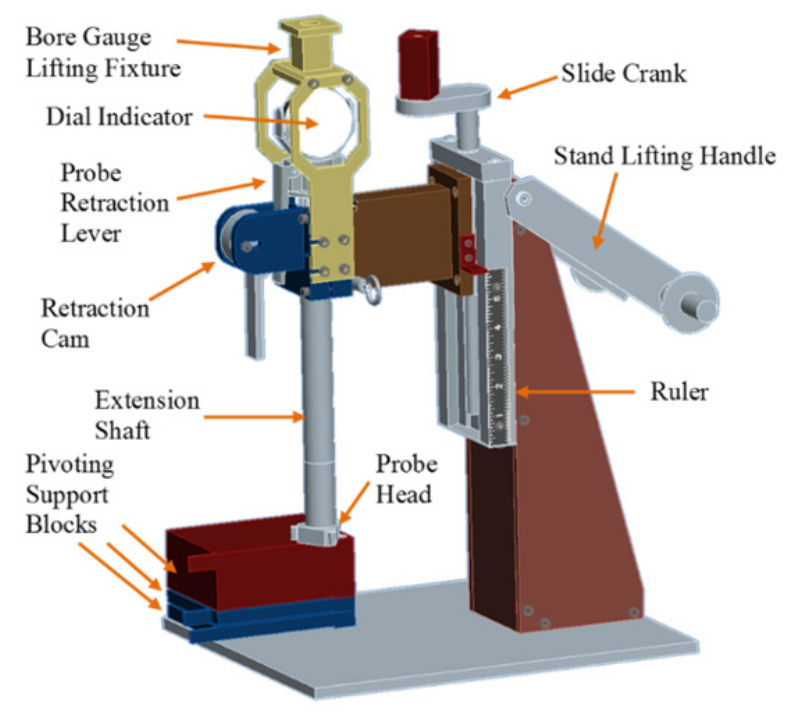

Figure 44. Inner diameter bore gauge metrology system used for inner, outer, and sink rings.

\subsection{Metrology Results}

\subsubsection{Fuel Compact Dimensional Changes}

Table 4 summarizes the measured, as-fabricated dimensions for each compact for which PIE measurements are also available. Recall from Table 1 that some capsules are "fuel bodies" and some are "standard" capsules. Of the fuel body capsules, only Capsule 4 was disassembled during metrology. Thus, no compact dimensional data were obtained for the other fuel body capsules (Capsules 2, 6, 9, and 11). During disassembly, the compacts were lodged within the inner ring of Capsule 4, and a press was used to push the compacts out of the inner rings. This resulted in damage to Compact 4-1, which made length and diameter measurements impossible. Capsule 5 compacts were also stuck within the inner ring, and Compact 5-1 suffered damage upon removal, preventing meaningful length measurements. Despite this damage, diameter measurements were still completed for Compact 5-1. The standard deviation listed for the diameter in the table is the standard deviation calculated from two measurements at two different axial locations along the compact. The lengths were only measured once prior to and after irradiation (Hunn et al. 2011). As a result, standard deviations are not available (N/A) for the compact lengths. Due to their negligible contribution, uncertainties associated with metrology equipment (Table 2) were not accounted for in Table 4.

Figure 45 shows the percent change in the compact diameters for each of the four compacts within each capsule. The $\mathrm{x}$-axis represents the capsule number. The compact level within each capsule is denoted in the legend. Recall that compact levels are numbered from bottom to top. Thus, Compact 7-1 is the bottom compact from the seventh capsule. The bottom compact from Capsule $\mathrm{X}$ is plotted at $x=\mathrm{X} .00$, the top compact from Capsule X is plotted at $x=\mathrm{X}$.75. The label "Cap 1" between $x=1$ and $x=2$ denotes Capsule 1, and the four points with $\mathrm{x}$-values $1 \leq x<2$ are for the four compacts from Capsule 1 .

Diametric shrinkage was observed in all compacts. Generally, the trend exhibited in Figure 45 follows the axial fluence profile within the experiment, meaning that the greater degree of diametric shrinkage was observed in compacts from capsules with the higher fluences. The error bars in Figure 45 represent one standard deviation in the percent change calculated by propagating the standard deviation calculated from pre-irradiation and post-irradiation measurements. Recall that the diameter of each compact was measured twice at two axial locations along the compact in both the pre- and post-irradiation measurements (see Table 3 and Figure 40). Uncertainty associated with measurement equipment (see Table 2) was not included in the error bars because this source of uncertainty is much smaller than the variability from measurement to measurement. 
Table 4. Dimensional changes and standard deviations for all AGR-3/4 compacts measured.

\begin{tabular}{|c|c|c|c|c|c|c|c|c|}
\hline \multirow[b]{2}{*}{ Compact } & \multicolumn{2}{|c|}{ As-Fabricated Dimensions } & \multicolumn{3}{|c|}{ Average Diameter Change } & \multicolumn{3}{|c|}{ Average Length Change } \\
\hline & $\begin{array}{l}\text { Diameter } \\
(\mathrm{mm})\end{array}$ & $\begin{array}{l}\text { Length } \\
(\mathrm{mm})\end{array}$ & $(\mathrm{mm})$ & $(\%)$ & $\begin{array}{c} \pm \sigma \\
(\mathrm{mm})\end{array}$ & $(\mathrm{mm})$ & $(\%)$ & $\begin{array}{c} \pm \sigma \\
(\mathrm{mm})\end{array}$ \\
\hline $1-1$ & 12.32 & 12.508 & -0.074 & -0.60 & 0.0064 & -0.0874 & -0.70 & $\mathrm{~N} / \mathrm{A}^{\mathrm{a}}$ \\
\hline $1-2$ & 12.32 & 12.520 & -0.090 & -0.73 & 0.0104 & -0.0994 & -0.79 & N/A \\
\hline $1-3$ & 12.32 & 12.486 & -0.089 & -0.72 & 0.0093 & -0.0908 & -0.73 & $\mathrm{~N} / \mathrm{A}$ \\
\hline $1-4$ & 12.32 & 12.553 & -0.093 & -0.76 & 0.0122 & -0.0943 & -0.75 & $\mathrm{~N} / \mathrm{A}$ \\
\hline $3-1$ & 12.33 & 12.520 & -0.193 & -1.56 & 0.0248 & -0.1121 & -0.90 & $\mathrm{~N} / \mathrm{A}$ \\
\hline $3-2$ & 12.32 & 12.495 & -0.196 & -1.59 & 0.0119 & -0.0998 & -0.80 & N/A \\
\hline $3-3$ & 12.32 & 12.518 & -0.196 & -1.59 & 0.0058 & -0.0593 & -0.47 & N/A \\
\hline $3-4$ & 12.32 & 12.533 & -0.193 & -1.57 & 0.0250 & -0.0743 & -0.59 & $\mathrm{~N} / \mathrm{A}$ \\
\hline $4-1$ & 12.32 & 12.468 & N/A & N/A & N/A & N/A & N/A & N/A \\
\hline $4-2$ & 12.32 & 12.537 & -0.154 & -1.25 & 0.0081 & -0.0402 & $-0.32 \%$ & N/A \\
\hline 4-3 & 12.33 & 12.475 & -0.155 & -1.26 & 0.0118 & 0.0599 & $0.48 \%$ & N/A \\
\hline 4-4 & 12.32 & 12.473 & -0.150 & -1.21 & 0.0089 & 0.0111 & $0.09 \%$ & N/A \\
\hline $5-1$ & 12.32 & 12.505 & -0.141 & -1.14 & 0.0180 & N/A & N/A & N/A \\
\hline $5-2$ & 12.32 & 12.52 & -0.153 & -1.25 & 0.0000 & 0.0403 & $0.32 \%$ & N/A \\
\hline $5-3$ & 12.31 & 12.484 & -0.146 & -1.18 & 0.0050 & 0.0509 & $0.41 \%$ & N/A \\
\hline $5-4$ & 12.32 & 12.504 & -0.128 & -1.04 & 0.0000 & 0.0563 & $0.45 \%$ & N/A \\
\hline $7-1$ & 12.33 & 12.494 & -0.234 & -1.90 & 0.0081 & -0.0226 & -0.18 & $\mathrm{~N} / \mathrm{A}$ \\
\hline $7-2$ & 12.32 & 12.499 & -0.251 & -2.04 & 0.0089 & 0.0105 & 0.08 & N/A \\
\hline $7-3$ & 12.32 & 12.546 & -0.249 & -2.02 & 0.0081 & -0.0111 & -0.09 & N/A \\
\hline $7-4$ & 12.32 & 12.498 & -0.226 & -1.84 & 0.0064 & 0.0115 & 0.09 & N/A \\
\hline $8-1$ & 12.31 & 12.506 & -0.169 & -1.37 & 0.0000 & -0.0092 & -0.07 & N/A \\
\hline $8-2$ & 12.33 & 12.479 & -0.192 & -1.56 & 0.0064 & -0.0076 & -0.06 & N/A \\
\hline $8-3$ & 12.32 & 12.498 & -0.181 & -1.47 & 0.0050 & -0.0139 & -0.11 & N/A \\
\hline $8-4$ & 12.31 & 12.515 & -0.184 & -1.49 & 0.0141 & -0.0055 & -0.04 & N/A \\
\hline $10-1$ & 12.32 & 12.467 & -0.181 & -1.47 & 0.0050 & -0.0718 & -0.58 & N/A \\
\hline $10-2$ & 12.32 & 12.509 & -0.179 & -1.45 & 0.0000 & -0.0757 & -0.61 & N/A \\
\hline $10-3$ & 12.32 & 12.546 & -0.179 & -1.45 & 0.0000 & -0.0873 & -0.70 & N/A \\
\hline $10-4$ & 12.32 & 12.508 & -0.168 & -1.36 & 0.0086 & -0.0747 & -0.60 & N/A \\
\hline $12-1$ & 12.32 & 12.528 & -0.064 & -0.52 & 0.0000 & -0.0693 & -0.55 & N/A \\
\hline $12-2$ & 12.32 & 12.496 & -0.068 & -0.56 & 0.0089 & -0.0627 & -0.50 & $\mathrm{~N} / \mathrm{A}$ \\
\hline $12-3$ & 12.32 & 12.515 & -0.066 & -0.54 & 0.0086 & -0.0563 & -0.45 & N/A \\
\hline $12-4$ & 12.32 & 12.529 & -0.054 & -0.44 & 0.0050 & -0.0576 & -0.46 & N/A \\
\hline
\end{tabular}

a. N/A: data not available. 


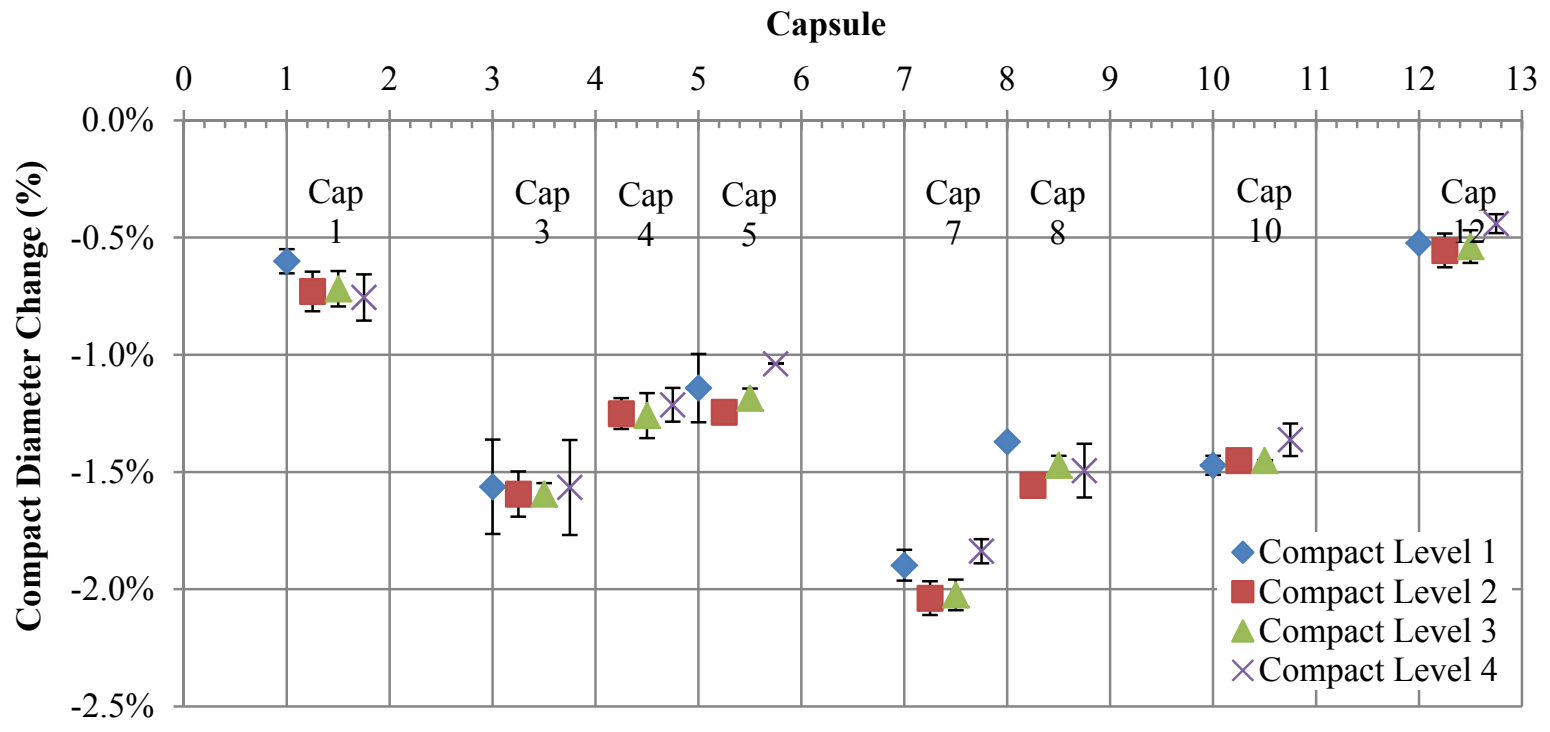

Figure 45. Relative change in compact diameter by compact and capsule. Error bars shows standard deviation from multiple measurements.

Figure 46 shows the percent length change in each of the four compacts from the various disassembled capsules. Recall that the lengths were only measured once prior to and after irradiation. As a result, no standard deviation is available for the compact lengths. The variation in the length change among compacts from the same capsule is larger than was observed for the diameter changes. Most compact lengths decreased; however, a positive length change was measured for most compacts in Capsules 4 and 5, as well as the Level 2 and Level 4 compacts from Capsule 7 (one of the hottest capsules having a TAVA temperature of $1345^{\circ} \mathrm{C}$ ). An explanation for the different behavior of these two Capsule 7 compacts (compared to compacts from other capsules) is related to the irradiation temperature and fluence and is presented in the discussion accompanying Figure 51. In Figure 47 the compact length change versus the compact diameter change is plotted. No trend is apparent from Figure 47.

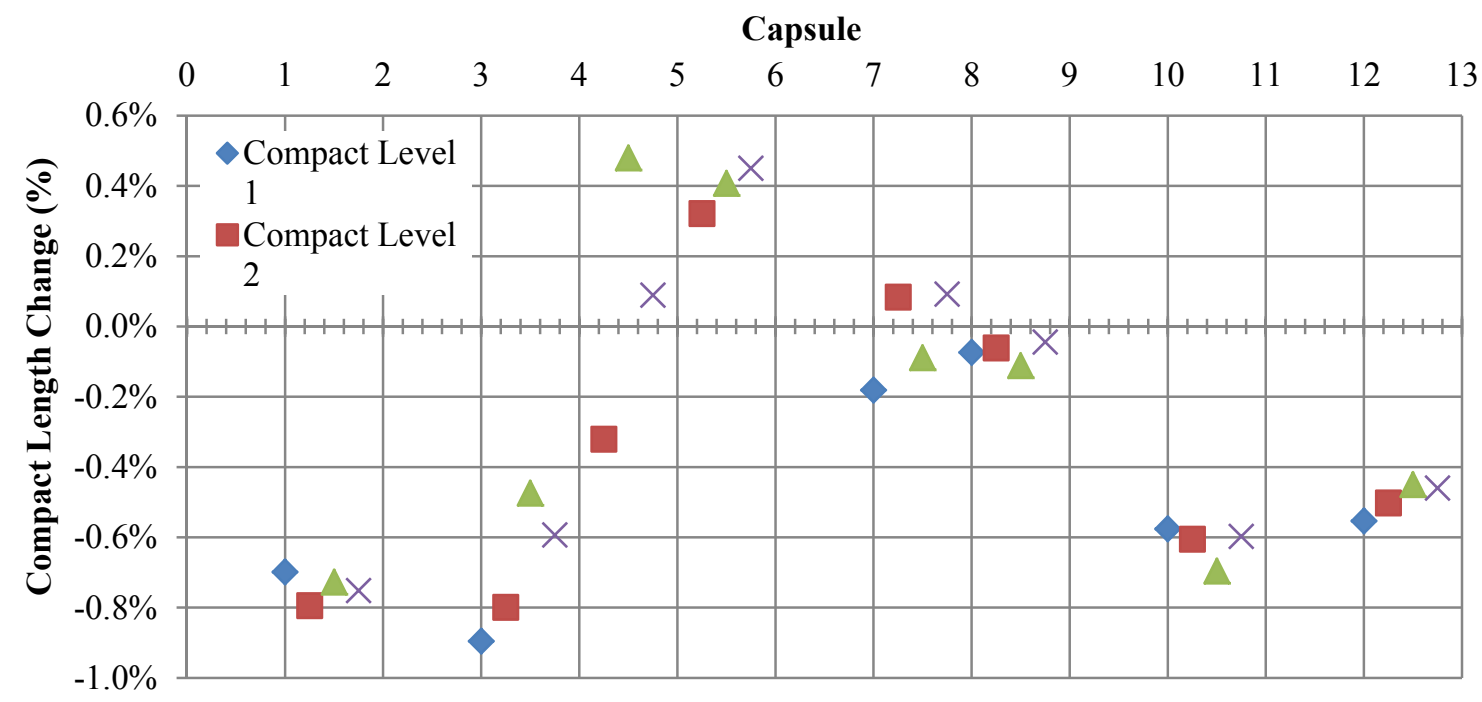

Figure 46. Relative change in compact length by compact and capsule. 


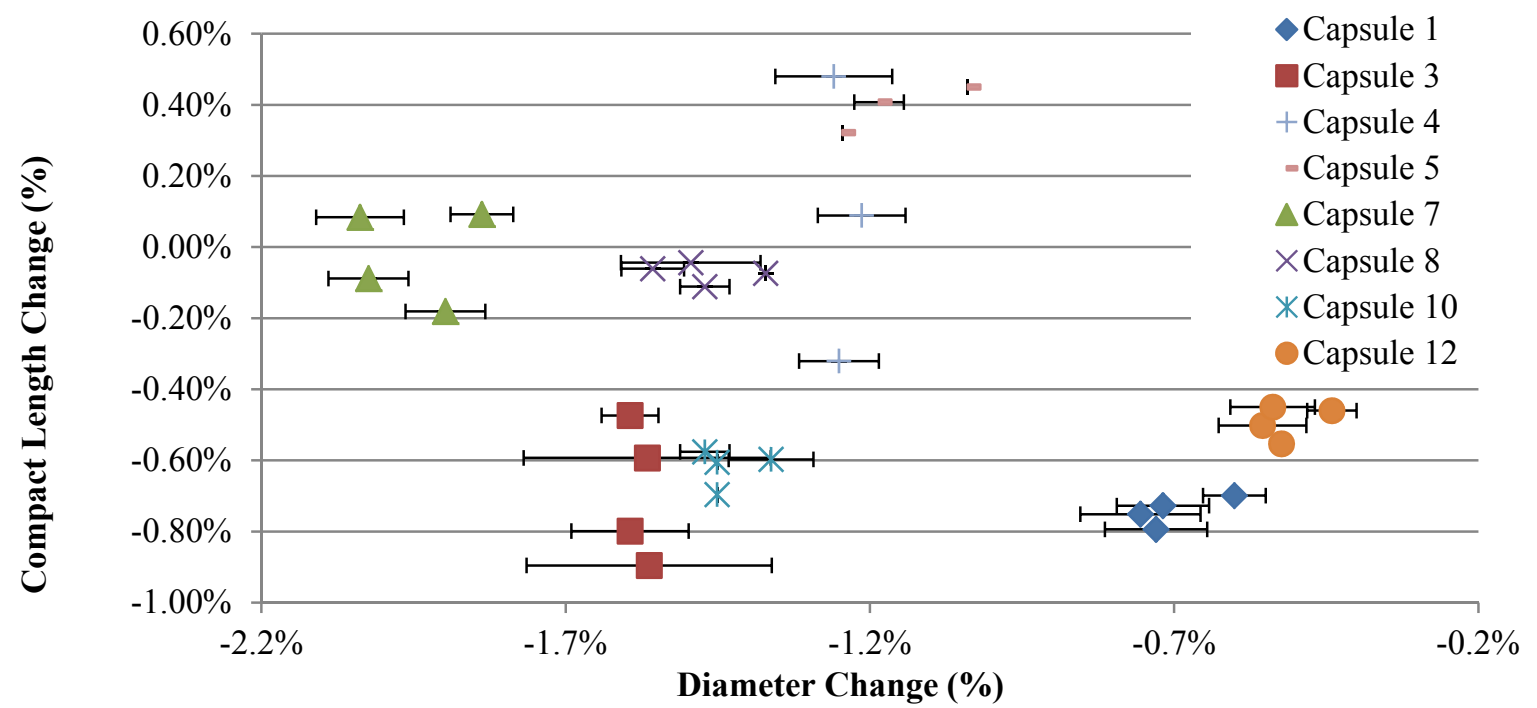

Figure 47. Compact length change versus compact diameter change.

The original thermal analysis used to calculate the compact temperatures was completed prior to completion of metrology, but has since been updated in ECAR-2807 Rev. 1 using the data obtained through metrology. The compact diameter and length changes are plotted here as a function of the compact TAVA temperatures reported in ECAR-2807 Rev. 1 (Hawkes 2016). Figure 48 plots the compact diameter change versus temperature, and Figure 49 plots the compact length change versus temperature. In Figure 48, the extent of diametric shrinkage increases linearly with the TAVA irradiation temperature. Recall that the TAVA temperature generally increases with fast fluence (see Figure 5). Thus, the effects of fluence are also embedded in Figure 48. Figure 49 shows that most lengths decreased except for most compacts from Capsules 4 and 5 and two compacts from Capsule 7. Not including Capsules 4 and 5, the extent of length decrease appears to increase with increasing irradiation temperature before turning-around above $1100^{\circ} \mathrm{C}$. Since the TAVA temperature variation loosely follows fast fluence (see Figure 5), the effects of fluence are masked within Figure 49. The grouping of data in Figure 49 is most likely influenced primarily by the neutron fluence, not the irradiation temperature (see Figure 50 and Figure 51). This is best seen by comparing the very different length changes of compacts from Capsules 3, 8, and 10. These capsules had roughly the same TAVA temperature, but different fluences. 


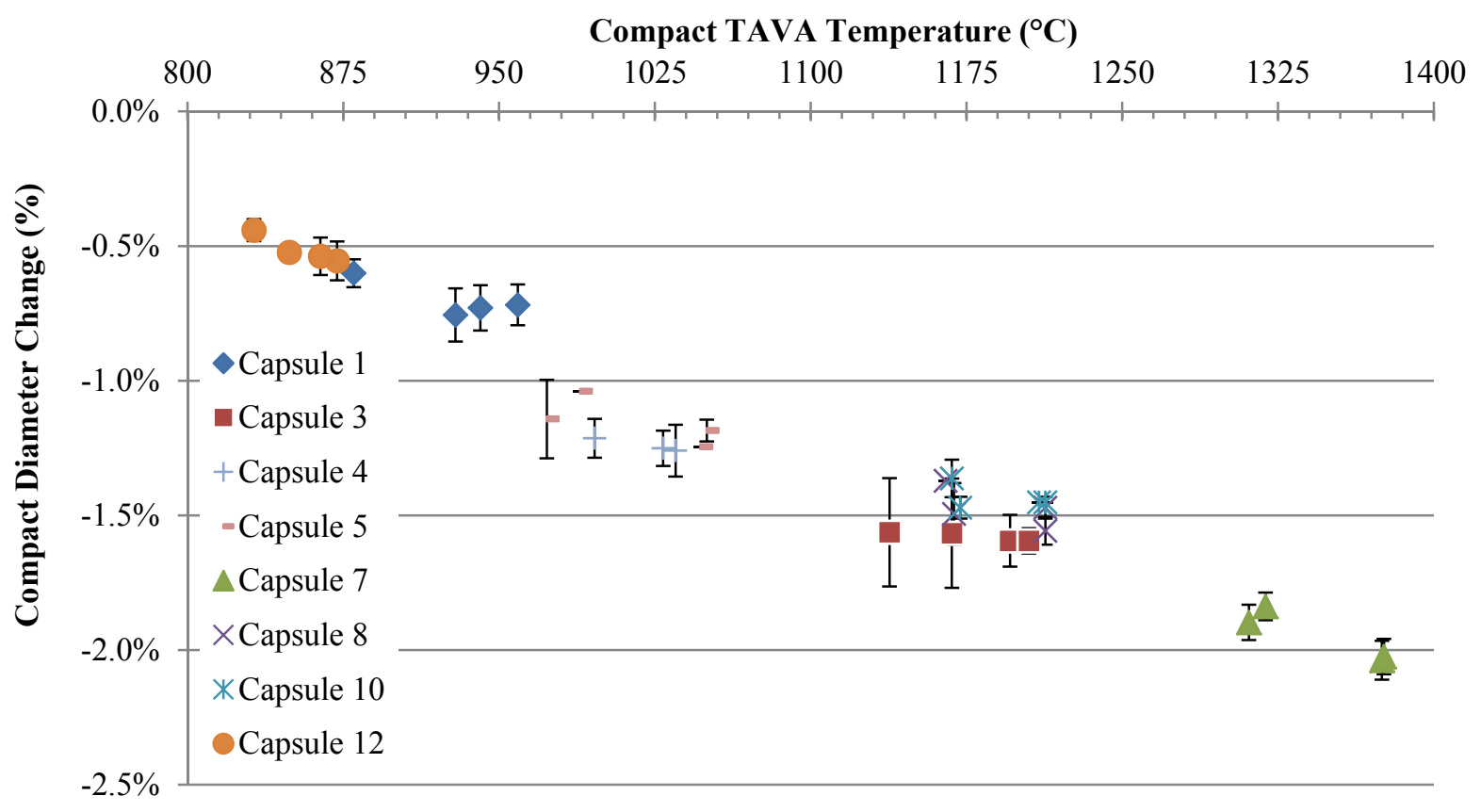

Figure 48. Compact diameter change versus TAVA temperature.

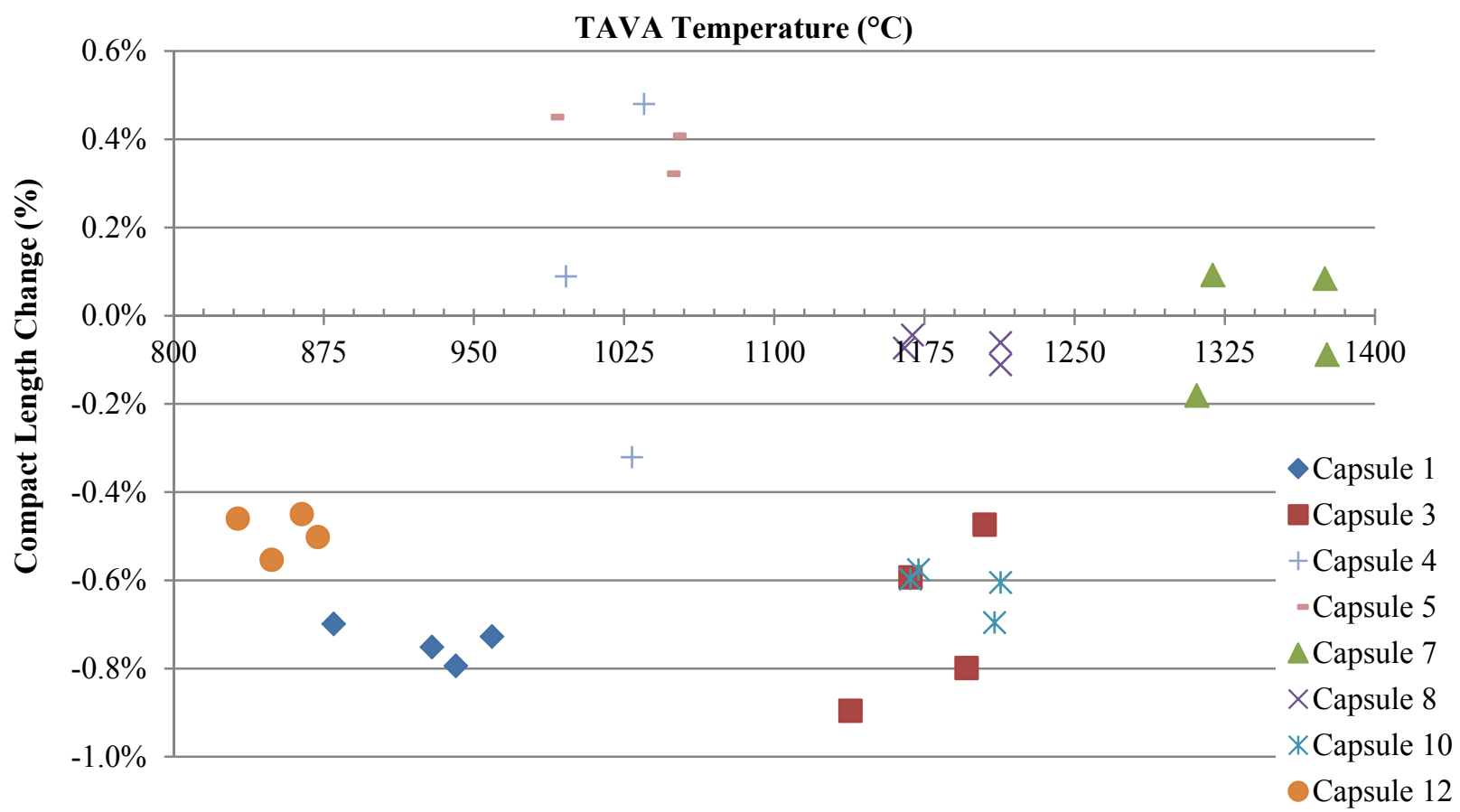

Figure 49. Compact length change versus TAVA temperature. 
Figure 50 and Figure 51 show the compact diameter and length changes, respectively, as a function of fast neutron fluence. The fluences used in these plots were taken from ECAR-2753 (Sterbentz 2015). In Figure 50, it is apparent that the compact diameter decreases with increasing fluence before indicating a turn-around beginning at about $4.2 \times 10^{25} \mathrm{n} / \mathrm{m}^{2}(\mathrm{E}>0.18 \mathrm{MeV})$. Figure 51 demonstrates more dramatic turn-around behavior for the length change than for the diameter change. Here, the compact length decreases with increasing fluence until reaching a minimum at a fluence of approximately $4 \times 10^{25} \mathrm{n} / \mathrm{m}^{2}(\mathrm{E}$ $>0.18 \mathrm{MeV}$ ). At fluences above $4.0 \times 10^{25} \mathrm{n} / \mathrm{m}^{2}$, the extent of length shrinkage decreases with increasing fluence until the length change is positive at a fluence greater than $5 \times 10^{25} \mathrm{n} / \mathrm{m}^{2}$ for five of six measured compacts from Capsules 4 and 5 and two compacts from Capsule 7. Capsule 7 was one of the hottest capsules with a TAVA temperature of $1345^{\circ} \mathrm{C}$. Generally, upon irradiation, isotropic graphite shrinks initially, then swells above a certain fluence (Burchell 2012). The fluence (and the extent of shrinkage) at which this turn-around occurs decreases with increasing irradiation temperature (Burchell 2012). Turnaround in the dimensional change explains the apparent trend observed in Figure 51.

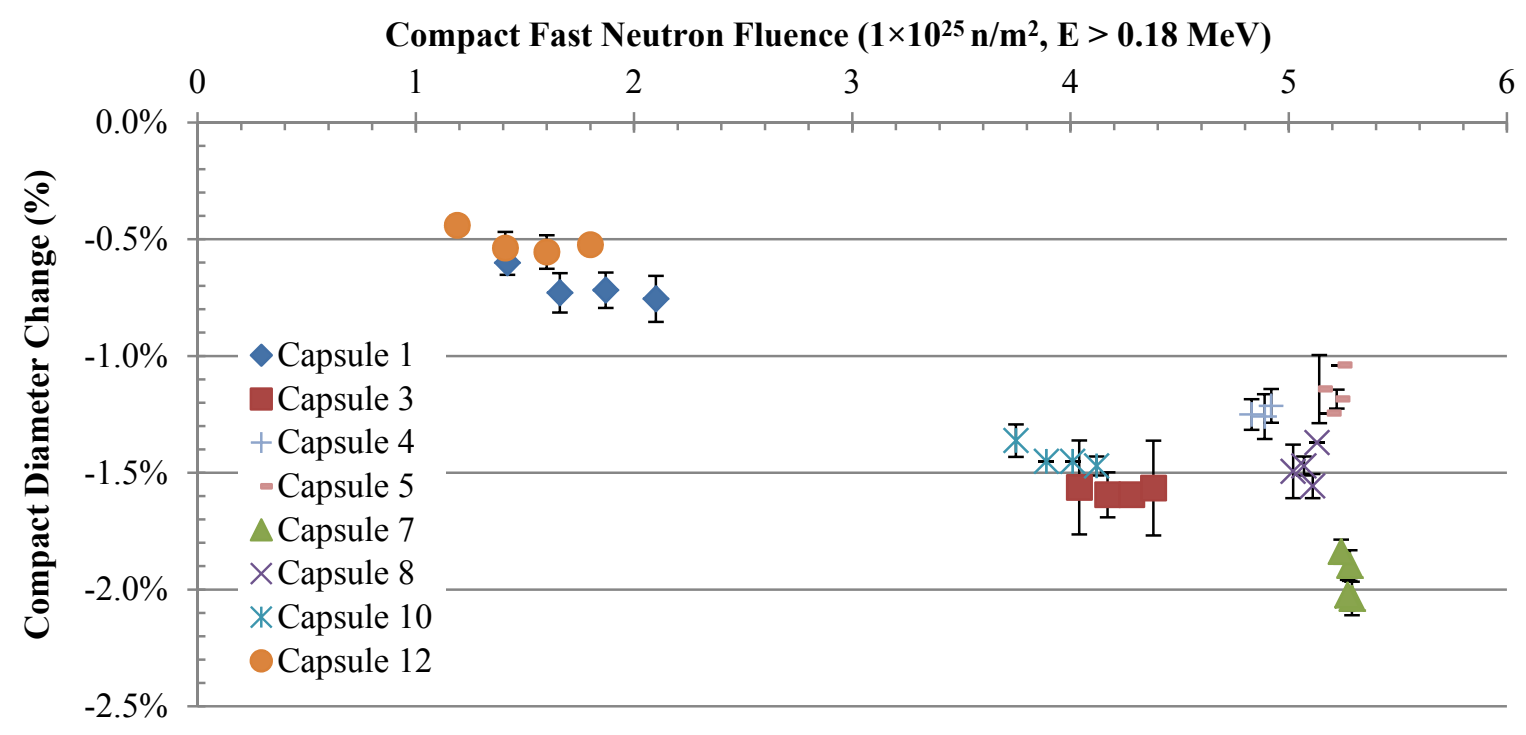

Figure 50. Compact diameter change versus fast neutron fluence.

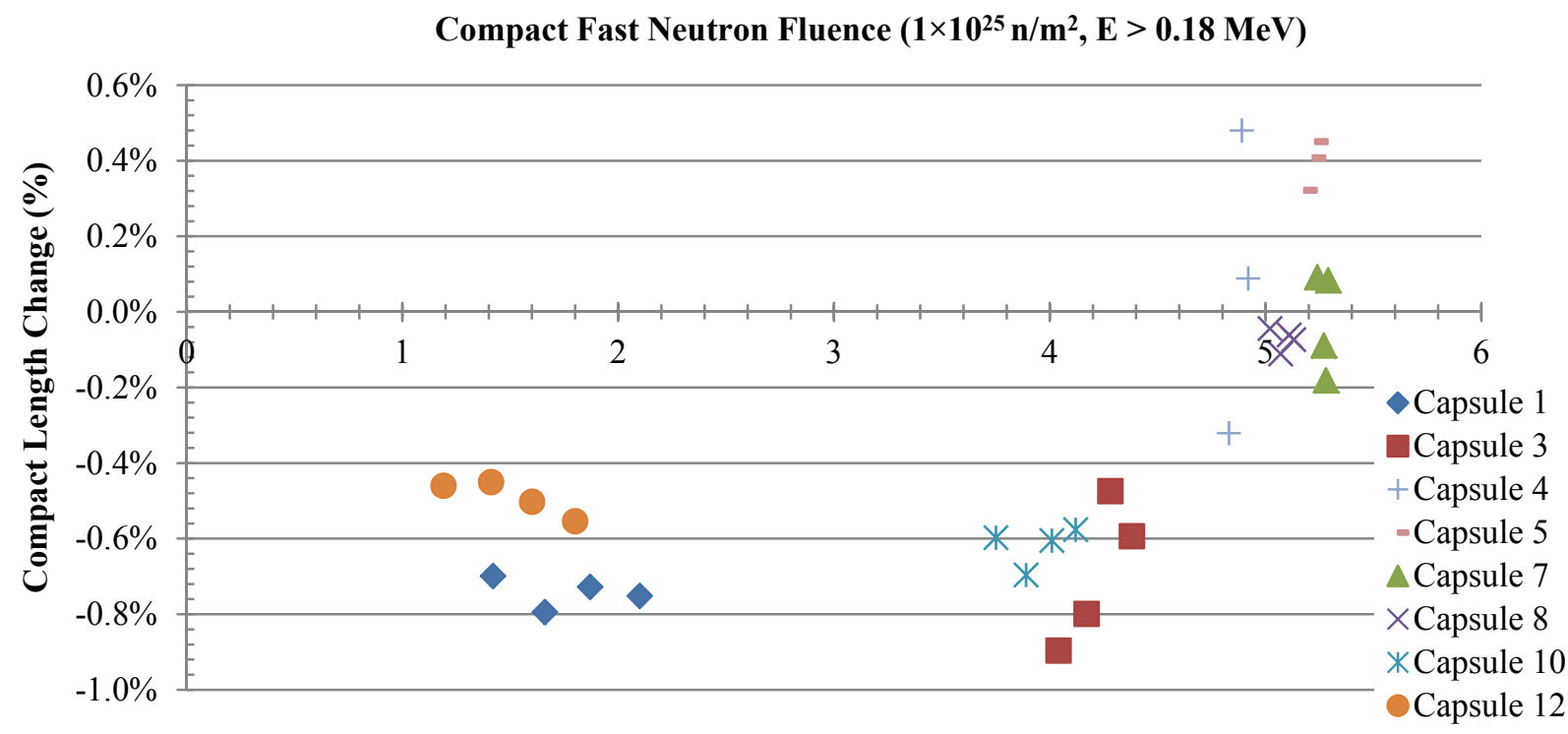

Figure 51. Compact length change as a function of fast neutron fluence. 


\subsubsection{Inner Ring Dimensional Changes}

Figure 52 and Figure 53 show the percent change in the IDs and ODs of the inner rings from Capsules $1,3,4,5,7,8,10$, and 12 as a function of fast neutron fluence and TAVA ring irradiation temperature, respectively. Table 5 summarizes the available pre-irradiation measurement data and the PIE metrology measurements for the inner rings. Other capsules $(2,6,9$, and 11$)$ are fuel bodies that were not disassembled. In each case, the measured ID increased and the OD decreased. In Figure 52, the extent of the dimensional change was greater as fluence increased. A subtle turn-around in the direction of the dimensional change may exist, beginning at a fluence of $4.8 \times 10^{25} \mathrm{n} / \mathrm{m}^{2}$. This is especially evident if the points from Capsule 7 are ignored. In Figure 53, no trend was apparent in relation to the irradiation temperature. Thus, the fluence is the dominant factor driving dimensional changes in the inner rings. The error bars in each figure represent one standard deviation in the percent change calculated by propagating the standard deviations calculated from pre-irradiation and post-irradiation measurements. Uncertainties associated with metrology equipment (Table 2) were not accounted for in the error bars because this source of uncertainty is much smaller than the variability from measurement to measurement. The ID and ODs of each ring were measured four times at four axial locations along the ring in post-irradiation measurements (see Table 3 and Figure 41). These measurements were then averaged in order to report a single value for the ring IDs and ODs. The pre-irradiation measurements were less rigorous. In some cases (denoted by "N/A" in Table 5), only one pre-irradiation measurement was made, meaning no standard deviations for the pre-irradiated dimensions were available. For dimensions where no preirradiation measurement standard deviations are available, the error bars represent the standard deviation from multiple post-irradiation measurements only. In this case, the error bars underestimate the standard deviation. In other cases, two pre-irradiation measurements of a particular dimension were made, and a standard deviation was calculated. In other instances, a range of values was reported for a specific preirradiation measurement. Because the number of measurements comprising this range was not known, it was assumed that the range represented two measurements, one at the top of the range and one at the bottom of the range, and a standard deviation was calculated accordingly. For Capsules 1 and 12, the error bars indicate that the change of the ID is not statistically significant.

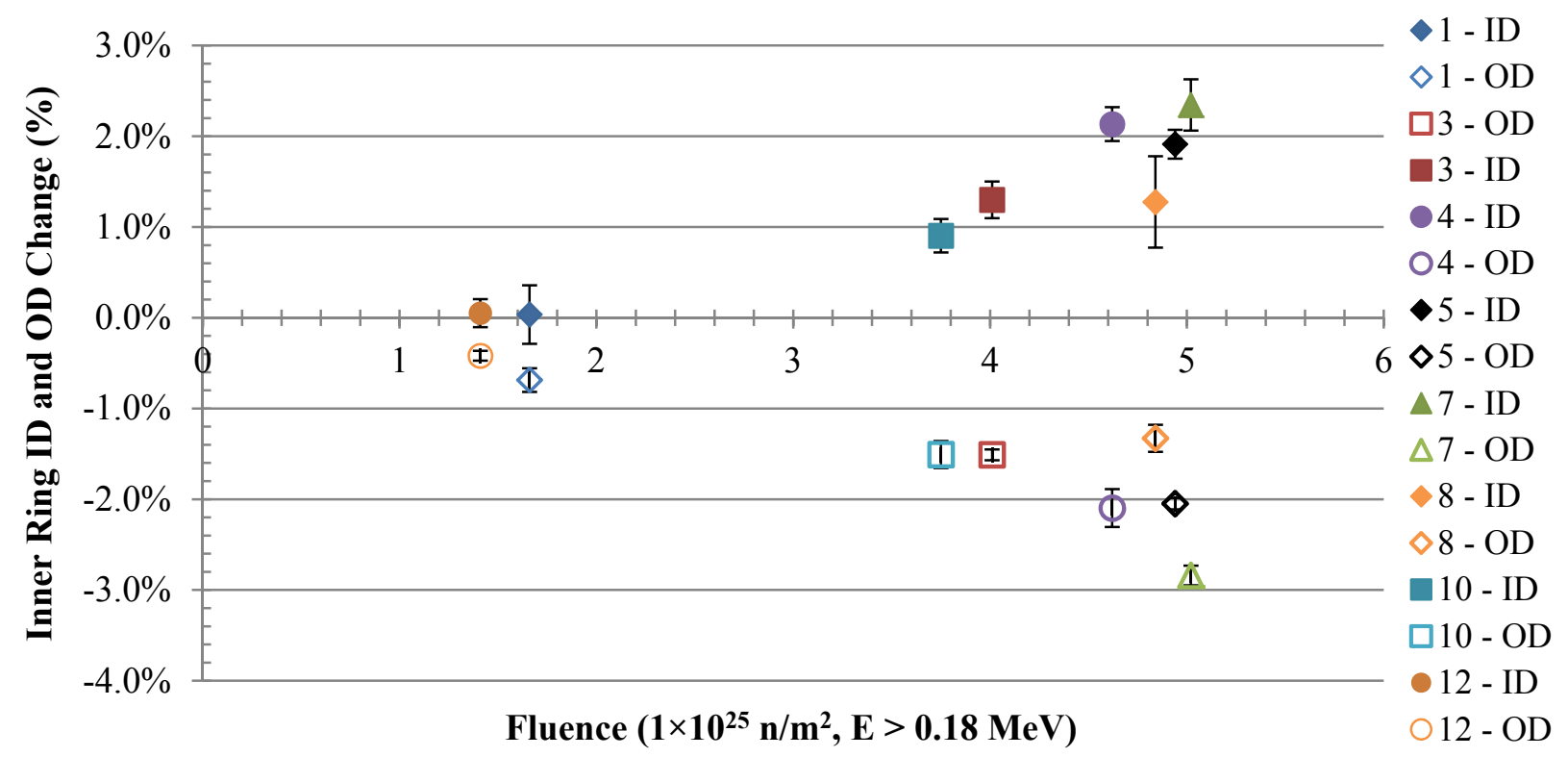

Figure 52. Percent change in the inner (ID) and outer (OD) diameters of the inner rings. 


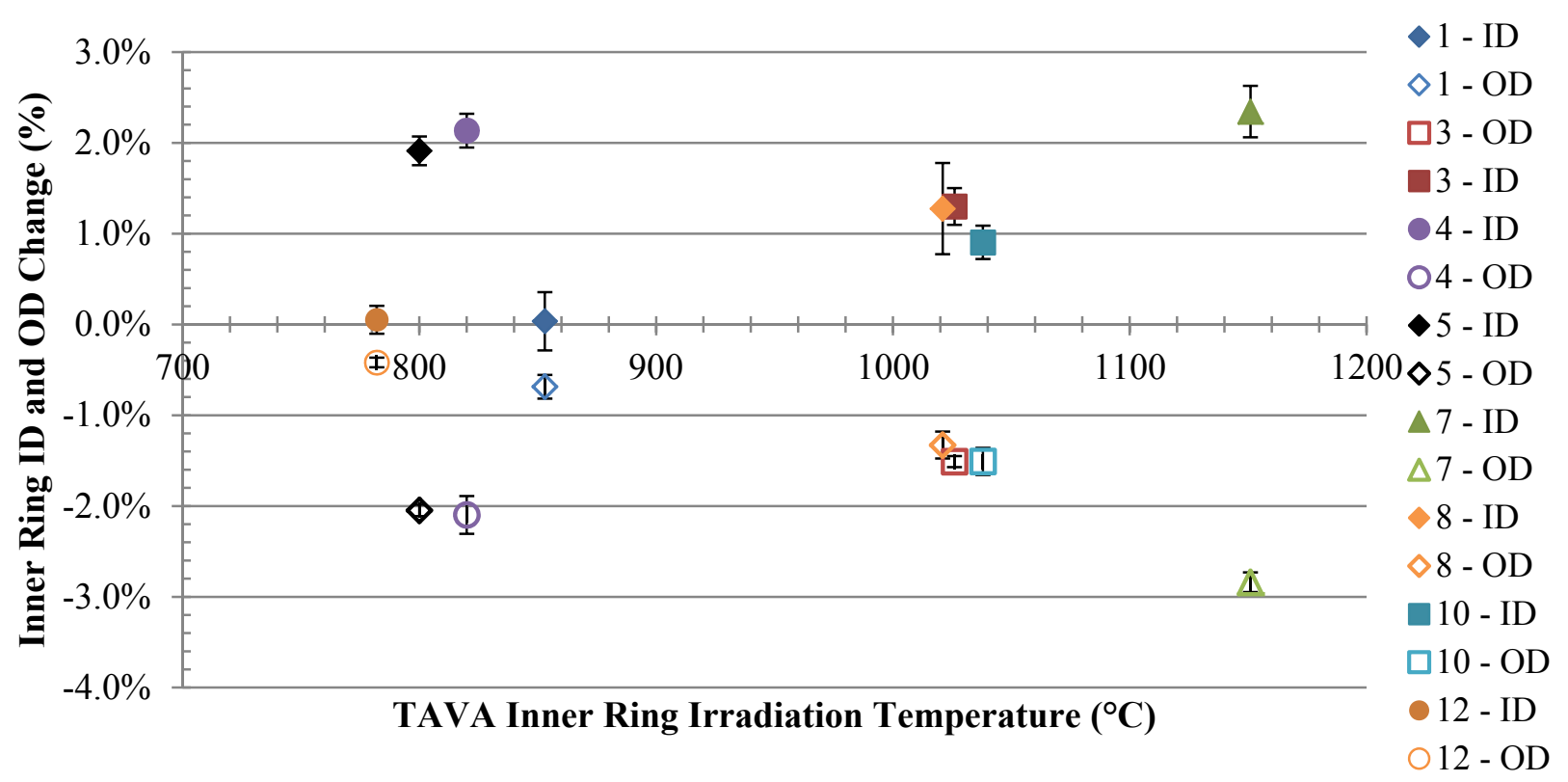

Figure 53. Percent change in inner ring dimensions as a function of inner ring irradiation temperature.

Temperatures from ECAR-2807 Rev. 1 (Hawkes 2016).

Table 5. Summary of inner ring inner diameter (ID) and outer diameter (OD) dimensions before and after irradiation.

\begin{tabular}{|c|c|c|c|c|c|c|c|c|c|c|}
\hline \multirow[b]{2}{*}{ Capsule } & \multicolumn{4}{|c|}{ As-Fabricated Dimensions } & \multicolumn{3}{|c|}{ PIE Inner Ring ID } & \multicolumn{3}{|c|}{ PIE Inner Ring OD } \\
\hline & $\begin{array}{c}\text { ID } \\
(\mathrm{mm})\end{array}$ & $\begin{array}{c}\text { ID } \\
\pm \sigma \\
(\mathrm{mm})\end{array}$ & $\begin{array}{c}\text { OD } \\
(\mathrm{mm})\end{array}$ & $\begin{array}{c}\text { OD } \\
\pm \sigma \\
(\mathrm{mm}) \\
\end{array}$ & $\begin{array}{c}\text { ID } \\
(\mathrm{mm})\end{array}$ & $\begin{array}{c} \pm \sigma \\
(\mathrm{mm})\end{array}$ & $\begin{array}{c}\% \\
\text { Change }\end{array}$ & $\begin{array}{c}\text { OD } \\
(\mathrm{mm})\end{array}$ & $\begin{array}{c} \pm \sigma \\
(\mathrm{mm})\end{array}$ & $\begin{array}{c}\% \\
\text { Change }\end{array}$ \\
\hline 1 & 12.4435 & 0.0010 & 23.7744 & $\mathrm{~N} / \mathrm{A}^{\mathrm{a}}$ & 12.5540 & 0.034 & 0.03 & 23.6113 & 0.031 & -0.69 \\
\hline 2 & 12.4587 & 0.0007 & 24.3332 & $\mathrm{~N} / \mathrm{A}^{\mathrm{a}}$ & $-\mathrm{b}$ & $-\mathrm{b}$ & $-\mathrm{b}$ & $-\mathrm{b}$ & $-\mathrm{b}$ & $-\mathrm{b}$ \\
\hline 3 & 12.4587 & 0.0007 & 24.3967 & $\mathrm{~N} / \mathrm{A}^{\mathrm{a}}$ & 12.6206 & 0.019 & 1.30 & 24.0281 & 0.015 & -1.51 \\
\hline 4 & 12.4346 & 0.0006 & 24.3840 & 0.0007 & 12.7127 & 0.001 & 2.13 & 23.8725 & 0.051 & -2.10 \\
\hline 5 & 12.4524 & 0.0004 & 24.3904 & 0.0004 & 12.6746 & 0.001 & 1.91 & 23.8906 & 0.015 & -2.05 \\
\hline 6 & 12.4587 & 0.0007 & 24.3396 & 0.0004 & $-{ }^{b}$ & $-\mathrm{b}$ & $-\mathrm{b}$ & $-\mathrm{b}$ & $-\mathrm{b}$ & $-^{b}$ \\
\hline 7 & 12.4587 & 0.0007 & 24.3586 & 0.0014 & 12.7508 & 0.033 & 2.34 & 23.6669 & 0.026 & -2.84 \\
\hline 8 & 12.4460 & 0.0014 & 24.3967 & $\mathrm{~N} / \mathrm{A}^{\mathrm{a}}$ & 12.6048 & 0.055 & 1.28 & 24.0725 & 0.036 & -1.33 \\
\hline 9 & 12.4587 & 0.0007 & 24.3332 & $\mathrm{~N} / \mathrm{A}^{\mathrm{a}}$ & $-^{\mathrm{b}}$ & $-^{\mathrm{b}}$ & $-^{\mathrm{b}}$ & $-^{\mathrm{b}}$ & $-^{\mathrm{b}}$ & $-^{\mathrm{b}}$ \\
\hline 10 & 12.4714 & $\mathrm{~N} / \mathrm{A}^{\mathrm{a}}$ & 24.4094 & $\mathrm{~N} / \mathrm{A}^{\mathrm{a}}$ & 12.5841 & 0.025 & 0.90 & 24.0413 & 0.036 & -1.51 \\
\hline 11 & 12.4460 & $\mathrm{~N} / \mathrm{A}^{\mathrm{a}}$ & 22.5044 & $\mathrm{~N} / \mathrm{A}^{\mathrm{a}}$ & ${ }^{\mathrm{b}}$ & ${ }^{\mathrm{b}}$ & $\square^{b}$ & ${ }^{\mathrm{b}}$ & $\square^{b}$ & ${ }^{\mathrm{b}}$ \\
\hline 12 & 12.4587 & 0.0007 & 24.3332 & $\mathrm{~N} / \mathrm{A}^{\mathrm{a}}$ & 12.4651 & 0.007 & 0.05 & 24.2313 & 0.013 & -0.42 \\
\hline
\end{tabular}

a. $\mathrm{N} / \mathrm{A}=$ not available.

b. $\quad-\quad=$ data that could be obtained in the future but are not currently available (i.e., PIE dimensions on inner rings of intact fuel bodies from Capsules 2, 6, 9, and 11).

Given that the compact diameters decreased and the inner ring inner diameters increased, the gaps between the Capsule 4 and 5 compacts and the Capsule 4 and 5 inner rings should have increased. This should have prevented the compacts from becoming stuck within these inner rings. However, since the compacts were indeed stuck, an explanation is needed. The most reasonable explanation is that the 
compacts had become slanted within the inner ring, as illustrated in Figure 54. The increased compactring gap could have enabled the compacts to become slanted at a greater angle than with a smaller gap. Pressing the compacts with the ram on the pushout table could have further wedged the compacts in place, requiring greater force from the arbor press. Capsule 4 and 5 compacts increased in length by up to $0.5 \%$, and this lengthening during irradiation could also have contributed to the problem if the slanted compacts increased in length while slanted against the inner ring inner surface.

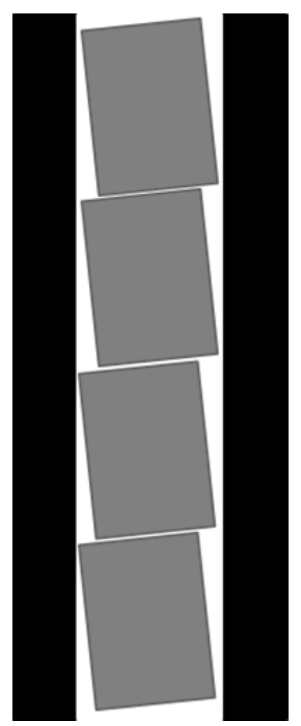

Figure 54. Possible orientation of compacts within Capsules 4 and 5 inner rings.

\subsubsection{Outer Ring Dimensional Changes}

Figure 55 shows the percent change in the IDs and ODs of the outer rings as a function of neutron fluence, Figure 56 shows the ID and OD changes as a function of irradiation temperature, and Table 6 summarizes the available pre-irradiation measurement data and PIE metrology measurements for the outer rings. The error bars in Figure 55 and Figure 56 represent one standard deviation in the percent change calculated by propagating the standard deviations calculated from pre-irradiation and postirradiation measurements. Uncertainties associated with metrology equipment (Table 2) were not accounted for in the error bars because this source of uncertainty is much smaller than the variability from measurement to measurement. The IDs and ODs of each ring were measured four times at four axial locations along the ring in post-irradiation measurements (see Table 3 and Figure 41). These measurements were then averaged in order to report a single value for the ring IDs and ODs. The preirradiation measurements were less rigorous. In some cases (denoted by "N/A" in Table 6), only one preirradiation measurement was made, in which case, no standard deviations for the pre-irradiated dimensions were available. For dimensions where no pre-irradiation measurement standard deviations are available, the error bars represent the standard deviation from multiple post-irradiation measurements only. In this case, the error bars underestimate the standard deviation. In other cases, two pre-irradiation measurements of a particular dimension were made, and a standard deviation was calculated. In other instances, a range of values was reported for a specific pre-irradiation measurement. Because the number of measurements comprising this range was not known, it was assumed that the range represented two measurements, one at the top of the range and one at the bottom of the range, and a standard deviation calculated accordingly. 


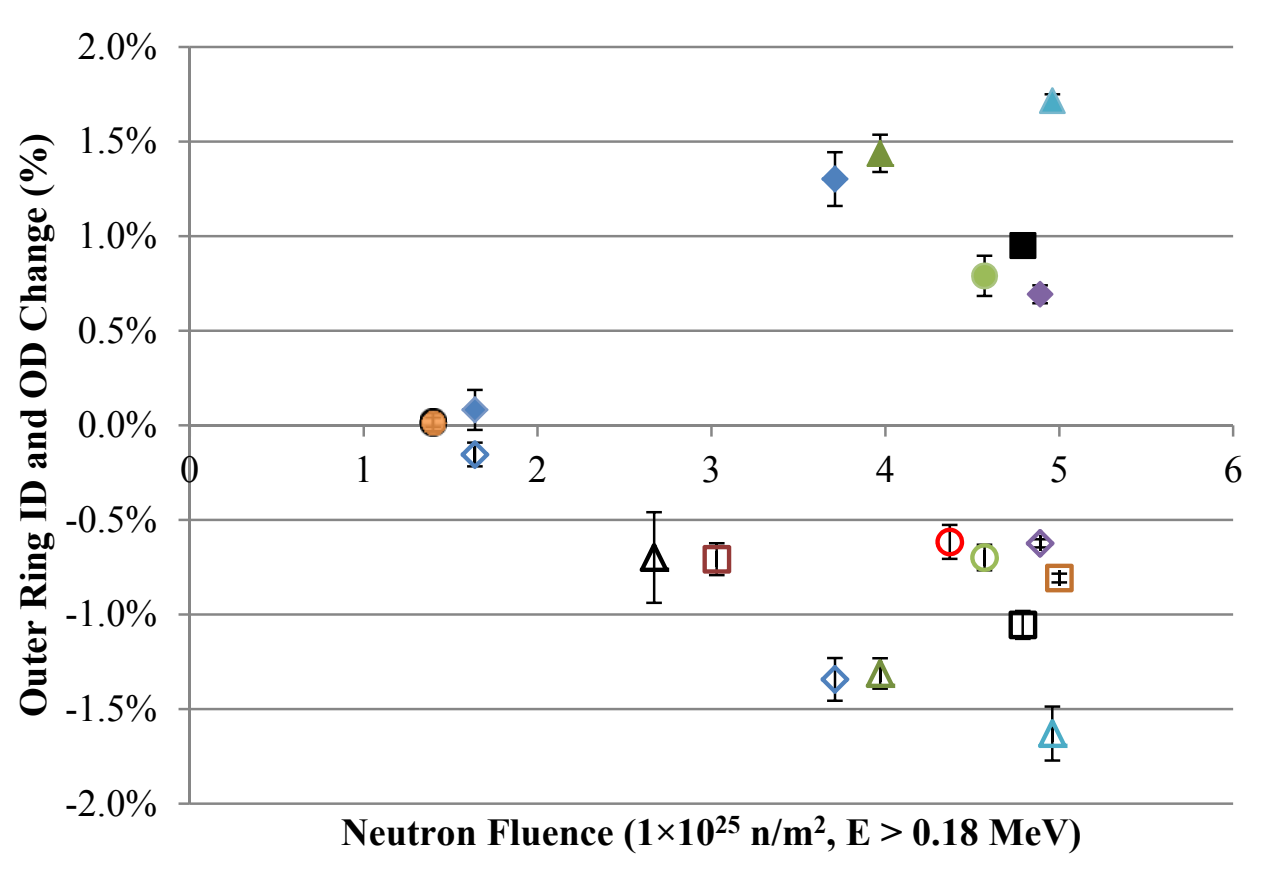

$\diamond 1-$ OD

$\checkmark 1$ - ID

$\square 2$ - OD

$\triangle 3$ - OD

$\triangle 3$ - ID

$\bigcirc 4$ - OD

- 4 - ID

$\diamond 5$ - OD

$\checkmark 5$ - ID

$\square 6$ - OD

$\triangle 7$ - OD

$\triangle 7$ - ID

8- OD

- 8 - ID

O9- OD

$\diamond 10$ - OD

$\checkmark 10$ - ID

$\Delta 11$ - OD

O 12 - OD

- 12 - ID

Figure 55. Percent change for the inner (ID) and outer (OD) diameters of the outer rings.

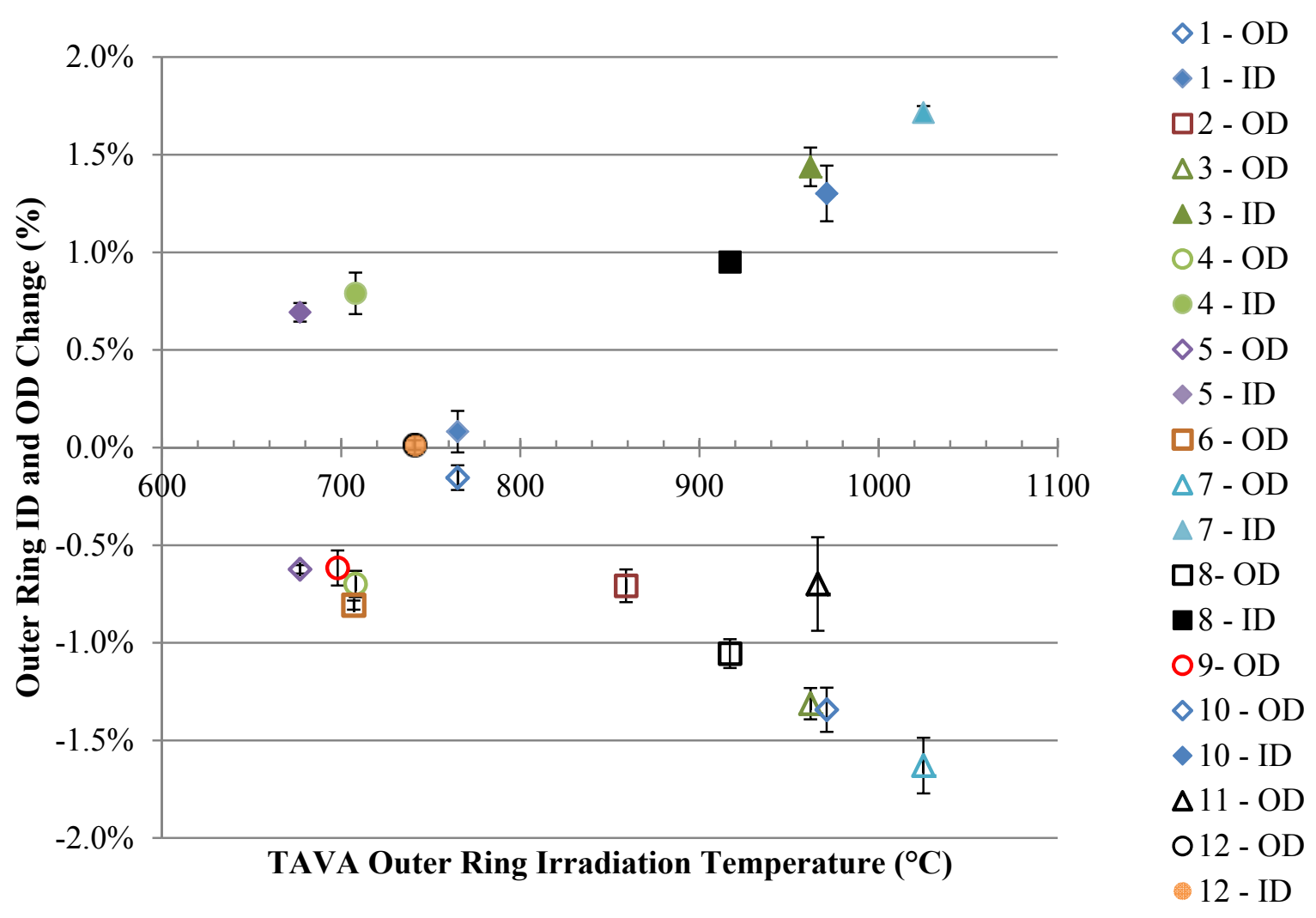

Figure 56. Outer ring dimensional changes as a function of TAVA irradiation temperature. Temperatures from ECAR-2807 Rev. 1 (Hawkes 2016). 
Table 6. Summary of outer ring inner diameter (ID) and outer diameter (OD) dimensions before and after irradiation.

\begin{tabular}{|c|c|c|c|c|c|c|c|c|c|c|}
\hline \multirow[b]{2}{*}{ Capsule } & \multicolumn{4}{|c|}{ As-Fabricated Dimensions } & \multicolumn{3}{|c|}{ PIE ID } & \multicolumn{3}{|c|}{ PIE OD } \\
\hline & $\begin{array}{c}\text { ID } \\
(\mathrm{mm})\end{array}$ & $\begin{array}{c}\text { ID } \\
\pm \sigma(\mathrm{mm})\end{array}$ & $\begin{array}{c}\text { OD } \\
(\mathrm{mm})\end{array}$ & $\begin{array}{c}\text { OD } \\
\pm \sigma(\mathrm{mm})\end{array}$ & $\begin{array}{c}\text { ID } \\
(\mathrm{mm})\end{array}$ & $\begin{array}{c} \pm \sigma \\
(\mathrm{mm})\end{array}$ & $\begin{array}{c}\% \\
\text { change }\end{array}$ & $\begin{array}{l}\text { OD } \\
\mathrm{mm}\end{array}$ & $\begin{array}{c} \pm \sigma \\
(\mathrm{mm})\end{array}$ & $\begin{array}{c}\% \\
\text { change }\end{array}$ \\
\hline 1 & 24.5085 & 0.025 & 33.5267 & 0.034 & 24.5285 & 0.007 & 0.08 & 33.5025 & 0.021 & -0.07 \\
\hline 2 & 24.5110 & N/A & 36.9799 & $\mathrm{~N} / \mathrm{A}^{\mathrm{a}}$ & ${ }^{\mathrm{b}}$ & $-^{\mathrm{b}}$ & ${ }^{\mathrm{b}}$ & 36.7181 & 0.031 & -0.71 \\
\hline 3 & 24.5110 & N/A & 33.5153 & 0.018 & 24.8634 & 0.024 & 1.44 & 33.0756 & 0.027 & -1.31 \\
\hline 4 & 24.5110 & N/A & 39.5186 & 0.005 & 24.7047 & 0.026 & 0.79 & 39.2425 & 0.027 & -0.70 \\
\hline 5 & 24.5110 & N/A & 39.6367 & 0.018 & 24.6809 & 0.012 & 0.69 & 39.3894 & 0.009 & -0.62 \\
\hline 6 & 24.5047 & 0.009 & 39.6494 & 0.000 & ${ }^{\mathrm{b}}$ & ${ }^{\mathrm{b}}$ & ${ }^{\mathrm{b}}$ & 39.3294 & 0.009 & -0.81 \\
\hline 7 & 24.5110 & N/A & 37.9730 & $\mathrm{~N} / \mathrm{A}^{\mathrm{a}}$ & 24.9317 & 0.008 & 1.72 & 37.3544 & 0.054 & -1.63 \\
\hline 8 & 24.5364 & N/A & 38.9636 & 0.036 & 24.7698 & 0.009 & 0.95 & 38.5525 & 0.029 & -1.06 \\
\hline 9 & 24.5110 & N/A & 39.5161 & 0.009 & $-^{b}$ & $-^{\mathrm{b}}$ & ${ }^{\mathrm{b}}$ & 39.2725 & 0.035 & -0.62 \\
\hline 10 & 24.5110 & N/A & 37.9857 & $\mathrm{~N} / \mathrm{A}^{\mathrm{a}}$ & 24.8301 & 0.035 & 1.30 & 37.4756 & 0.043 & -1.34 \\
\hline 11 & 24.4983 & N/A & 33.5280 & $\mathrm{~N} / \mathrm{A}^{\mathrm{a}}$ & ${ }^{\mathrm{b}}$ & ${ }^{\mathrm{b}}$ & ${ }^{\mathrm{b}}$ & 33.2938 & 0.080 & -0.70 \\
\hline 12 & 24.5110 & N/A & 34.9758 & $\mathrm{~N} / \mathrm{A}^{\mathrm{a}}$ & 24.5142 & 0.011 & 0.01 & 34.9806 & 0.009 & 0.01 \\
\hline
\end{tabular}

a. $\quad \mathrm{N} / \mathrm{A}=$ data that are not available.

b. $\quad-=$ data that could be obtained in the future but are not currently available (e.g., PIE dimensions on IDs of outer rings of intact fuel bodies, i.e. rings from Capsules 2, 6, 9, and 11).

Once again, IDs increased with fluence while the ODs decreased with increasing fluence. The extent (absolute value) of the dimensional change increases with fluence, although this dependence appears weaker here than it was for the inner rings. Capsules 2, 6, 9, and 11 were fuel bodies that were not disassembled; therefore, no ID measurements were made for the outer rings from these capsules. Figure 55 appears to show a turn-around in the dimensional change (especially if the points from Capsule 7 are ignored) at a fast fluence of about $4.0 \times 10^{25} \mathrm{n} / \mathrm{m}^{2}$. This apparent turn-around occurs at the same fluence here as it did in the compact length changes discussed in Subsection 5.2.1 and observed in Figure 51.

Figure 56 shows the ID and OD changes as function of the TAVA irradiation temperatures of the outer rings. Some temperature dependence is apparent, especially at temperatures greater than or equal to $750^{\circ} \mathrm{C}$. The irradiation temperature is likely responsible for the difference in the dimensional changes between Capsules 5 and 7 . The inner rings of these capsules have similar fluences, but very different irradiation temperatures, and significantly different degrees of ID swelling and OD shrinkage. The fluence is still a significant driver behind the dimensional changes, however. This is evident by considering Capsules 4, 5, and 8. The ID and OD changes are very similar for the outer rings in these capsules despite their very different TAVA temperatures. The similar dimensional changes are due to the fluences which are between $4.6 \times 10^{25} \mathrm{n} / \mathrm{m}^{2}$ and $4.9 \times 10^{25} \mathrm{n} / \mathrm{m}^{2}$ for the outer rings from these three capsules.

\subsubsection{Sink Ring Dimensional Changes}

Figure 57 shows the percent changes in the IDs and ODs of the sink rings for all capsules (except for Capsule 11) as a function of fast neutron fluence, Figure 58 shows dimensional changes as a function of sink ring irradiation temperature, and Table 7 summarizes the available pre-irradiation measurement data and PIE metrology measurements for the sink rings. The error bars in Figure 57 and Figure 58 represent one standard deviation in the percent change calculated by propagating the standard deviations calculated from pre-irradiation and post-irradiation measurements. Once again, uncertainties associated with 
metrology equipment (Table 2) were not accounted for in the error bars because this source of uncertainty is much smaller than the variability from measurement to measurement. The Capsule 11 sink ring cracked during disassembly and was not measured. The IDs and ODs of each ring were measured four times at four axial locations along the ring in post-irradiation measurements (see Table 3 and Figure 41). These measurements were then averaged in order to report a single value for the ring IDs and ODs. The preirradiation measurements were less rigorous. In some cases (denoted by "N/A" in Table 7), only one preirradiation measurement was made, in which case, no standard deviations for the pre-irradiated dimensions were available. For dimensions where no pre-irradiation measurement standard deviations are available, the error bars in Figure 57 and Figure 58 represent the standard deviation only from multiple post-irradiation measurements. In this case, the error bars underestimate the standard deviation. In other cases, two pre-irradiation measurements of a particular dimension were made, and a standard deviation was calculated. In other instances, a range of values was reported for a specific pre-irradiation measurement. Because the number of measurements comprising this range was not known, it was assumed that the range represented two measurements, one at the top of the range and one at the bottom of the range, and a standard deviation was calculated from these two measurements.

Table 7. Summary of sink ring inner diameter (ID) and outer diameter (OD) dimensions before and after irradiation.

\begin{tabular}{|c|c|c|c|c|c|c|c|c|c|c|}
\hline & \multicolumn{4}{|c|}{ As-Fabricated Dimensions } & \multicolumn{3}{c|}{ PIE ID } & \multicolumn{3}{c|}{ PIE OD } \\
\cline { 2 - 12 } Capsule & $\begin{array}{c}\text { ID } \\
(\mathrm{mm})\end{array}$ & $\begin{array}{c}\text { ID } \\
\pm(\mathrm{mm})\end{array}$ & $\begin{array}{c}\text { OD } \\
(\mathrm{mm})\end{array}$ & $\begin{array}{c}\text { OD } \\
\pm(\mathrm{mm})\end{array}$ & $\begin{array}{c}\text { ID } \\
(\mathrm{mm})\end{array}$ & $\begin{array}{c} \pm \sigma \\
(\mathrm{mm})\end{array}$ & $\begin{array}{c}\% \\
\text { change }\end{array}$ & $\begin{array}{c}\text { OD } \\
\mathrm{mm}\end{array}$ & $\begin{array}{c} \pm \sigma \\
(\mathrm{mm})\end{array}$ & $\begin{array}{c}\% \\
\mathrm{change}\end{array}$ \\
\hline 1 & 41.1455 & 0.025 & 61.6839 & 0.014 & 41.2083 & 0.020 & 0.15 & 61.5888 & 0.019 & -0.15 \\
\hline 2 & 40.0304 & N/A & 62.1919 & 0.018 & 39.3256 & 0.007 & -1.76 & 62.0456 & 0.024 & -0.24 \\
\hline 3 & 41.1391 & 0.027 & 63.9763 & 0.009 & 41.4211 & 0.007 & 0.69 & 63.5644 & 0.038 & -0.64 \\
\hline 4 & 40.0304 & N/A & 63.7159 & 0.018 & 39.4801 & 0.007 & -1.37 & 63.3213 & 0.016 & -0.62 \\
\hline 5 & 40.0431 & N/A & 64.1223 & 0.018 & 39.5415 & 0.020 & -1.25 & 63.6113 & 0.030 & -0.80 \\
\hline 6 & 40.0304 & N/A & 63.7159 & 0.018 & 39.4811 & 0.006 & -1.37 & 63.2950 & 0.012 & -0.66 \\
\hline 7 & 40.0304 & N/A & 64.1477 & 0.018 & 39.5319 & 0.011 & -1.25 & 63.6288 & 0.024 & -0.81 \\
\hline 8 & 40.0558 & N/A & 64.2112 & N/A & 39.5700 & 0.015 & -1.21 & 63.6406 & 0.020 & -0.89 \\
\hline 9 & 40.0558 & N/A & 63.4619 & N/A & 39.4589 & 0.010 & -1.49 & 63.0838 & 0.031 & -0.60 \\
\hline 10 & 40.0304 & N/A & 63.7286 & N/A & 39.3954 & 0.017 & -1.59 & 63.4300 & 0.020 & -0.47 \\
\hline 11 & 41.1607 & N/A & 60.4139 & 0.018 & N/A & N/A & N/A & N/A & N/A & N/A \\
\hline 12 & 40.0304 & N/A & 61.6903 & 0.009 & 39.3383 & 0.012 & -1.73 & 61.5963 & 0.030 & -0.15 \\
\hline
\end{tabular}

a. $\mathrm{N} / \mathrm{A}=$ data that are not available. PIE measurements of the sink ring from Capsule 11 were not made due to cracks in the ring. 


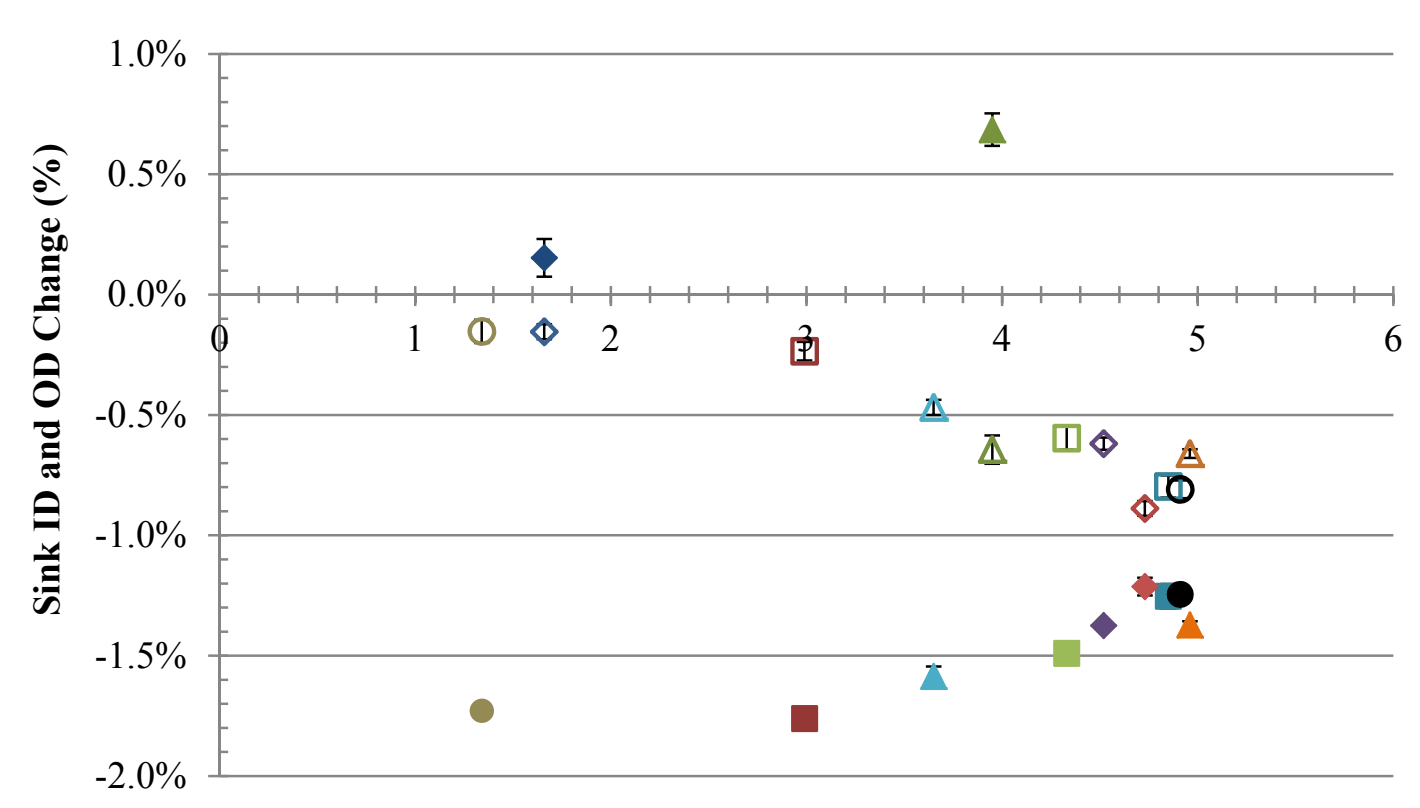

$\diamond 1$ - OD

$\square 2$ - OD

$\triangle 3$ - OD

$\checkmark 4$ - OD

$\square 5$ - OD

$\triangle 6$ - OD

O 7 - OD

$\diamond 8$ - OD

$\square 9$ - OD

$\triangle 10$ - OD

O 12 - OD

$\checkmark 1$ - ID

2 - ID

$\triangle 3$ - ID

44 - ID

5 - ID

$\triangle 6$ - ID

- 7 - ID

8 - ID

9 - ID

Fluence $\left(1 \times 10^{25} \mathrm{n} / \mathrm{m}^{2}, \mathrm{E}>0.18 \mathrm{MeV}\right)$

$\triangle 10$ - ID

- 12 - ID

Figure 57. Percent change in the inner (ID) and outer (OD) diameters of the sink rings.

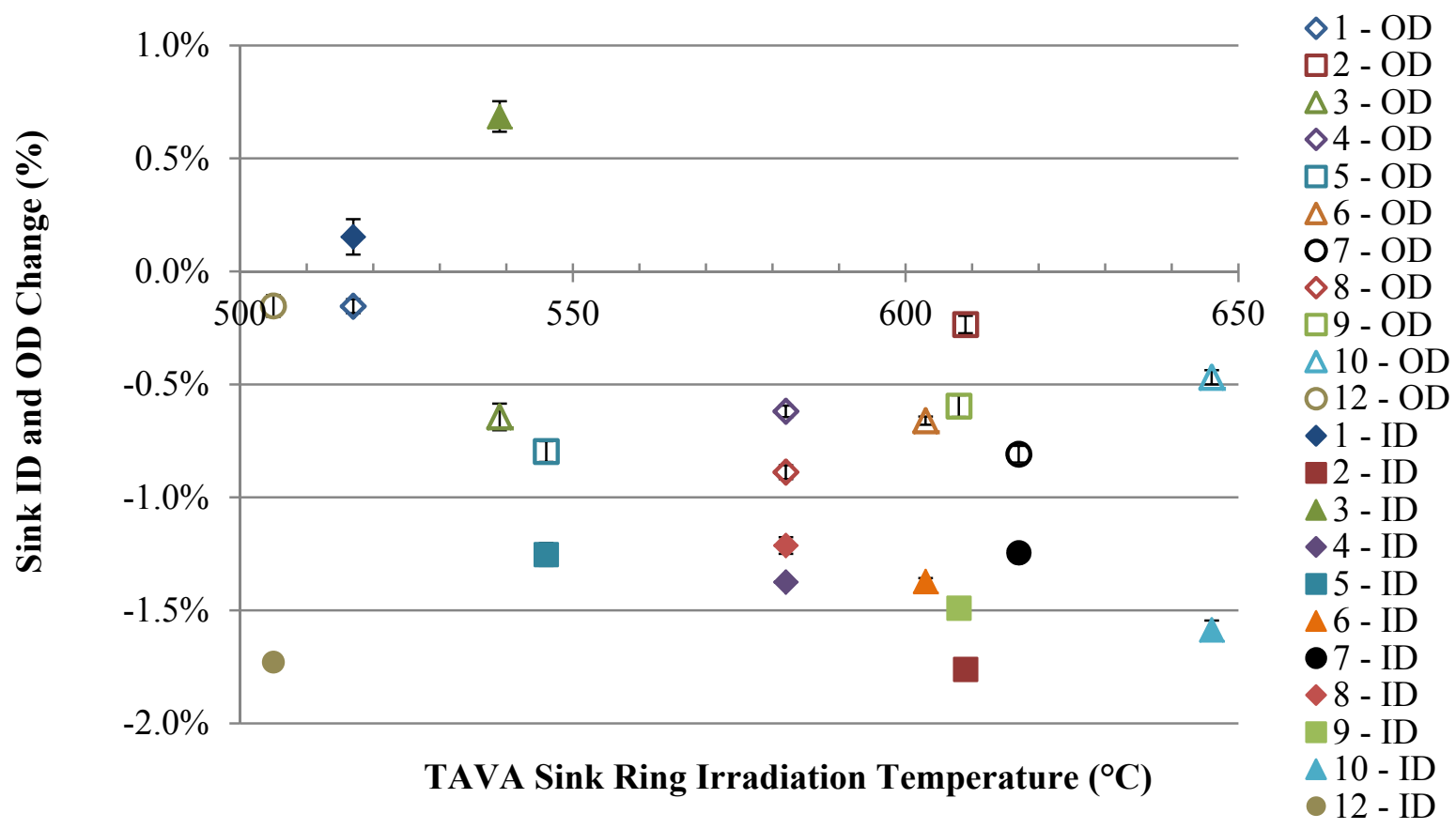

Figure 58. Percent change in sink ring diameters as a function of TAVA irradiation temperature. Temperatures from ECAR-2807 Rev. 1 (Hawkes 2016). 
Except for the IDs of Capsules 1 and 3, all diameters decreased. The IDs of the sink rings of Capsules 1 and 3 were re-measured, and the increase in their IDs was confirmed. Figure 57 shows that the extent of OD shrinkage increases with fluence, but the extent of ID shrinkage decreases with fluence. This indicates rapid shrinkage in the IDs at low fluences. This was not expected and is different from the behavior observed in the inner and outer rings which changed gradually with fluence and whose IDs increased and ODs decreased. At approximately $4.2 \times 10^{25} \mathrm{n} / \mathrm{m}^{2}$, there appears to be an inflection point where the degree of OD shrinkage begins to decrease and the extent of ID shrinkage begins to increase The cause of this behavior is not known, but it may be related to a turn-around in the direction of the dimensional change above a fluence threshold as discussed in Subsections 5.2.1 and 5.2.3. A trend is not readily discernable in Figure 58.

The original thermal model used to calculate temperatures in the experiment assumed that the IDs and ODs of the inner, outer, and sink rings would decrease with fluence. This is not what was observed for the inner and outer rings. While the ID and OD of the sink ring decreased in most cases, the rapid shrinkage of the ID was not expected. The information obtained from metrology was used to update the thermal calculations in ECAR-2807 Rev. 0 (Hawkes 2015) to ECAR-2807 Rev. 1 (Hawkes 2016).

\section{SUMMARY AND CONCLUSIONS}

Visual examinations of the irradiated AGR-3/4 test train exterior did not indicate dimensional distortion, and only two small discolored areas were observed on the outside of the bottom of Capsules 8 and 9. However, no corresponding discoloration was found on the inside of these capsules. Prior to disassembly, the two test train sections were subjected to analysis via the PGS, which did not indicate that any gross fuel relocation had occurred.

A series of specialized tools had been designed and fabricated to carry out test train disassembly and recovery of capsule components. This equipment performed well for separating each capsule in the test train and extracting the capsule components. Only a few problems were encountered. In one case, the outermost ring (the sink ring) was cracked during removal of the capsule through tubes. In Capsules 4 and 5, the compacts could not be removed from the inner rings using the standard procedure. An arbor press was utilized to press the compacts out of the inner rings without damaging the rings.

Dimensional measurements were made on the compacts, inner rings, outer rings, and sink rings. The diameter of all compacts decreased by 0.5 to $2.0 \%$. Generally, the extent of compact diametric shrinkage increased with increasing neutron fluence. A turn-around in the direction of the compact diametric change was apparent at a fluence of $4.2 \times 10^{25} \mathrm{n} / \mathrm{m}^{2}$. Most compact lengths also decreased. Compact lengths decreased with increasing fluence, reaching maximum shrinkage of about $0.9 \%$ at a fast fluence of $4.0 \times 10^{25} \mathrm{n} / \mathrm{m}^{2}(\mathrm{E}>0.18 \mathrm{MeV})$. Above this fluence, the extent of length shrinkage appeared to turn around and decrease with fluence, and some compacts from Capsules 4, 5, and 7 had increased in length after a fluence of $5.0 \times 10^{25} \mathrm{n} / \mathrm{m}^{2}$.

The inner rings exhibited a decrease in the ODs and an increase in the IDs with increasing fluence. This indicates that the ring wall thickness decreased with fluence. A near-zero change was observed for the lowest-fluence capsules (Capsules 1 and 12 at a fluence of approximately $1.5 \times 10^{25} \mathrm{n} / \mathrm{m}^{2}$ ). For

Capsule 7, the highest fast fluence capsule $\left(5 \times 10^{25} \mathrm{n} / \mathrm{m}^{2}\right)$, the ID was found to have increased by $2.3 \%$, and the OD was found to have decreased by $2.8 \%$. A subtle turn-around in the direction of the dimensional change may exist at a fluence of $4.8 \times 10^{25} \mathrm{n} / \mathrm{m}^{2}$.

The outer rings exhibited the same trend in diametric change as the inner rings in that the IDs increased and the ODs decreased; however, a turn-around in the dimensional change appears to occur at a fast fluence of approximately $4.0 \times 10^{25} \mathrm{n} / \mathrm{m}^{2}$. This is about the same fluence at which an apparent turnaround occurred in the compact lengths. The extent of ID increase and OD decrease increased with increasing fluence up to $4.0 \times 10^{25} \mathrm{n} / \mathrm{m}^{2}$. Above this fluence, the extent of diametric change decreased with increasing fluence. 
Generally, the sink rings exhibited shrinkage of both the IDs and ODs with the inner diameters shrinking more than the outer diameters. The extent of OD shrinkage increased with fluence. Two exceptions were noted. In Capsules 1 and 3, the IDs increased while the ODs decreased. Oddly, the extent of ID shrinkage decreased with increasing fluence. This indicates atypically rapid ID shrinkage at low fluences.

The thermal model used to calculate temperatures in the experiment assumed that the IDs and ODs of the inner, outer, and sink rings would all decrease with fluence. This is not what was observed for the inner and outer rings. While the IDs and ODs of the sink rings decreased in most cases, the rapid shrinkage of the IDs was not expected. The information obtained from metrology was used to produce Rev. 1 of the thermal calculations in ECAR-2807 (Hawkes 2016).

The overarching goal of the AGR-3/4 experiment is to study fission product transport within graphitic matrix material and nuclear-grade graphite. Through ongoing and future PIE activities (including physical sampling and gamma scanning of the rings) fission product concentration profiles within the rings can be determined. These data can be used to elucidate fission product transport parameters (e.g., diffusion coefficients within the test materials) which will be used to inform and refine models of fission product transport.

\section{REFERENCES}

Burchell, T.D., 2012, “4.10 - Radiation Effects in Graphite,” in Comprehensive Nuclear Materials, Vol. 4, Ed. R.J.M. Konings, Elsevier, Waltham, MA, USA.

Collin, B.P., 2015a, AGR-3/4 Irradiation Test Final As-Run Report, INL/EXT-15-35550, Idaho National Laboratory, Rev. 0.

Collin, B.P., 2015b, PLN-3867, “AGR-3/4 Irradiation Experiment Test Plan,” Idaho National Laboratory Rev. 1.

Hawkes, G.L., 2015, ECAR-2807, “AGR-3/4 Daily As-Run Thermal Analyses,” Idaho National Laboratory, Rev. 0.

Hawkes, G.L., 2016, ECAR-2807, “AGR-3/4 Daily As-Run Thermal Analyses,” Idaho National Laboratory, Rev. 1.

Hunn, J., M.P. Trammell, and F.C. Montgomery, 2011, Data Compilation for AGR-3/4 Designed-to-Fail (DTF) Fuel Compact Lot (LEU03-10TOP2/LEU03-07DTF-OP1)-Z, ORNL/TM-2011/124, Oak Ridge National Laboratory.

INL, 2010a, DWG-768117, “MFC 785 AGR Compact Metrology Equipment Metrology Equipment Assembly," Idaho National Laboratory.

INL, 2010b, DWG-768118, “MFC 785 AGR Compact Metrology Equipment V Block Modified,” Idaho National Laboratory.

INL, 2010c, DWG-768119, “MFC 785 AGR Compact Metrology Equipment Support Block,” Idaho National Laboratory.

INL, 2010d, DWG-768120, “MFC 785 AGR Compact Metrology Equipment Stop Block,” Idaho National Laboratory.

INL, 2010e, MFC-EQP-0068, “AGR Compact/Graphite Holder Metrology Equipment Phase I, II Qual Plan,” Idaho National Laboratory, Rev. 0.

INL, 2011a, DWG-602701, “ATR Advanced Gas Reactor (AGR-3/4) Capsule 1 Assembly and Details," Idaho National Laboratory. 
INL, 2011b, DWG-602702, “ATR Advanced Gas Reactor (AGR-3/4) Capsule 2 Assembly and Details,” Idaho National Laboratory.

INL, 2011c, DWG-602703, “ATR Advanced Gas Reactor (AGR-3/4) Capsule 3 Assembly and Details," Idaho National Laboratory.

INL, 2011d, DWG-602704, “ATR Advanced Gas Reactor (AGR-3/4) Capsule 4 Assembly and Details,” Idaho National Laboratory.

INL, 2011e, DWG-602705, "ATR Advanced Gas Reactor (AGR-3/4) Capsule 5 Assembly and Details," Idaho National Laboratory.

INL, 2011f, DWG-602706, “ATR Advanced Gas Reactor (AGR-3/4) Capsule 6 Assembly and Details," Idaho National Laboratory.

INL, 2011g, DWG-602707, “ATR Advanced Gas Reactor (AGR-3/4) Capsule 7 Assembly and Details,” Idaho National Laboratory.

INL, 2011h, DWG-602708, “ATR Advanced Gas Reactor (AGR-3/4) Capsule 8 Assembly and Details,” Idaho National Laboratory.

INL, 2011i, DWG-602709, “ATR Advanced Gas Reactor (AGR-3/4) Capsule 9 Assembly and Details," Idaho National Laboratory.

INL, 2011j, DWG-602710, “ATR Advanced Gas Reactor (AGR-3/4) Capsule 10 Assembly and Details," Idaho National Laboratory.

INL, 2011k, DWG-602711, “ATR Advanced Gas Reactor (AGR-3/4) Capsule 11 Assembly and Details," Idaho National Laboratory.

INL, 20111, DWG-602712, “ATR Advanced Gas Reactor (AGR-3/4) Capsule 12 Assembly and Details," Idaho National Laboratory.

INL, 2011m, DWG-602716, “ATR Advanced Gas Reactor (AGR-3/4) Matrix Sleeve Detail,” Idaho National Laboratory.

INL, 2012, TEV-1665, “AGR-3/4 Metrology Equipment for HFEF PIE,” Idaho National Laboratory, Rev. 0.

INL, 2013a, DWG-774612, "MFC-785 ARG 3-4 Metrology Graphite Sleeve Measuring Assembly," Idaho National Laboratory.

INL, 2013b, DWG-774616, “MFC-785 ARG 3-4 Metrology Graphite Sink Measure Assembly,” Idaho National Laboratory.

INL, 2013c, DWG-774620, “MFC-785 ARG 3-4 Metrology Matrix Sleeve Measuring Assembly,” Idaho National Laboratory.

INL, 2014a, LWP-13410, “Planning, Performing, and Documenting Inspection for Acceptance," Idaho National Laboratory, Rev. 4.

INL, 2014b, MFC-EQP-0163, "Remote Equipment Qualification Procedure: AGR-3/4 Graphite Outside Diameter Metrology Equipment (Phase I and II), EJ-1195," Idaho National Laboratory, Rev. 0.

INL, 2014c, MFC-EQP-0182, "Remote Equipment Qualification Procedure: AGR-3/4 Bore Gauge Metrology Equipment (Phase I and II), EJ-119," Idaho National Laboratory, Rev. 0.

INL, 2015a, HFEF-LI-0072, “AGR-3/4 Metrology,” Idaho National Laboratory, Rev. 1.

INL, 2015b, LWP-13455, "Control of Measuring and Test Equipment," Idaho National Laboratory, Rev. 4. 
INL, 2015c, PLN-3636, “Technical Program Plan for INL Advanced Reactor Technologies Development Office/Advanced Gas Reactor Fuel Development and Qualification Program,” Idaho National Laboratory, Rev. 4.

INLa, SK-JDW-5/7/15, “TBD,” Idaho National Laboratory.

INLb, SK-JDW-10/31/13-001, “AGR 3-4 Matrix Sleeve Standard,” Idaho National Laboratory.

INLc, SK-JDW-10/31/13-002, “AGR 3-4 Graphite Sleeve Standard,” Idaho National Laboratory.

INLd, SK-JDW-10/31/13-003, “AGR 3-4 Graphite Sink Standard,” Idaho National Laboratory.

Petti, D.A., J.T. Maki, J.D. Hunn, P.J. Pappano, C.M. Barnes, J.J. Saurwein, S.G. Nagley, J.M. Kendall, and R.R. Hobbins, 2010, The DOE Advanced Gas Reactor Fuel Development and Qualification Program, JOM, Vol. 62, No. 9, pp. 62-66.

Scates, D.M., 2015, ECAR-2457, "Release-to-Birth Ratios for the AGR-3/4 Operating Cycles 151A-155B,” Idaho National Laboratory, Rev. 1.

Sterbentz, J.W., 2015, ECAR-2753, “JMOCUP As-Run Daily Physics Depletion Calculation for the AGR-3/4 TRISO Particle Experiment in ATR Northeast Flux Trap,” Idaho National Laboratory, Rev. 1. 